Florida International University FIU Digital Commons

$5-6-2014$

\title{
Connectivity of fragmented amphibian populations in a Neotropical landscape
}

Aaron J. Nowakowski

Florida International University, anowa001@fiu.edu

DOI: $10.25148 /$ etd.FI14071193

Follow this and additional works at: https://digitalcommons.fiu.edu/etd

\section{Recommended Citation}

Nowakowski, Aaron J., "Connectivity of fragmented amphibian populations in a Neotropical landscape" (2014). FIU Electronic Theses and Dissertations. 1515.

https://digitalcommons.fiu.edu/etd/1515 


\title{
FLORIDA INTERNATIONAL UNIVERSITY
}

Miami, Florida

\section{CONNECTIVITY OF FRAGMENTED AMPHIBIAN POPULATIONS IN A} NEOTROPICAL LANDSCAPE

\author{
A dissertation submitted in partial fulfillment of the \\ requirements for the degree of \\ DOCTOR OF PHILOSOPHY \\ in \\ BIOLOGY
}

by

Aaron Justin Nowakowski 
To: Interim Dean Michael R. Heithaus

College of Arts and Sciences

This dissertation, written by Aaron Justin Nowakowski, and entitled Connectivity of Fragmented Amphibian Populations in a Neotropical Landscape, having been approved in respect to style and intellectual content, is referred to you for judgment.

We have read this dissertation and recommend that it be approved.

J. Andrew DeWoody

$\begin{array}{r}\hline \text { Joel Heinen } \\ \hline \text { Michael R. Heithaus } \\ \hline \text { Philip Stoddard } \\ \hline \text { James Watling } \\ \hline \text { Maureen Donnelly, Major Professor }\end{array}$

Date of Defense: May 6, 2014

The dissertation of Aaron Justin Nowakowski is approved.

Interim Dean Michael R. Heithaus College of Arts and Sciences

Dean Lakshmi Reddi
University Graduate School

Florida International University, 2014 
(C) Copyright 2014 by Aaron Justin Nowakowski

All rights reserved. 


\section{DEDICATION}

This dissertation is dedicated to my son, Adrián, and my wife, Marylin 


\section{ACKNOWLEDGMENTS}

Throughout the dissertation process, I have received assistance and support from many people whom I have had the good fortune to meet. In no particular order, I will try to list many of them here. I thank my lab mates, Rudi von May, Vivian Maccachero, Robert Hegna, Kelsey Reider, Lilly Eluvithingal, Monica Isola, Seiichi Murasaki, Luke Linhoff, Michelle Thompson and Michael Britton for their advice, feedback, and camaraderie. I especially thank Steven Whitfield for being a good mentor in Costa Rica.

Over the course of the dissertation, I benefited greatly from my interactions with faculty at FIU, especially Mike Heithaus, Philip Stoddard, and Joel Heinan who served as committee members, Dee Mills who introduced me to genetics work in her lab, Lidia Kos and Steve Oberbauer for benevolence in their administrative roles. I thank Andrew DeWoody and his lab group, who provided excellent guidance and made me feel like a part of the lab while I completed molecular work at Purdue University. I owe special thanks to James Watling, because he has been an excellent collaborator and mentor throughout the entire process.

In the field, I was lucky to have dedicated assistants like Virginia Weigand-Noble, Amanda Lee, and Marylin Veiman. I could not have completed the work without their help and good company on those torrential nights in the forest. My worldview was changed through my interactions with landowners who graciously allowed us to work on their properties. Many of these individuals were of humble means, but extended a type of hospitality I have not experienced elsewhere. I am especially grateful to Manuel Flores, who led us, at least part of the way, to Volcán Cacho Negro. 
I thank the staff of The Organization for Tropical Studies for their logistical support. I especially thank Bernal Matarrita, Carlomagno Soto, and Carlos de la Rosa, as well as the kitchen staff, the taller, and the cleaning staff at La Selva Biological Station. For essential diversionary contributions, I thank Diego Dierick, Diego Salazar, Matt Fagan, Benoit Guenard, Vladislav Nechav, Kelsey Reider, Terry McGlynn, Martina Nagy, and Rhitu Shrestha and many many others who stopped by the rocking chairs. I am extremely grateful to my friends and family who were ever supportive throughout the dissertation and provided respite from the science world when needed.

Ultimately, I am greatly indebted to Mo Donnelly for her guidance and confidence in me over the years. Her unyielding support for her graduate students is admirable and made this project possible. I am fortunate to have conducted my dissertation in the Donnelly lab, because of the indelible experiences it has led to and because I was able to learn tropical biology from an excellent mentor.

This dissertation was completed with funding from CAS Dean's Office, The Organization for Tropical Studies, a Florida International University Dissertation Evidence Acquisition Fellowship, a Florida International University Dissertation Year Fellowship, Tinker Foundation travel funds, an Idea Wild equipment grant, and a Judith Evans Parker Scholarship. 


\section{ABSTRACT OF THE DISSERTATION \\ CONNECTIVITY OF FRAGMENTED AMPHIBIAN POPULATIONS IN A NEOTROPICAL LANDSCAPE \\ by}

Aaron Justin Nowakowski

Florida International University, 2014

Miami, Florida

\section{Professor Maureen Donnelly, Major Professor}

A high proportion of amphibian species are threatened with extinction globally, and habitat loss and degradation are the most frequently implicated causes. Rapid deforestation for the establishment of agricultural production is a primary driver of habitat loss in tropical zones where amphibian diversity is highest. Land-cover change affects native assemblages, in part, through the reduction of habitat area and the reduction of movement among remnant populations. Decreased gene flow contributes to loss of genetic diversity, which limits the ability of local populations to respond to further environmental changes. The focus of this dissertation is on the degree to which common land uses in Sarapiquí, Costa Rica impede the movement of two common species of amphibians. First, I use field experiments, including displacement trials, and a behavioral landscape ecology framework to investigate the resistance of pastures to movement of Oophaga pumilio. Results from experiments demonstrate that pastures do impede movement of $O$. pumilio relative to forest. Microclimatic effects on movement performance as well as limited perceptual ranges likely contribute to reduced return rates through pastures. Next, I linked local processes to landscape scale estimates of resistance. 
I conducted experiments to measure habitat-specific costs to movement for O. pumilio and Craugastor bransfodrii, and then used experimental results to parameterize connectivity models. Model validation indicated highest support for resistance estimates generated from responses to land-use specific microclimates for both species and to predator encounters for $O$. pumilio. Finally, I used abundance and experiment-derived resistance estimates to analyze the effects of prevalent land uses on population genetic structure of the two focal species. While $O$. pumilio did not exhibit a strong response to landscape heterogeneity and was primarily structured by distances among sites, $C$. bransfordii genetic variation was explained by resistance estimates from abundance and experiment data. Collectivity, this work demonstrates that common land uses can offer different levels of resistance to amphibian movements in Sarapiquí and illustrates the value of investigating local scales processes to inform interpretation of landscape-scale patterns. 


\section{TABLE OF CONTENTS}

CHAPTER

PAGE

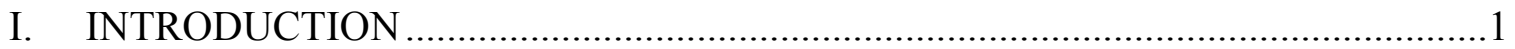

II. CHAPTER 1: LANDSCAPE RESISTANCE TO MOVEMENT OF THE POISON FROG, OOPHAGA PUMILIO, IN THE LOWLANDS OF NORTHEASTERN

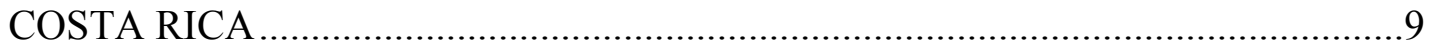

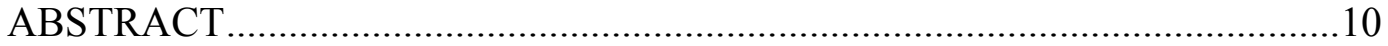

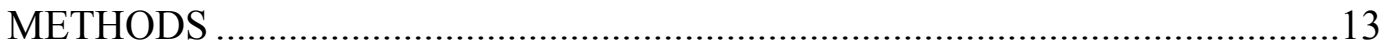

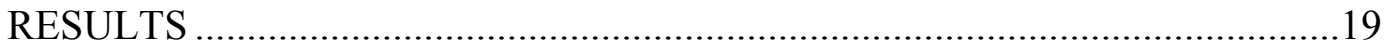

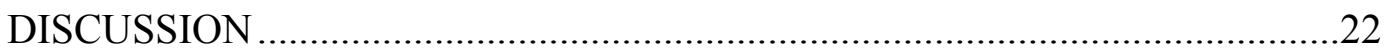

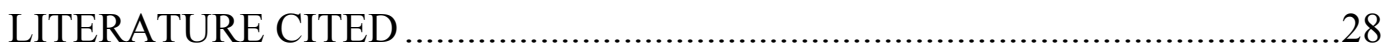

III. CHAPTER 2: EVALUATING CONNECTIVITY FOR TWO TROPICAL AMPHIBIANS USING EXPERIMENTALLY PARAMETERIZED

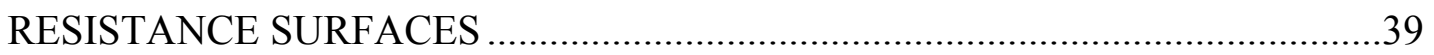

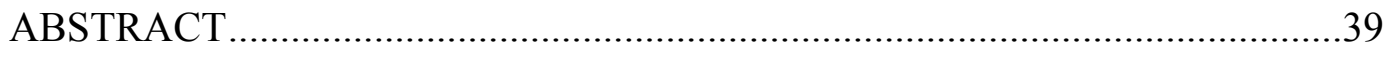

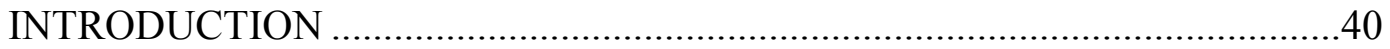

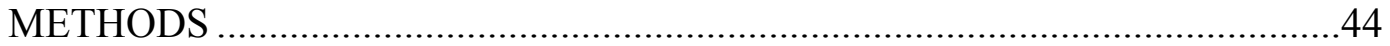

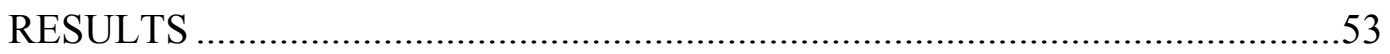

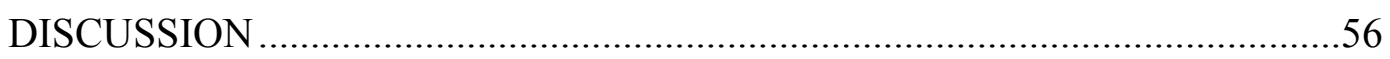

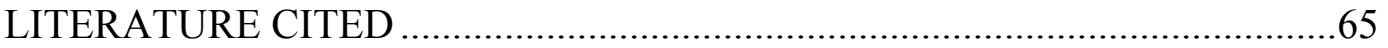

IV. CHAPTER 3: DISPERSAL COSTS AND ABUNDANCES EXPLAIN

GENETIC DIFFERENTIATION OF TWO AMPHIBIANS IN A COMPLEX

NEOTROPICAL LANDSCAPE ................................................................. 80

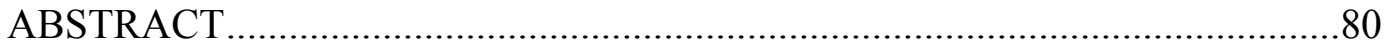

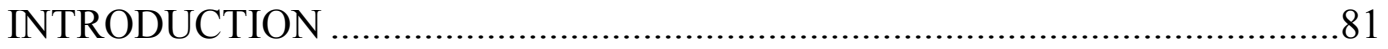

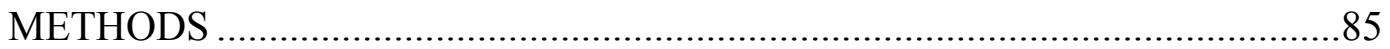

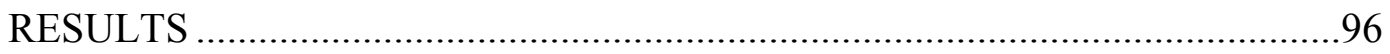

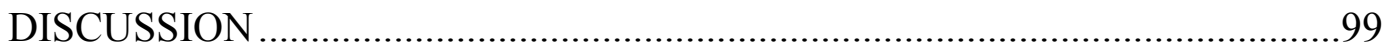

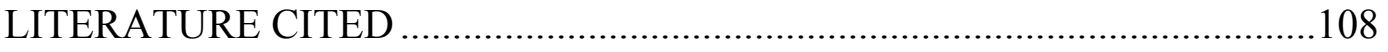

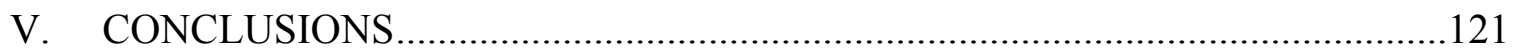

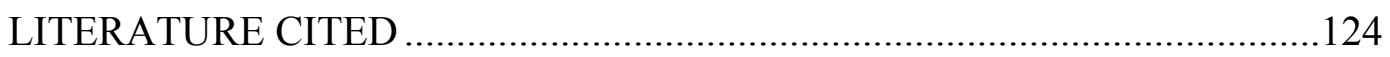

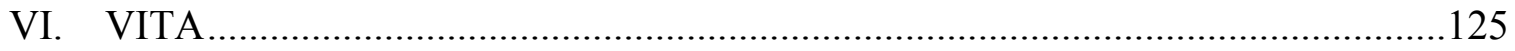




\section{LIST OF TABLES}

TABLE

PAGE

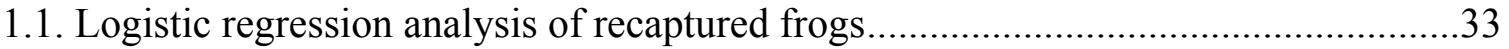

2.1. Analyses of water loss and survival during microclimatic exposure experiments .....71

2.2. Model results for substrate resistance trials and tethering experiments ...................72

2.3. Correlation coefficients between experiment and survey-derived current maps........73

3.1. Analyses of genetic distances and resistance distances ......................................116 


\section{LIST OF FIGURES}

FIGURES

PAGE

1.1. Images of a forest-pasture edge, an Oophaga pumilio, and the release platform.......34

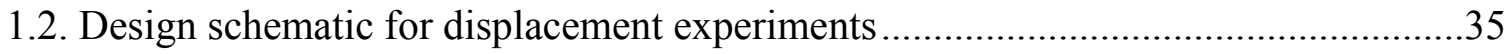

1.3. Boxplots of travel times following exposure experiments ...................................36

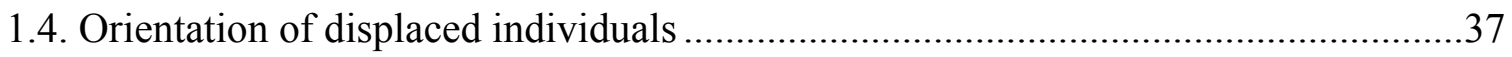

1.5. Frequencies of distances among forest fragments on the study landscape .................38

2.1. A replícate field site in Sarapiquí, Costa Rica ..................................................74

2.2. Relationships between temperature, water loss, and survival...............................75

2.3. Mean travel times across substrates and predator encounter rates ..........................76

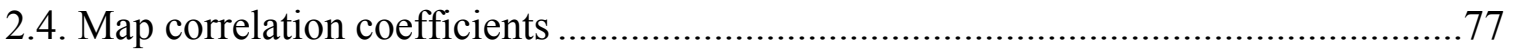

2.5. Relationships among three connectivity measures .......................................... 78

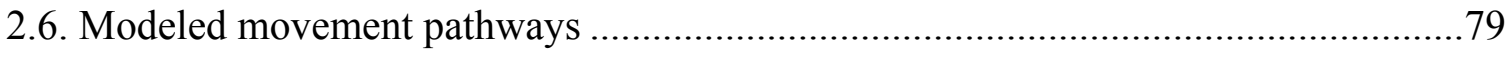

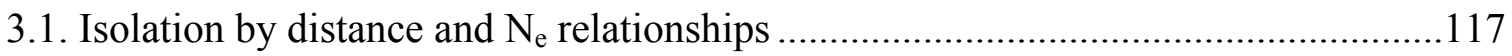

3.2. Map of study area and pie charts showing percent ancestry ...............................118

3.3. Genetic distances and resistance distances derived from abundances ....................119

3.4. Model support for experiment-derived resistance estimates for litter frogs ............120 


\section{INTRODUCTION}

Amphibian declines, land use change, and connectivity

Global biodiversity is threatened by the growing impact of human populations and amphibians have become a focus of efforts to quantify and abate what is now widely considered a period of mass extinction (Diamond 1989, Wilson 2002, Wake and Vredengerg 2008). Assessment of the conservation status of vertebrate groups has been thorough in comparison with other taxa (e.g., insects and plants), and amphibians are among the most vulnerable vertebrate classes with population declines documented for $43 \%$ of the species evaluated (Stuart et al. 2004, IUCN 2008). Rapid declines of amphibian populations are occurring disproportionately in the Neotropics and are now the focus of urgent conservation initiatives aimed at monitoring, research, and captive breeding programs (Lips et al. 2005, Mendelson et al. 2006, Whitfield et al. 2007). Habitat loss and degradation are considered the most prevalent threats to amphibian diversity, (Stuart et al. 2004). In the tropics, forests are being cleared and converted to other land-uses at a rate of $58,000 \mathrm{~km}^{2}$ per year (Achard et al. 2002). Sixty percent of total forest conversion in Latin America from 1990-2000 resulted in establishment of permanent agriculture, which includes livestock pastures, exotic tree plantations and food crop cultivation (FAO 2009). Other proximate causes of declines include exotic species invasion, over-exploitation, climate change, pesticide contamination, and pathogenic infection (Collins and Storfer 2003, Lips 2005). These factors likely contribute synergistically with land-use change to species loss (Wake and Vredenburg 2008). Reduced size and connectivity of remnant populations following land-use change often results in reduced genetic diversity that can decrease larval 
survival (Hitchings and Beebee 1997), and increase susceptibility to UV-B radiation (Weyrauch and Grubb 2006), pathogens (Pearman and Garner 2005), and ultimately to extirpation (Frankham et al. 2002). Therefore, maintenance of connectivity among recently isolated habitat fragments may be vital to buffer local populations against changing environmental conditions (e.g., invasive species, climate change, and spread of pathogens).

In a fragmented landscape, rates of individual dispersal and gene flow, factors that influence spatial patterns of gene frequencies and species abundances, are dependent upon the interaction of species traits and the composition of the landscape matrix surrounding patches (Tischendorf and Fahrig 2000, Rickets 2001, With 2004). Organisms may exhibit functional responses to complex landscapes, whereby avoidance of certain matrix elements can result in asymmetrical dispersal rates among patches separated by comparable straight-line distances (With 2004, Fitzgibbon et al. 2007). Several studies have found that alternative routes, least cost distances, and matrix composition metrics explain more variation in gene flow, local abundances, and occupancy than straight-line distance measures of isolation (Storfer et al. 2007, Prugh et al. 2008, Watling et al. unpublished data).

Many amphibians have evolved a distinct dispersal phase which is presumably adaptive in environments where resources are spatially and temporally dynamic (Semlitsch 2001, Smith and Green 2005). However, frequent dispersal through an anthropogenically-altered landscape may represent an 'ecological trap' in which amphibian populations experience greater overall mortality and extinction risk than they do in unaltered landscapes (Gibbs 1998, Fahrig 2001). Several studies have documented 
increased mortality and extinction probability associated with particular landscape elements (e.g., roads) and in species with greater dispersal tendencies (Gibbs 1998, Carr and Fahrig 2001, Homan et al. 2004).

At the landscape scale, connectivity effects can be observed in patterns of distribution, population genetic structure, and movement of organisms in response to different habitat types (Ricketts 2001, Fitzgibbon et al. 2007, Richardson ). At the local scale, it is possible to quantify the mechanisms underlying landscape-scale patterns, such as habitat-specific mortality rates (Rothermel and Semlitsch 2006), time spent searching for habitat, which can be affected by physical ability to move through the matrix and ability to detect destination habitat (Stevens et al. 2004), and avoidance of certain matrix elements (Mazerolle and Desrochers 2005, Rittenhouse and Semlitsch 2006).

\section{Dissertation overview}

In this dissertation, I present a case study of landscape connectivity for two amphibians in the lowlands of northeastern Costa Rica. In Chapter 1, I used experimental approaches grounded in a behavioral landscape ecology framework (Knowlton and Graham 2010) to evaluate resistance of pastures to movement of Oophaga pumilio, a common dart-poison frog. I translocated individuals from capture sites at varying distance into forest and pasture and compared return rates as an index of landscape resistance. I followed up with two experiments that measured possible mechanisms underlying differences in return rates between pasture and forest, movement performance under different microclimatic conditions and orientation ability at various distances from capture sites. 
In Chapter 2, I use experiments to measure relative costs among land cover types in terms of processes related to connectivity. These local processes included habitatspecific desiccation risk and associated survival, movement speeds across different substrates, predator encounter rates, and substrate choice. For amphibians, migrant survival is likely influenced by susceptibility to thermal stress, evaporative water loss, and predation. Amphibians tend to dehydrate more quickly in areas with low cover (Rothermel and Luhring 2005) and on dry substrates (Mazerolle and Desrochers 2005). Limited cover and differences in predator abundances and composition in disturbed habitats may contribute to contrast in perceived risk or survival in among land cover types. Dispersal behavior, such as orientation, may be an important aspect of functional connectivity. As amphibians seem to lack the ability to detect differences among habitats at long-distances (Rothermel 2004), they may use localized substrate, vegetation, or olfactory cues for orientation during dispersal (McGregor and Teska 1989, Rittenhouse et al. 2004, Stevens et al. 2006a).

By measuring different local processes using experiments, I was able to assign empirical cost values to resistance surfaces that were in turn used as input for connectivity models. Few studies to date have used experiments to measure costs among landscape features, despite the potential to specify possible mechanisms underlying connectivity (Stevens et al. 2006a,b). Empirical data are more likely to provide relative cost values that reflect biologically relevant contrasts among landscape elements than commonly used expert opinion methods or model fitting.

In Chapter 3, I analyzed patterns of population genetic structure Oophaga pumilio and Craugastor bransfordii in northeastern Costa Rica. Most landscape genetic studies 
are have not directly measured biological processes potentially underlying observed patterns (e.g., survival, predations risk, and behavior; Cushman 2006). Here, I combined landscape genetics, field surveys and field experiments to explain genetic variation across a landscape while focusing on dispersal limitation as a potential mechanism shaping patterns of differentiation. I used resistance surfaces developed in Chapter 2 as input for connectivity models. In turn, estimated effective distances were used as explanatory variables in analyses of pairwise genetic differentiation. 


\section{LITERATURE CITED}

Achard, F., H. D. Eva, H. Stibig, P. Mayaux, J. Gallego, T. Richards, J. Malingreau. 2002. Determination of deforestation rates of the world's humid tropical forests. Science 297:999-1002.145-152.

Carr, L. W., and L. Fahrig. 2001. Effect of road traffic on two amphibian species of differing vagility. Conservation Biology 15:1071-1078.

Collins, J. P., and A. Storfer. 2003. Global amphibian declines: sorting the hypotheses. Diversity and Distributions 9:89-98.

Cushman, S. A. 2006. Effects of habitat loss and fragmentation on amphibians: a review and prospectus. Biological Conservation 128:231-240.

Diamond, J.M. 1989. The present, past and future of human-caused extinctions. Phil. Trans. R. Soc. Lond. B 325: 469-477.

Fahrig, L. 2001. How much habitat is enough? Biological Conservation 100:65-74.

FAO. 2009. State of the world's forests. FAO, United Nations, Rome, Italy.

FitzGibbon, S.I., D. A. Putland, and A. W. Goldizen. 2007. The importance of functional connectivity in the conservation of a ground-dwelling mammal in an urban Australian landscape. Landscape Ecology 22: 1513-1525.

Frankam, R., J. D. Ballou, and D. A. Briscoe. 2002. Introduction to Conservation Genetics. Cambridge University Press, Cambridge.

Gibbs, J. P. 1998. Distribution of woodland amphibians along a forest fragmentation gradient. Landscape Ecology 13:263-268.

Hitchings, S. P., and T. J. C. Beebee. 1997. Genetic substructuring as a result of barriers to gene flow in urban Rana temporaria (common frog) populations: implications for biodiversity conservation. Heredity 79:117-127.

Homan, R. N., B. S. Windmiller, and J. M. Reed. 2004. Critical thresholds associated with habitat loss for two vernal pool-breeding amphibians. Ecological Applications 14:1547-1553.

IUCN 2008. 2008 IUCN Red List of Threatened Species. www.iucnredlist.org. 
Knowlton, J. L., and C. H. Graham (2010). Using behavioral landscape ecology to predict species' responses to land-use and climate change. Biological Conservation 143, 1342-1354.

Lips, K. R., P. A. Burrowes, J. R. Mendelson, and G. Parra-Olea. 2005. Amphibian population declines in Latin America: a synthesis. Biotropica 37:163-165.

McGregor, J. H., and W. R. Teska. 1989. Olfaction as an orientation mechanism in migrating Ambystoma maculatum. Copeia 1989:770-781.

Mendelson, J. R., K. R. Lips, R. W. Gagliardo, G. B. Rabb, J. P. Collins, J. E. Diffendorfer, P. Daszak, R. Ibanez, K. C. Zippel, et al. 2006. Confronting amphibian declines and extinctions. Science 313:48.

Pearman, P.B.,and T.W.J. Garner. 2005. Susceptibility of Italian agile frog populations to an emerging strain of Ranavirus parallels population genetic diversity. Ecology Letters 8:401-408.

Prugh, L. R., K. E. Hodges, A. R. E. Sinclair, and J. S. Brashares. 2008. Effect of habitat area and isolation on fragmented animal populations. PNAS 105:20770-20775.

Ricketts , T. 2001. The matrix matters: effective isolation in fragmented landscapes. The American Naturalist 158: 87-99.

Rittenhouse, T.A.G., M. C. Doyle, C. R. Mank, B. B. Rothermenl, and R. D. Semlitsch. 2004. Substrate cues influence habitat selection by spotted salamanders. J. Wildlife Management 68: 1151-1158.

Rittenhouse, T.A.G., and R.D. Semlitsch. 2006. Grasslands as movement barriers for a forest-associated salamander: migration behavior of adult and juvenile salamanders as a distinct habitat edge. Biological Conservation 132: 14-22.

Rothermel, B.B. 2004. Migratory success of juveniles: a potential constraint on connectivity for pond-breeding amphibians. Ecological Applications 14:15351546.

Rothermel, B. B. and T. M. Luhring. 2005. Burrow availability and desiccation risk of mole salamanders (Ambystoma talpoideum) in harvested versus unharvested forest stands. Journal of Herpetology 39: 619-626.

Rothermel, B.B., and R.D. Semlitsch. 2006. Consequences of forest fragmentation for juvenile survival in spotted (Ambystoma maculatum) and marbled (Ambystoma opacum) salamanders. Canadian Journal of Zoology 84: 797-807. 
Semlitsch, R. D. 2008. Differentiating migration and dispersal processes for pondbreeding amphibians. The J. Wildlife Management 72: 260-267.

Smith, A. M., and D. M. Green. 2005. Dispersal and the metapopulation paradigm in amphibian ecology and conservation: are all amphibian populations metapopulations? Ecography 28:110-128.

Storfer, A., M. A. Murphy, J. S. Evans, C. S. Goldberg, S. Robinson, S. F. Spear, R. Dezzani, E. Delmelle, L. Vierling, and L P. Waits. 2007. Putting the 'landscape' in landscape genetics. Heredity 98:128-142.

Stuart, S.N., J. S. Chanson, N. A. Cox, B. E. Young, A. S. L. Rodrigues, D. L. Fischman, and R. W. Walker. 2004. Science 306: 1783-1786.

Stevens, V.M., E. Leboulenge, R. A. Wesselingh, and M. Baguette. 2006a. Quantifying functional connectivity: experimental assessment of boundary permeability for the Natterjack toad (Bufo calamita). Oecologia 150: 161-171.

Stevens, V. M., C. Verkenne, S. Vanderwoestijne, R. A. Wesselincgh, and M. Baguette. 2006b. Gene fow and functional connectivity in the natterjack toad. Molecular Ecology 15:2333-2344.

Tischendorf, L. and L. Fahrig. 2000. On the usage and measurement of landscape connectivity. Oikos 90:7-19.

Wake, D. B., and V. T. Vredenburg. 2008. Are we in the midst of the sixth mass extinction? A view from the world of amphibians. PNAS 105: 11466-11473.

.Weyrauch, S. L. and T. C. Grubb Jr. 2006. Effects of the interaction between genetic diversity and UV-B radiation on woodfrog fitness. Conservation Biology 20: $802-810$

Whitfield, S. M., K. Bell, T. Philippi, M. Sasa, F. Bolan, G. Chaves, J. Saveage, amd M. Donnelly. 2007. Amphibian and reptile declines over 35 years at La Selva, Costa Rica. Proceedings of the National Academy of Science 104: 8352-8356.

Wilson, E. O. 2002. The Future of Life. Vintage Books, New York.

With, K. 2004. Metapopulation dynamics: perspectives from landscape ecology. Pages 23-44 in I. Hanski, and O. E. Gaggiotti, editors. Ecology, genetics, and evolution of metapopulations. Elsevier Academic Press, New York. 


\section{CHAPTER 1: LANDSCAPE RESISTANCE TO MOVEMENT OF THE POISON}

FROG, OOPHAGA PUMILIO, IN THE LOWLANDS OF NORTHEASTERN COSTA RICA

\section{ABSTRACT}

Conversion of forests to agricultural land or pastures is occurring at a rapid rate in many tropical regions. Amphibians may be particularly susceptible to changes in landscape composition and connectivity because of their physiological characteristics and complex life cycles. We experimentally assessed landscape resistance for the dart-poison frog, Oophaga pumilio, associated with two prevalent land-cover types, secondary forest and pasture, in the northeastern lowlands of Costa Rica. We measured recapture rates of individuals displaced into forest and into pasture, the effects of microclimate on the movement performance of individuals, and the influence of land-cover type and displacement distance on orientation ability of $O$. pumilio. Results showed a significant interaction between displacement distance and land-cover type indicating greater resistance to movement experienced by individuals displaced into pasture compared to frogs displaced into forest. Microclimatic conditions in pasture appear to have a detrimental effect on the movement performance of $O$. pumilio and initial orientation was both distance and habitat dependent. Understanding the magnitude of resistance presented by different land uses to amphibian dispersal is important for the development of successful conservation strategies in human-altered landscapes. 


\section{INTRODUCTION}

Landscapes are being drastically altered by human activities such as agriculture and urban development, causing loss of connectivity and fragmentation of previously continuous habitat (Fahrig, 2003: Rittenhouse and Semlitsch, 2006; FAO, 2009). In the tropics, forest conversion is occurring at a rate of approximately $58,000 \mathrm{~km}^{2}$ per year resulting in a mosaic of human-land uses (Achard et al., 2002; FAO, 2009) in which organisms occur in patches of remnant habitat. It is clear that habitat loss is the primary driver of widespread-global amphibian declines, but we currently lack an understanding of how landscape mosaics mediate connectivity for remnant amphibian populations, and in turn, to what extent altered connectivity affects population persistence (Lips et al., 2005; Gardner et al., 2007a; Vié et al., 2009).

Theoretical and empirical studies have demonstrated the importance of dispersal in the dynamics of fragmented populations and communities (Anderson and Danielson, 1997; Mouquet and Loreau, 2003; Smith and Green, 2005). Dispersal of organisms among remnant habitat patches helps prevent local extinction, promotes genetic diversity and allows colonization of new habitat patches (Mouquet and Loreau, 2003; Vellend, 2005; Ronce, 2007). Establishment in new habitat depends on the ability of organisms to detect and reach suitable patches (Mazerolle et al., 2005; Zollner and Lima, 2005; Baquette and Van Dyck, 2007). Dispersal success can be associated with distance between patches or the degree of functional connectivity (Ricketts, 2001; Calabrese and Fagan, 2004; Mazerolle et al., 2005; Ovaskainen et al., 2008) which is defined as the resistance of landscape components to the movement of organisms (Tischendorf and Fahrig, 2000). Functional landscape connectivity is a determined by the quality of the 
matrix through which individuals must move (Henein and Merriam, 1990; Rothermel and Semlitsch, 2002; Ricketts, 2001; Vandermeer and Carvajal, 2001; Kupfer et al., 2006; FitzGibbon et al., 2007) and is also dependent on multiple taxon-specific variables, such as survival, individual behavior, and movement ability (Fahrig, 2001; Belisle, 2005; Lees and Peres, 2009). For amphibians, migration rates are likely influenced by an individual organism's ability to overcome factors such as predation, risk of desiccation, resistance of substrates to movement, and stressful microclimatic conditions (Stevens et al., 2004; Mazzerole and Desrochers, 2005; Rittenhouse et al., 2008). The amount of time that dispersing amphibians are exposed to these risks via suboptimal dispersal routes may depend on their ability to detect and orient toward suitable habitat.

Currently, little is known about behavioral responses of amphibians to land-uses in the tropics (Gardner at al., 2007a; 2007b). This absence of data will inhibit efforts to predict the effects of current and future land-use change on threatened groups of organisms. Translocation experiments, which involve displacing animals from areas of capture into novel habitats represent a set of methods for investigating perceptual range, homing tendencies and the manner in which abiotic and biotic landscape features influence movement behaviors (Marsh et al. 2004, Belisle, 2005; Knowlton and Graham, 2010). Information obtained from translocation experiments can be used to parameterize individual-based and graph theory-based models of landscape connectivity (McRae et al., 2008) that are often parameterized with user-defined values as opposed to empirical data.

The objective of this study was to experimentally assess landscape connectivity associated with predominant land-cover types for amphibians in a lowland tropical region in Costa Rica. We examined if secondary forest and pasture offer different levels of 
resistance to dispersal for a common dart-poison frog, Oophaga pumilio. We conducted three experiments, one to obtain an index of landscape resistance by analyzing recapture rates of frogs displaced into either forest or pasture at different distances, and two experiments to examine mechanisms underlying potential differences in landscape resistance. We expected that return rates would be lower for frogs displaced into pastures because pastures differ greatly in vegetation structure and microclimate from forests. Conditions in pastures generally include a thick groundcover composed of grasses, with few shrubs or trees to provide cover and shade, conditions that may inhibit movement of frogs and result in mortality from desiccation or predation (Fig 1a; Nowakowski et al., unpublished data). We investigated the effects of microclimatic conditions found in forest and pasture on movement performance of $O$. pumilio by first exposing frogs to temperature and humidity conditions found in these habitats and then testing locomotory performance. Heat stress and dehydration may affect dispersal success of amphibians by reducing movement ability (Miller 1982), which can result in greater time spent searching for suitable habitat and ultimately increased risk of predation or desiccation.

We also observed the initial orientation of $O$. pumilio when displaced into forest and pasture habitat and whether orientation direction was influenced by the distance from original capture sites. We expected frogs to be better able to orient toward their territories when displaced into forest than into pasture because of presumed familiarity with sensory cues found in forest habitat. We also expected that this ability to orient would decrease as displacement distance increased as a result of attenuation of homing cues (Sinsch 2006). It is important to note that homing responses could be attributed to differences in ability to orient or differences in motivation between habitats. If 
motivation is the primary factor affecting orientation responses, we would then expect stronger directional orientation by frogs displaced into pasture than into forest, because pasture represents a novel habitat in which perceived risk may be greater. By displacing frogs into both pastures adjacent to familiar territory and far from familiar territory, we tested whether $O$. pumilio were orienting toward the forest because (1) they were homing toward familiar territory or (2) because they responded to cues from forest habitat in general.

\section{METHODS}

\section{Study organism}

In northeastern Costa Rica, O. pumilio is a small red frog with blue, purple or black hind limbs, and is commonly found in tree plantations and forest habitat in lowland moist and wet forest zones (Fig 1b; Savage, 2002). Oophaga pumilio is a diurnal species that typically occurs at relatively high population densities, although recent population declines have been recorded in old-growth forests at La Selva Biological Station (Whitfield et al., 2007). Adult size ranges from 17.5 to $24 \mathrm{~mm}$ snout-vent length (SVL; Savage, 2002) and they are known to maintain home ranges from approximately 2 to 15 $\mathrm{m}^{2}$ (Donnelly, 1989). McVey et al., (1981) showed that $O$. pumilio individuals displaced up to $20 \mathrm{~m}$ from their home range within the same habitat were able to home to the site of capture. 


\section{Study area}

We conducted this study in La Selva Biological Station and in adjacent forests and pastures in the Sarapiquí region of northeastern Costa Rica. The study area is located in the Lowland Atlantic Wet Forest habitat described by Savage (2002). The Sarapiquí area receives approximately $4 \mathrm{~m}$ of rain annually (Sanford et al., 1994). Mean monthly temperature ranges from $24.7^{\circ} \mathrm{C}$ to $27.1^{\circ} \mathrm{C}$ (Sanford et al., 1994). Northeastern Costa Rica has been extensively fragmented since the 1950s resulting in a landscape mosaic dominated by remnant forest (29\% of the landscape) and pasture lands (20\%; Sesnie et al., 2008). We located pasture sites running parallel to secondary forests using landcover maps and aerial photographs of La Selva and the surrounding landscape.

\section{Displacement experiment}

We measured recapture rates of $O$. pumilio individuals when displaced into either forest or pasture. We established $10 \mathrm{~m}$ wide collection zones (e.g., Marsh et al. 2004) within three replicate secondary-forest fragments along forest-pasture edges. Within these collection zones, we captured a total of 120 O. pumilio individuals and gave each a unique mark using toe clips. At the time of initial capture, individuals were randomly assigned to a land-cover type and displacement distance. Sixty individuals were displaced into pasture and 60 individuals were displaced into forest at distances of 20 or $30 \mathrm{~m}$ from their site of capture (Fig 2). Capture sites were marked with fluorescent flagging tape. We searched each capture site the day after initial displacement and subsequent searches occurred once per day as we visited sites over a two-week period until a total of 10 searches were completed. During each visit, we searched for 
individuals within a $3 \mathrm{~m}$ radius of the capture site for 3 minutes. An index of landscape resistance was obtained from the recapture rates for individuals returning from each landcover type.

\section{Movement performance}

We measured the effects of microclimatic conditions associated with secondary forest and pasture on movement performance of individual frogs. We captured 38 adult O. pumilio individuals from secondary forest and recorded snout-to-vent length (SVL) and sex of each individual. Individuals used in this experiment ranged in size from 17-22 mm (SVL). Trials were conducted between 3 July 2010 and 29 July 2010. For each trial, we placed an individual frog inside a cylindrical enclosure $(15 \mathrm{~cm}$ diameter $)$ made of metallic wire and gray screen fabric. Each trial involved placing three frogs in pasture enclosures and three in forest enclosures. The frogs were placed into the enclosures for a period of 27-30 min to expose them to the microclimatic conditions found in forest and pasture habitats during mornings or afternoons without rain between the hours of $1100 \mathrm{~h}$ and $1600 \mathrm{~h}$. Enclosures were placed at least $10 \mathrm{~m}$ apart and were installed by cutting a ring into the soil with a shovel and inserting the open bottom of the enclosure several centimeters into the ground, which left the substrate inside the enclosure intact. Temperature and relative humidity $(\mathrm{RH})$ were measured outside and inside of each enclosure using iButton hygrochron temperature and humidity sensors (Maxim Integrated Products).

After exposure to microclimatic conditions, frogs were removed from enclosures, placed into clean plastic containers and taken to a nearby ambient-air lab where we 
measured movement performance. Time between removal from exposure site and start of movement trials was on average 21 minutes $(\mathrm{SD}=5 \mathrm{~min})$. The order in which frogs were entered into movement trials was randomized. Individuals were placed into one end of a $2 \times 0.25 \mathrm{~m}$ arena constructed from particle board. Lines were drawn on the floor of the arena at $5 \mathrm{~cm}$ increments. We measured the time it took each frog to move $180 \mathrm{~cm}$ from one end of the arena to the other. Each trial lasted a maximum of three minutes. If the frog did not finish crossing the arena in the time given, a three-minute time was recorded and the distance moved was recorded. When a frog stopped for $5 \mathrm{~s}$ we placed a wooden dowel $(\mathrm{dia}=20 \mathrm{~mm})$ behind the individual at the nearest $5 \mathrm{~cm}$ mark to induce movement. Stimulation was equally applied on all trials so that frogs' propensity to move was standardized (Stevens et al., 2004). We compared movement performance, measured as the time it took to traverse the length of the arena, for frogs exposed to conditions in forest and pasture.

We also exposed frogs to simulated microclimatic conditions of pastures in a controlled lab setting. We captured 44 adult $O$. pumilio from secondary forest habitat and randomly assigned individuals to a high temperature-low humidity treatment and a control. For each trial we placed 10-12 frogs into individual plastic cups (266 ml) partially filled with sand. A piece of paper towel was placed on top of the sand and a piece of nylon mesh screen was secured to the top of each cup with a rubber band to prevent frogs from escaping. For the simulated pasture treatment, cups were placed into a drying oven set to the mean temperature observed in pastures $\left(37^{\circ} \mathrm{C}\right)$. The door of the drying oven was opened to regulate humidity. Both temperature and humidity were monitored using a Kestral 3000 weather meter and ibutton hydrochron sensors. For the 
control, cups were placed in an ambient-air lab and paper towels were wetted with collected rainwater. Temperatures for the control were similar to the surrounding forest. In each trial, frogs were exposed to microclimatic conditions for $30 \mathrm{~min}$ and then removed and placed into clean plastic containers numbered on the bottom with each frog's ID. Frogs were then submitted to movement performance trials as described above. These trials were conducted blind to eliminate possible influence of observer bias. To estimate water loss during the experiment, we weighed frogs before exposures and after movement trials.

\section{Orientation experiment}

We conducted an experiment to measure orientation tendencies of displaced frogs at three replicate forest-pasture edges in the landscape surrounding La Selva Biological Station (Fig 1a). Each forest-pasture edge was oriented along a different directional axis. Collection zones were established in secondary forest within 10 meters of the forestpasture edge and delimited with flagging tape. Over a four-week period, a total of 180 frogs were captured from collection zones, measured, and held for up to approximately four hours in the forest in opaque plastic containers with moist leaf litter until testing. Frogs were randomly assigned to one of twelve displacement treatments $(n=15)$ : at distances of $25,50,75$, or $100 \mathrm{~m}$ into forest adjacent to capture sites, pasture adjacent to capture sites, or unfamiliar pasture located 300 meters along edge from capture sites (Fig 2). We used a meter tape and compass to displace frogs along an axis from each capture site that was perpendicular to the forest-pasture edge. 
Frogs were released onto a $1 \times 1 \mathrm{~m}$ platform that was constructed with plywood and divided in half and into four triangular quadrants with brown tape (Fig 1c). The platform was placed so that one quadrant faced toward the forest-pasture edge according to a compass heading taken along the edge, and the other three were oriented away from the edge (see Fig 2). During trials, a frog was placed onto the center of the platform and covered with a small opaque plastic enclosure for 90 seconds. We alternated placement orientation of frogs under the enclosure during placement on the release platform (i.e., facing forest, parallel, or toward pasture). The plastic enclosure was lifted using a string positioned over the platform and hung from a PVC frame so that the enclosure rose from the center of the platform. Observers lifted the enclosure from a distance of $10 \mathrm{~m}$. We recorded the amount of time taken by each frog to leave the platform and scored the direction of orientation in two ways, by recording the half (toward forest or away from forest) and the quadrant crossed when the frog left the platform. Each quadrant was assigned a specific label: " $\mathrm{H}$ " referred to the quadrant closest to the forest-pasture edge, "A1" was the quadrant closest to the observer, "A2" the quadrant directly opposite $\mathrm{H}$, and "A3" the quadrant directly opposite A1. After leaving the platform, frogs were recaptured and released within the collection zone. Temperature and humidity were measured during each trial with a Kestral 3000 weather meter.

\section{Statistical analyses}

We analyzed recapture status using a logistic regression model. Recapture status was the response variable and land-cover type, displacement distances, and the interaction between land-cover type and displacement distance served as the independent 
variables. Movement times were compared between treatments with one-tailed t-tests in which variances were not assumed to be equal because variances differed between treatments even after transformation. Movement times from the laboratory experiment were log-transformed to achieve normality. The number of hops per movement bout, $\mathrm{RH}$, temperature, and percent-change-in-mass were compared between treatments using two-tailed t-tests. A logistic regression model with forward selection routine was used to analyze the effects of displacement distance, land-cover type, SVL, placement orientation, and temperature on initial orientation. We used the more conservative quadrant score as the dependent variable. A general linear model was used to analyze the effects of treatment and covariates on time taken to leave platform. Because time taken by frogs to leave the platform was a non-normal variable, we analyzed log-transformed times. All analyses were completed using SPSS 16.0. In addition, we described the frequency distribution of nearest-neighbor distances between pairs of forest patches using $0.5 \mathrm{~m}$ resolution aerial photographs measured in ArcMap 10 (ESRI). We digitized six $2.5 \times 2.5 \mathrm{~km}$ quadrats, which we located haphazardly on the study landscape so that they did not overlap with continuous forest. We measured nearest neighbor distances between edges of all pairs of forest patches within these quadrats. Forest patches were defined as closed canopy groups of trees with diameters $\geq 100 \mathrm{~m}$.

\section{RESULTS}

\section{Displacement experiment}

After 10 surveys of the initial capture sites, we recaptured $64(56 \%)$ of the 120 displaced individuals. We recaptured 42 of the 60 individuals displaced $20 \mathrm{~m}$ from 
capture sites; of these, 20 individuals ( $67 \%$ of 30 ) had been displaced into forest and 22 (73\%) into pasture. In comparison, we only recaptured 22 of the 60 individuals displaced $30 \mathrm{~m}$ from capture sites; 17 (57\%) of these recaptured individuals had been displaced into the forest and $5(17 \%)$ were displaced into pasture. The full model showed a nonsignificant relationship between recapture rates and land cover types (Table 1); however, this effect was significant when the interaction term was dropped from the model $(\beta=$ $0.838, \mathrm{df}=1, P=0.036$ ). The effect of displacement distance on recapture rates was significant and there was a significant interaction between displacement distance and land-cover type.

\section{Movement performance}

Statistical analysis showed that frogs from pasture moved more slowly than frogs exposed to conditions in the forest $(t=2.604, \mathrm{df}=22.379, P=0.008$; Fig. 3 ). There was no significant difference when comparing number of hops per bouts between treatments $(t=0.115, \mathrm{df}=31.9, P=0.455)$. Simple linear regression analysis also demonstrated no relationship between time and body length $\left(R^{2}=0.01, P=0.4897\right)$, and mean times did not differ by $\operatorname{sex}(\mathrm{t}=-1.379, \mathrm{df}=14.688, P=0.0943)$. Mean relative humidity measures

were significantly different between forest $(\bar{X}=94.2 \%$, S.E. $=0.91 \%, \min =86.7 \%$, $\max$ $=100 \%)$ and pasture $(\bar{X}=63.1 \%$, S.E. $=1.82 \%, \min =48.4 \%, \max =74.8 \%)$ land-cover types $(t=16.844, \mathrm{df}=26.562, P=<0.0001)$. Difference in mean temperature was also significant between forest $\left(\bar{X}=28.6^{\circ}\right.$ C, S.E. $\left.=0.16, \min =27.2, \max =29.8\right)$ and pasture $\left(\bar{X}=37.5^{\circ}\right.$ C, S.E. $\left.=0.51, \min =33.3, \max =42.0\right)$ land-cover types $(t=14.995, \mathrm{df}=$ 23.032, $P=<0.0001)$. Relative humidity measures were significantly different between 
inside and outside of the enclosures $(\mathrm{t}=3.512, \mathrm{df}=34, P=0.0013)$ in forest study sites, while for pasture sites measures were not significantly different $(t=0.265, \mathrm{df}=33.735, P$ $=0.793)$. Temperature measured inside and outside was not significantly different in forest or pasture $(t=0.451, \mathrm{df}=33.359, P=0.655$ and $t=1.652, \mathrm{df}=34.017, P=0.108)$. Under laboratory conditions, frogs assigned to the high temperature-low humidity treatment moved more slowly in movement trials than frogs assigned to the control $(t=$ $3.815, \mathrm{df}=30.7, P=0.001$; Fig. 3 ). Percent change in mass during the experiment was greater for frogs exposed to the simulated pasture conditions $(\bar{X}=14.7 \%$, S.D. $=5.6 \%)$ than for frogs exposed to the control $(\bar{X}=2.8 \%$, S.D. $=2.4 \% ; t=9.069, \mathrm{df}=41, P$ $<0.001)$.

\section{Orientation experiment}

Orientation direction was significantly affected by distance from forest-edge collection zones $(\beta=-0.031, \mathrm{df}=1, P=<0.001)$ and land cover type $(\beta=-0.592, \mathrm{df}=1$, $P=0.011 ;$ Fig 4a). Placement orientation, SVL, sex, and temperature did not enter the model. There was a significant difference in mean time taken by frogs to leave the platform (Corrected model $F=3.088, \mathrm{df}=1, P=0.001$; Fig $4 \mathrm{~b}$ ). Frogs displaced into forest took significantly longer to leave the release platform than frogs displaced into pasture $(F=7.754, \mathrm{df}=2, P=0.001)$, while times were unaffected by distance from collection zones $(F=0.271, \mathrm{df}=3, P=0.846)$ and temperature $(F=2.006, \mathrm{df}=1, P=$ 0.159). The frequency distribution of nearest neighbor distances between pairs of fragments showed that $82 \%$ of forest patches on the landscape were separated by more than $50 \mathrm{~m}$ (Fig 5) Only 3\% of forest patches were separated by $25 \mathrm{~m}$ or less. 


\section{DISCUSSION}

Amphibians may be especially susceptible to the effects of habitat loss and landuse change because of their physiological traits and complex life cycles (Rothermel and Semlitsch, 2002; Becker et al., 2007). The biphasic-life cycles of many amphibians are often associated with seasonal migrations between terrestrial and aquatic resources, and alteration of terrestrial habitat can influence landscape patterns of occurrence and species richness (Pope et al., 2000; Semlitsh, 2008; Becker et al., 2007). While there is a paucity of information on the dispersal tendencies of tropical amphibian species, many temperate amphibians exhibit long-distance dispersal among local demes (Smith and Green, 2005). There are currently no direct observations of $O$. pumilio dispersal; however, population genetic data suggest moderate rates of gene flow occur between geographically distinct sites (Wang and Summers, 2010). Long-distance dispersal in most tropical landscapes would necessitate travel through agricultural areas with little cover and microclimates that differ dramatically from forested habitats. Because amphibians tend to lose water rapidly through skin when exposed to dry air (Wells, 2007), dispersing through pasture could increase mortality rates and lower dispersal success among populations.

Our study suggests that $O$. pumilio experienced increased resistance to movement in pastures in comparison to secondary forest. The results of the displacement experiment showed a significant effect of the interaction between displacement distance and land-cover type on recapture rates; the majority of recaptures from pastures were of frogs displaced $20 \mathrm{~m}$ while proportions of recaptured individuals displaced 20 and $30 \mathrm{~m}$ into forest were similar. It is possible that individuals displaced into pasture chose to remain at the release site instead of returning to capture sites more often than frogs 
displaced into forest, potentially to avoid competition with frogs defending territories in the forest. However, this scenario seems unlikely given that microclimatic conditions frequently occurring in pastures can be detrimental to sustained activity and survival, because temperatures can reach as high as $42^{\circ} \mathrm{C}$ (this study) and longer exposure times increase probability of mortality (Nowakowski et al., unpublished data). In addition, $O$. pumilio are relatively uncommon in pastures, particularly in areas far from the forest edge and where there are few remnant trees. The interaction between land-cover type and distance most likely reflects a distance-dependent difference in landscape resistance between secondary forest and pasture for $O$. pumilio.

One factor that may have contributed to differences in return rates from pasture and forest is impaired movement ability resulting from heat stress of frogs exposed to high temperature-low-humidity conditions that characterize pasture. Reduced movement ability in pastures could have increased the amount of time displaced frogs were exposed to inhospitable microclimatic conditions, which may have resulted in higher mortality rates in pasture. Previous studies have demonstrated that extreme temperatures (high or low) reduce movement performance in amphibians (Putnam and Bennett, 1981; Miller, 1982) and that mortality rates can differ between forested and open habitats (Rothermel and Luhring, 2005; Rittenhouse et al., 2008). Lower return rates could also be explained by higher rates of predation in pastures, where predator assemblages presumably differ from those found in forest. When field temperatures and humidity conditions were simulated in the laboratory, movement times were similar to those observed during field trials and weight loss was greater under simulated pasture conditions than in the control, 
which supports our assumption that microclimate influenced differences in movement times observed during field experiments.

The perceptual range of an organism or its ability to detect cues associated with habitat may determine dispersal success through novel habitats by influencing search times and thereby the amount of time individuals experience risks associated with disturbed habitats (Lima and Zollner, 1996; Belisle, 2005; Knowlton and Graham, 2010). Little is known about perceptual ranges in amphibians, despite the potential importance of this parameter in models of behavioral landscape ecology (Lima and Zollner, 1996). Evidence suggests that some amphibians use fine-scale cues, such as olfaction, substrate cues, microclimate, or vegetation cues to orient toward and select habitat and therefore may have generally limited perceptual ranges (McGregor and Teska, 1989; Rittenhouse et al., 2004). While some species may also use celestial or magnetic cues during dispersal and migration (Sinsch 2006), this form of navigation is not likely to aid in finescale habitat selection or avoidance of potentially inhospitable land-uses. Orientation in amphibians has been experimentally examined in some temperate species to determine if habitat alteration causes changes in migration behavior. These studies demonstrated that travel routes tend to be strongly directional towards forest habitat and away from open habitat such as pastures and roads (Gibbs, 1998; Mazarolle and Desrochers, 2005; Rittenhouse and Semlitsch, 2006), suggesting that adults may learn favorable migration routes that exclude disturbed habitats.

We found that initial orientation toward capture cites was non-random in disturbed habitat but not in natural habitat. Differences between undisturbed and disturbed habitats, in this case forest and pasture, were likely attributable to differences in 
motivation; frogs displaced into pasture may have perceived greater risk and were more motivated to return to forest habitat. This explanation is supported by our findings that frogs displaced into forest consistently spent more time on the release platform than frogs displaced into pasture. In addition, there was an effect of displacement distance on orientation direction for frogs displaced into pasture but not into forest. If frogs displaced into forest were motivated to return to capture sites, but were unable to orient at greater distances because of attenuation of homing cues, we would have still expected to see non-random orientation at the $25 \mathrm{~m}$ distance on the basis of results from our initial displacement experiment. We also show that frogs displaced into pasture were unable to orient toward forest beyond a distance of $50 \mathrm{~m}$, which likely represents a limit in perceptual range for O. pumilio.

The landscape in Sarapiquí Costa Rica is highly dynamic and supports an impressive diversity of amphibians. While natural forests cover approximately one-third of the region, it is extensively fragmented and remnant forest patches are predominantly surrounded by a transitional matrix of pasture and cultivated lands (Sesnie et al. 2008). In our study system, there is variation among species in sensitivity to habitat fragmentation effects, with $O$. pumilio exhibiting moderate sensitivity compared to other species (Bell and Donnelly 2006). Despite the absence of data on physiological tolerances, O. pumilio is generally considered to be somewhat robust to habitat alteration because of reports that populations can attain high densities in secondary forest and abandoned cacao plantations (Savage 2002, Whitfield et al. 2007). However, this species is quite uncommon in prevalent land-uses such as pastures and heart-of-palm plantations and may be absent in fragments surrounded by intensive agriculture (Nowakowski et al., 
Kurz et al., unpublished data) suggesting that some land-uses are distinctly inhospitable for O. pumilio.

The configuration of remnant forest in our study area represents a scenario in which most nearest-neighbor fragments in relation to a given focal patch are beyond the perceptual range of $O$. pumilio and possibly other species of amphibians (Fig 5). For inter-patch movement to occur, frogs must often travel across a matrix in which the probability of return was lower for displaced $O$. pumilio, movement performance was reduced, and individuals were unable to orient towards habitat at distances greater than $50 \mathrm{~m}$ from forest edge. This information could help guide active reforestation and corridor efforts in the region. Specifically, experimental results reported here can serve to parameterize individual-based and graph-theoretic models of landscape connectivity (Belisle and Desrochers, 2002; Stevens et al., 2006; McRae et al., 2008) that could in turn be used to evaluate the effects of alternative land-use scenarios involving forest-pasture configuration on amphibian populations.

Increasingly, researchers are recognizing the importance of connectivity in modulating the effects of habitat loss and fragmentation in terrestrial systems (Ricketts, 2001; Watling et al., 2011). However, in the tropics, we currently lack a basic understanding of the effects of common land-uses on amphibians, which will hinder the development of effective conservation strategies targeting amphibian communities in these rapidly changing landscapes (Gardner et al., 2007b; Shanker and Ganeshaiah, 2010). Successful species conservation in the Neotropics will likely depend on the ability to incorporate human-land uses into recovery and management plans (Ranganathan and Daily, 2007). Initiatives that target networks of habitat and aim to restore connectivity 
within landscape mosaics will need to consider the relative resistance of widespread landuses to geneflow and dispersal, and the role of behavior in processes that allow for the establishment and persistence of variants within populations (Mouquet and Loreau, 2003; Ronce, 2007; Semlitsch, 2008). Our results show that pasture, a predominant land-use in the Sarapiquí region of Costa Rica, likely acts as a semi-permeable dispersal barrier between patches of forest habitat for $O$. pumilio.

\section{ACKNOWLEDGEMENTS}

We thank M. Veiman and A. Lee for their assistance in the field, R. Jiménez, L. Johnson, M. Klein and S. Thompson for their help in the laboratory, and J. Stynoski, K. Reider and J. Watling for comments that improved the manuscript. We also thank the landowners who allowed us to work on their properties, The Organization for Tropical Studies and the staff at La Selva Biological Station. This project was funded by NSF grant number DBI 0851933 and NSF OISE-0854259 and carried out with FIU-IACUC permission number 09-007. 


\section{LITERATURE CITED}

Achard, F., Eva, H. D., Stibig, H., Mayaux, P., Gallego, J., Richards, T., \& Malingreau, J. (2002). Determination of deforestation rates of the world's humid tropical forests. Science 297, 999-1002.

Anderson, G. S. \& Danielson, B. J. (1997). The effects of landscape composition and physiognomy on metapopulation size: role of corridors. Landscape Ecology 12, 261-271.

Baguette, M., \& Van Dyck, H. (2007). Landscape connectivity and animal behavior: functional grain as a key determinant for dispersal. Landscape Ecology 22, 11171129.

Becker, C. G., Fonseca, C. R., Haddad, C. F. B., Batista, R. F., \& Prado, P. I. (2007). Habitat split and the global decline of amphibians. Science 318, 1775-1777.

Belisle, M., \& Desrochers, A. (2002). Gap-crossing decisions by forest birds: an empirical basis for parameterizing spatially-explicit individual-based models. Landscape Ecology 17, 219-231.

Belisle, M. (2005). Measuring landscape connectivity: the challenge of behavioral landscape ecology. Ecology 86, 1988-1995.

Bell, K.E., \& Donnelly, M.A. (2006). Influence of forest fragmentation on community structure of frogs and lizards in northeastern Costa Rica. Conservation Biology 20, 1750-1760.

Calabrese, J. M. \& Fagan, W. F. (2004). A comparison-shopper's guide to connectivity metrics. Frontiers in Ecology and Environment 2, 529-536.

Donnelly, M. A. (1989). Effects of reproductive resource supplementation on space-use patterns in Dendrobates pumilio. Oecologia 81, 212-218.

FAO. (2009). State of the world's forests. FAO, United Nations, Rome, Italy.

Fahrig, L. (2001). How much habitat is enough? Biological Conservation 100, 65-74.

Fahrig, L. (2003). Effects of habitat fragmentation and biodiversity. Annual Review of Ecology, Evolution and Systematics 34, 487-515.

Fitzgibbon, S. I., Putland, D. A. \& Goldizen, A. W. (2007). The importance of functional connectivity in the conservation of a ground-dwelling mammal in an urban Australian landscape. Landscape Ecology 22, 1513-1525. 
Gardner, T. A., Barlow, J. \& Peres C. A. (2007a). Paradox, presumption and pitfalls in conservation biology: The importance of habitat change for amphibians and reptiles. Biological Conservation 138, 166-179.

Gardner, T.A., Barlow, J., Parry, L.W. \& Peres, C. A. (2007b). Predicting the uncertain future if tropical forest species in a data vacuum. Biotropica 39, 25-30.

Gibbs, J. P. (1998). Amphibian movements in response to forest edges, and streambeds in Southern New England. The Journal of Wildlife Management 62, 584-589.

Henein, K. \& Merriam, G. (1990). The elements of connectivity where corridor quality is variable. Landscape Ecology 4, 157-170.

Knowlton, J. L., \& Graham, C. H. (2010). Using behavioral landscape ecology to predict species' responses to land-use and climate change. Biological Conservation 143, $1342-1354$.

Kupfer, J., Malanson, G. P., \& Franklin, S. B. (2006). Not seeing the ocean for the islands: the mediating influence of matrix-based processes on forest fragmentation effects. Global Ecology \& Biogeography. 15, 8-20.

Lees, A. C., \& Peres, C. (2009). Gap-crossing movements predict species occupancy in Amazonian forest fragments. Oikos 118, 280-290.

Lima, S. L., \& Zollner, P. A. (1996). Towards a behavioral ecology of ecological landscapes. TREE 11, 131-135.

Lips, K. R., Burrowes, P. A., Mendelson, J. R., \& Parra-Olea, G. (2005). Amphibian population declines in Latin America: a synthesis. Biotropica 37, 163-165.

Malmgren, J. C. (2002). How does a newt find its way from a pond? Migration patterns after breeding and metamorphosis in great crested newts (Triturus cristatus) and smooth newts (T. vulgaris). Herpetological Journal 12, 29-35.

Marsh, D. M., Thakur, K. A., Bulka, K. C., \& Clarke, L. B. (2004). Dispersal and colonization through open fields by a terrestrial, woodland salamander. Ecology 85, 3396-3405.

Mazerolle, M. J., and A. Desrochers. 2005. Landscape resistance to frog movement. Can. J. Zool. 83:455-464.

Mazerolle, M. J., Desrochers, A. \& Rochefort, L. (2005). Landscape characteristics influence pond occupancy by frogs after accounting for detectability. Ecological Applications 15, 824-834. 
McGregor, J. H., \& Teska, W. R. (1989). Olfaction as an orientation mechanism in migrating Ambystoma maculatum. Copeia 1989, 779-781.

McRae, B. H., Dickson, B. G., Keitt, T. H., \& Shah, V. B. (2008). Using circuit theory to model connectivity in ecology, evolution, and conservation. Ecology 89, 27122724.

McVey, M. E., Zahary, R. G., Perry, D. \& MacDougal, J. (1981). Territoriality and homing behavior in the poison dart frog (Dendrobates pumilio). Copeia 1, 1-8.

Miller, K. (1982). Effect of temperature on sprint performance in the frog Xenopus laevis and the salamander Necturus maculosus. Copeia 1982, 695-698.

Mouquet, N., \& Loreau, M. (2003). Community patterns in source-sink metacommunities. The American Naturalist 162, 544-557.

Ovaskainen, O., Luoto, M., Ikonen, I., Rekola, H., Meyke, E., \& Kuussaari, M. (2008). An empirical test of a diffusion model: predicting clouded Apollo movements in a novel environment. The American Naturalist 171, 61-619.

Pope, S. E., Fahrig, L., \& Merriam, H. G. (2000). Landscape complementation and metapopulation effects on leopard frog populations. Ecology 81, 2498-2508.

Putnam, R. W., \& Bennett A. F. (1981). Thermal dependence of behavioural performance of anuran amphibians. Animal Behavior 29, 502-509.

Ranganathan, J., \& Daily, G. C. (2007). La biogeographía del paisaje rural: oportunidades de conservacíon para paisajes de Mesoamérica manejados por humanos. In: Evaluación de biodiversidad en paisajes freagmentados de Mesoamérica (eds Harvey, C. A., and J. C. Sáenz), pp. 15-25. Editorial INBio, Costa Rica.

Ricketts, T. H. (2001). The matrix matters: effective isolation in fragmented landscapes. The American Naturalist 158, 88-98.

Rittenhouse, T.A.G., Doyle, M.C., Mank, C.R., Rothermel, B.B., Semlitsch, R.D. (2004). Substrates cues influence habitat selection by spotted salamanders. Journal of Wildlife Management 68, 1151-1158.

Rittenhouse, T.A.G., \& Semlitsch, R. D. (2006). Grasslands as movement barriers for a forest associated salamander: Migration behavior of adult and juvenile salamanders at a distinct habitat edge. Biological Conservation 131, 14-22. 
Rittenhouse, T. A. G., Harper, E. B., Rehard, L. R. \& Semlitsch, R. D. (2008). The role of microhabitats in the disseccation and survival of anurans in recently harvested oak-hickory forest. Copeia 4, 807-814.

Ronce, O. (2007). How does it feel to be like a rolling stone? Ten questions about dispersal evolution. Annual Reviews in Ecology, Evolution \& Systematics. 38, 231-53.

Rothermel, B. B., \& Semlitsch, R. D. (2002). An experimental investigation of landscape resistance of forest versus old-field habitat to emigrating juvenile amphibians. Conservation Biology 16, 1324-1332.

Rothermel, B. B., \& Luhring, T. M. (2005). Burrow availability and desiccation risk of mole salamanders (Ambystoma talpoideum) in harvested versus unharvested forest stands. Journal of Herpetology 39, 619-626.

Sanford, R. L. Jr., Paaby, P., Luvall, J. C. \& Phillips, E. (1994). Climate, geomorphology, and aquatic systems. In McDade, L.A.,Bawa, K.S., Hespenheide, H. A. \& Hartshorn, G.S. (Eds). La Selva: ecology and natural history of a neotropical rainforest. The University of Chigago Press, Chicago, IL.

Savage, J. M. (2002). The amphibians and reptiles of Costa Rica: A herpetofauna between two continents, two seas. The University of Chicago Press, Chicago, IL.

Sesnie, S. E., Gessler, P. E., Finegan, B. \& Thessler, S. (2008). Integrating Landsat TM and SRTM-DEM derived variables with decision trees for habitat classification and change detection in complex neotropical environments. Remote Sensing of Environment 112, 2145-2159.

Semlitsch, R. D. (2008). Differentiating migration and dispersal processes for pondbreeding amphibians. Journal of Wildlife Management 72, 260-267.

Shaanker, R. U., \& Ganeshaiah, K. N. (2010). Is there enough science for conservation Action? Biotropica 42, 563-565.

Sinsch, U. (2006). Orientation and navigation in Amphibia. Marine and Freshwater Behaviour and Physiology 39, 65-71.

Stevens, V., Pollus, E., Wesselingh, R. A., Schitckzelle, N. \& Baguette, M. (2004). Quantifying functional connectivity: experimental evidence for patch specific resistance in the Natterjack toad (Bufo calamita). Landscape Ecology 19, 829842. 
Stevens, V., Verkenne, C., Vandewoestijne, S., Wesselingh, R. A., \& Baguette, M. (2006). Gene flow and functional connectivity in the natterjack toad. Molecular Ecology 15, 2333-2344.

Smith, M. A. and Green, D. M. (2005). Dispersal and the metapopulation paradigm in amphibian ecology and conservation: are all amphibian populations metapopulations? Ecography 28, 110-128.

Tischendorf, L. \& Fahrig, L. (2000). On the usage and measurement of landscape connectivity. Oikos 90, 7-19.

Wang, I. J., \& Summers, K. (2010). Genetic structure is correlated with phenotypic divergence rather that geographic isolation in the highly polymorphic strawberry poison-dart frog. Molecular Ecology 19, 447-458.

Watling, J. I., Nowakowski, A. J., Donnelly, M. A., \& Orrock, J. L. (2011). Metaanalysis reveals the importance of matrix composition for animals in fragmented habitat. Global Ecology \& Biogeography. 20, 209-217.

Wells, K. D. (2007). The ecology and behavior of amphibians. The University of Chicago Press, Chicago, IL.

Whitfield, S. M., Bell, K. E., Philippi, T., Sasa, M., Bolaños, F., Chaves, G., Savage, J. M. \& Donnelly M. A. (2007). Amphibian and reptile declines over 35 years at La Selva, Costa Rica. Proceedings of the National Academy of Science 104, 83528356.

Vandermeer, J., \& Carvajal, R. (2001). Metapopulation dynamics and the quality of the matrix. The American Naturalist 158, 211-220.

Vellend M. (2005). Species diversity and genetic diversity: parallel processes and correlated patterns. The American Naturalist 166, 199-115.

Vié, J.C., Hilton-Taylor, C. \& Stuart, S.N. (eds.) (2009). Wildlife in a Changing WorldAn Analysis of the 2008 IUCN Red List of Threatened Species. Gland, Switzerland: IUCN.

Zollner, P. A., \& Lima., S. L. (2005). Behavioral tradeoffs when dispersing across a patchy landscape. Oikos 108, 219-230. 
Table 1.1. Parameter estimates from binary-logistic regression analysis where recapture rates were entered as the dependent variable, and land cover type, displacement distance, and the interaction between landcover and displacement distance are independent variables.

\begin{tabular}{lcccc}
\hline Term & Estimate $(\beta)$ & $\mathrm{SE}$ & $\mathrm{Chi}^{2}$ & $P$ \\
\hline Constant & 5.417 & 0.062 & 13.77 & $<0.001$ \\
Distance & -0.231 & 2.063 & 2.73 & $<0.001$ \\
Land-cover type & -3.41 & 0.082 & 4.29 & 0.098 \\
Land-cover type x distance & 0.171 & 1.511 & 12.85 & 0.038 \\
\hline
\end{tabular}




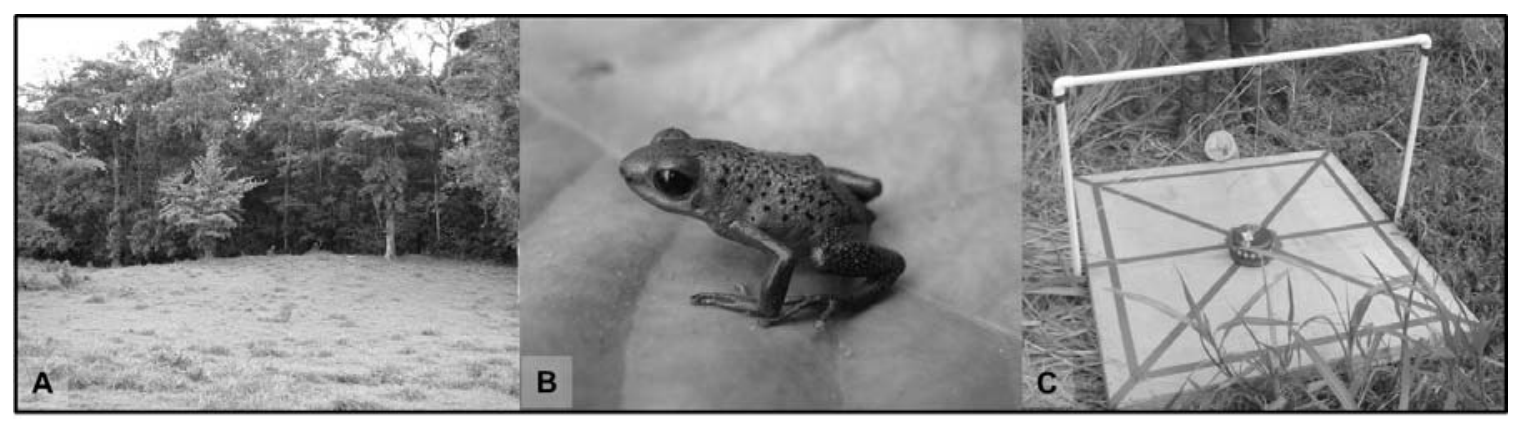

Figure 1.1. A) Forest-pasture edge at one of the study sites where displacement experiments were conducted in Sarapiquí, Costa Rica. B) An adult Oophaga pumilio. C) The release platform used during orientation experiments. 


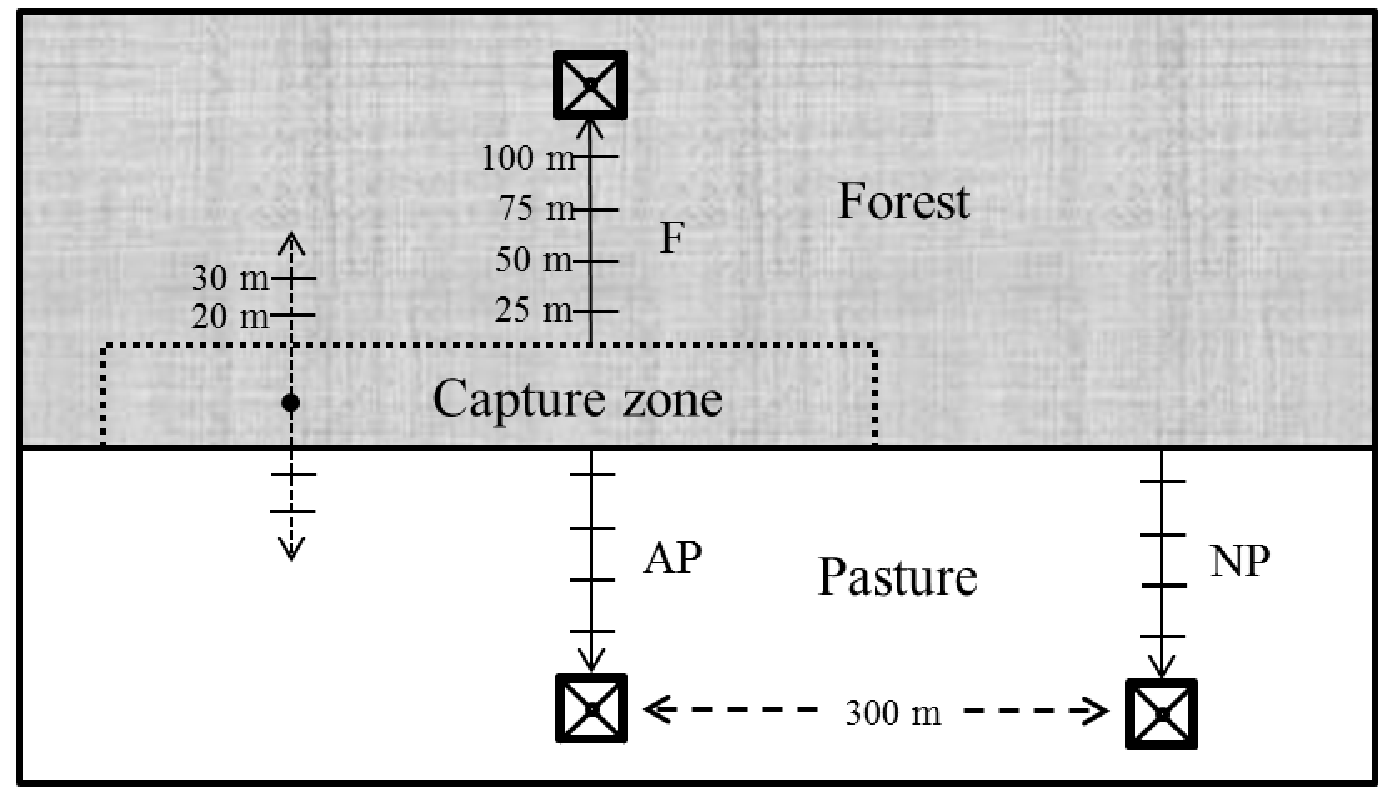

Figure 1.2. Design schematic for displacement experiments. Experiment in which return rates were measured is represented on the left; individuals were displaced either 20 or 30 $\mathrm{m}$ from capture sites. The orientation experiment involved displacing individuals from the boundaries of the collection zone adjacent to each capture site into forest $(\mathrm{F})$, adjacent pasture (AP), or novel pasture (NP). Boxes represent release platform. 


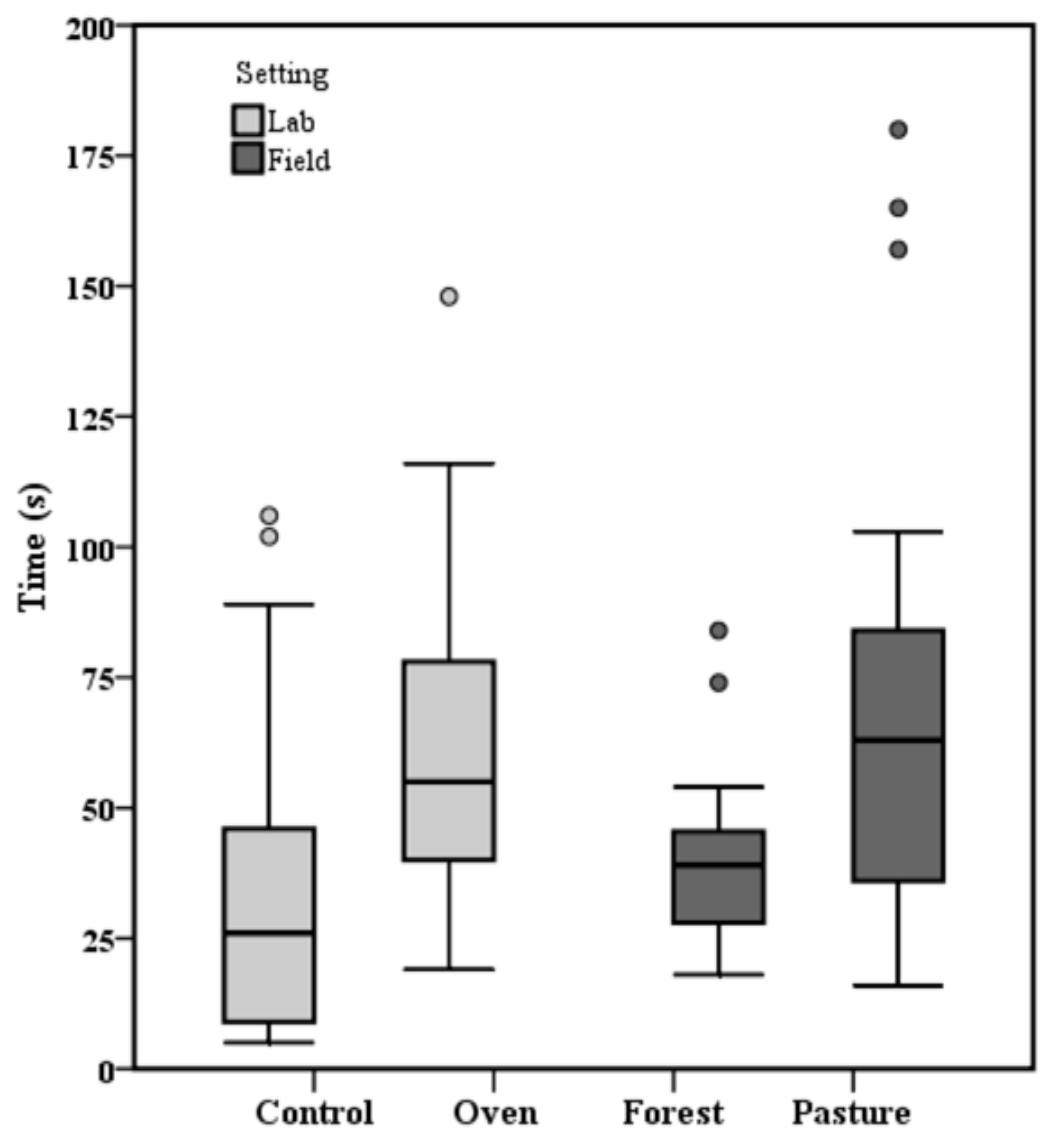

Figure 1.3. Boxplots display median, interquartile range, range, and outliers for travel times of $O$. pumilio following exposure to microclimatic conditions found in forest and pasture and under laboratory conditions. 


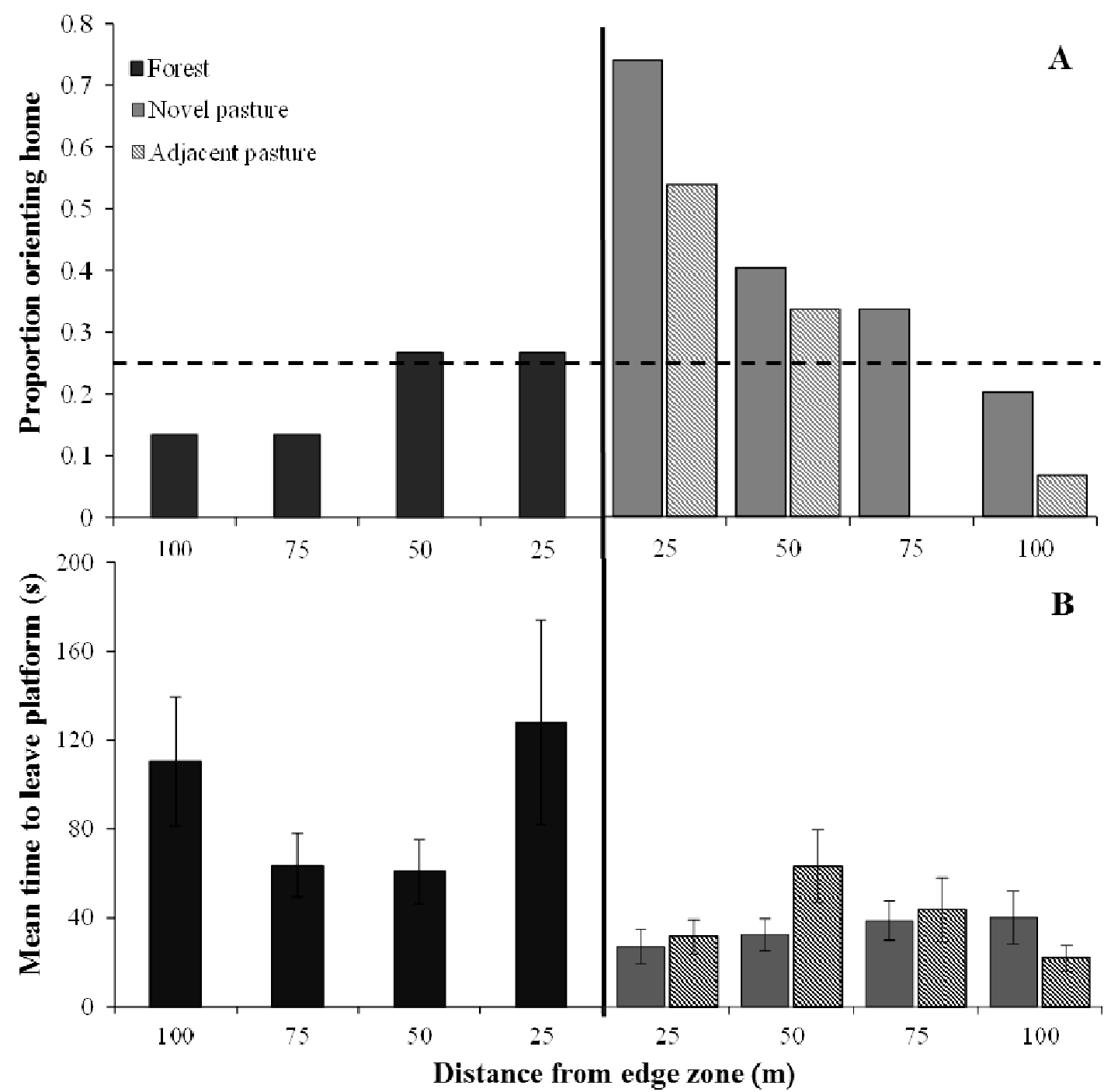

Figure 1.4. Proportion of displaced individuals orienting toward the forest edge was significantly affected by land-cover type and distance (A). Vertical solid line represents the collection zone and the horizontal dashed line represents the expected random probablity of orienting toward the edge $(0.25)$. Mean time taken to leave release platform (B) was significanlty different for frogs displaced into forest, adjacent pasture and novel pasture. Error bars represent the standard error. 


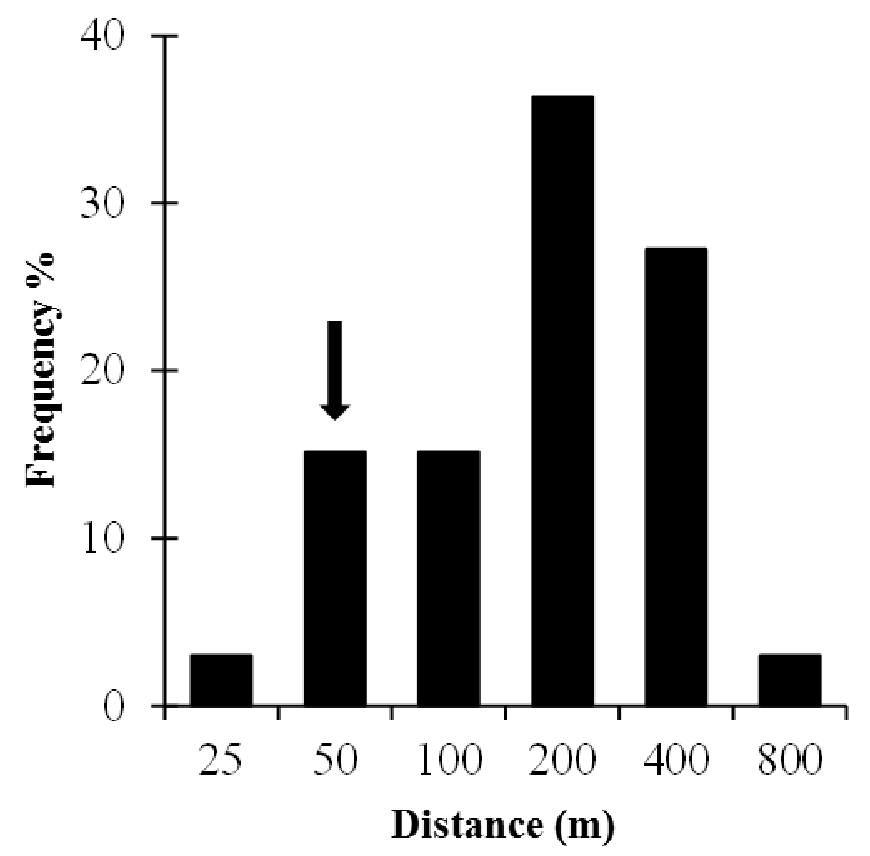

Figure 1.5. Frequencies of nearest neighbor distances of forest fragments within a 37.5 $\mathrm{km}^{2}$ area on the study landscape. Distances were measured from fragment edges using aerial photos. Fragments were defined as closed-canopy patches of trees with a diameter $\geq 100 \mathrm{~m}$. Arrow indicates the distance class $(26-50 \mathrm{~m})$ at which returns rates and orientation ability were reduced in pastures. 


\section{CHAPTER 2: EVALUATING CONNECTIVITY FOR TWO TROPICAL AMPHIBIANS USING EXPERIMENTALLY PARAMETERIZED RESISTANCE SURFACES}

\section{ABSTRACT}

Agricultural expansion continues to drive forest loss in species-rich tropical systems, and often disrupts distributions and movement of organisms. The ability of species to occupy and move through altered habitats likely depends on the level of contrast between natural forest and surrounding land uses. Connectivity models, such as circuit theory models, are widely used in conservation biology, and their primary input consists of resistance surfaces representing relative movement costs associated with landscape features. Cost values are most frequently determined by expert opinion which may not capture relevant levels of contrast among features. Here, we parameterized resistance surfaces using experiments that represent different local mechanisms hypothesized to affect connectivity for two neotropical amphibian species. We used relative abundance data in three land uses to generate independent resistance surfaces for evaluating the level of agreement between current-density maps derived from experiments and survey data. Consistency among movement pathways predicted for each species and among three commonly used connectivity measures was also analyzed. We found that microclimates associated with altered habitats significantly affected desiccation risk and survival for both species. Resistances estimate from microclimate experiments were concordant with those from survey data for both species. For one focal species, resistance estimates based on predator encounter rates were also highly correlated with abundance-derived resistance estimates. There was generally low agreement among estimates from different connectivity models, 
which underscores the importance of choosing models that best fit stated objectives or hypotheses. Overall, similarity among linkages modeled for each species was high, but decreased with amount of forest cover. Our results highlight the value of experiments for drawing inferences about processes in resistance modeling as well as the need to consider model differences and species-specific responses to landscapes when developing strategies to maintain connectivity.

\section{INTRODUCTION}

Human-population growth continues to drive deforestation and agricultural expansion in species-rich tropical ecosystems (FAO 2009). The common result is widespread loss and restructuring of habitat from once continuous forests into mosaics of remnant forest and anthropogenic land uses. These land uses vary in their habitat suitability and permeability for native organisms (Kupfer et al. 2006, Watling et al. 2011, Driscoll et al. 2013). Suitability and permeability likely depend on the level of contrast with natural forest in the amount and structure of remnant-native vegetation, composition of predator and parasite communities, microclimate, and availability of reproductive resources (Fischer and Lindenmayer 2007, McKenzie 2007, Felton et al. 2010, Karp et al. 2012). Measurement and integration of key variables that underlie habitat contrasts for focal organisms will help improve models of fragmented populations in complex landscapes (Biswas and Wagner 2012).

The disruption of natural flows of individuals and resources across the landscape is a major consequence of land-cover change and the associated contrast among forest and non-forest habitats. Landscape connectivity has emerged as a key concept in 
conservation biology, landscape ecology, and population genetics, because the interaction between landscape structure and species responses drives ecologically and evolutionarily important processes (Kool et al. 2013, Manel and Holderegger 2013). Among these processes, dispersal of individuals and geneflow are considered crucial for maintaining genetic diversity of local populations, allowing populations to respond to changing environments, and lowering risk of inbreeding depression and extinctions that translate to species loss at the community level (Frankham et al. 2002, Campbell Grant et al. 2010, Eklöf et al. 2012).

However, major challenges remain related to the characterization of connectivity, understanding its effects on population and community structure, and the application of research findings to the design of corridors and reserve networks (Beier et al. 2008).

These challenges include identifying appropriate methods for measuring connectivity and linking processes at local scales to landscape-scale patterns. Connectivity is most often evaluated at the landscape level using patch-derived or landscape metrics (Watling et al. 2011, Fahrig 2013), individual-based simulations, or graph theory-derived models (Urban and Keitt 2001, McRae and Beier 2007). Implementation of the graph-theory family of models often involves the use of resistance surfaces, which has become a fundamental approach in landscape genetics studies and forms the input for least-cost path and circuittheory models (Adriaensen et al. 2003, McRae et al. 2008).

Resistance surfaces provide a critical link between information on landscape configuration and species-specific responses to landscape features (Adriaensen et al. 2003). Typically, resistance surfaces consist of raster grids in which individual cells are assigned costs values that represent the degree to which landscape features impede or 
conduct the movement of individuals (Spear et al. 2010, Zeller et al. 2012). In addition to explaining patterns of movement and population structure in relation to landscape features, resistance surfaces can also represent specific mechanisms hypothesized to affect connectivity (Spear et al. 2010). Evaluating the importance of local mechanisms could help strengthen connectivity models and interpretation of landscape-scale studies (Stevens et al. 2006).

An important challenge associated with the use of resistance surfaces is the assignment of non-arbitrary weights to individual cells. Most studies to date have relied on expert opinion to parameterize cost surfaces, while others have used empirical methods, including radio telemetry data, field surveys, and population genetic parameters (Zeller et al. 2012). However, few studies have employed experimental methods to derive cost values for resistance surfaces, despite the potential for evaluating specific mechanisms underlying connectivity (Stevens et al. 2006).

Population and community-level effects of landscape connectivity are the aggregate results of local interactions between individual organisms and their environment that scale up to landscape-level patterns of distributions and gene flow. Connectivity is dependent upon species-specific physiology, motility, behavior, and trophic level as well as interactions with multiple biotic and abiotic features of the focal landscape (Cushman et al. 2011, Baguette et al. 2012, Nowakowski et al. 2013). Therefore, focus on potential underlying mechanisms should be informed by existing taxon-specific information. We focus here on amphibians, a group for which a high proportion of species are threatened with extinction and habitat loss is the most frequently identified cause of declines (Vié et al 2009). Because amphibians are small- 
bodied, have permeable skin and typically exhibit low vagility (Smith and Green 2005, Wells 2007), they may be exceptionally vulnerable to land-use change and the consequent loss of connectivity among remnant populations.

We used field experiments to measure the relative costs associated with five local mechanisms that may be important determinants of landscape resistance of forests, pastures, and heart-of-palm plantations to amphibian movement in northeastern Costa Rica. For two common species of anuran, we measured desiccation risk and associated mortality, predation risk, physical resistance of substrates to movement, and behavioral choice of substrates associated with each land-cover type. We used the response ratios from these experiments to parameterize resistance surfaces for six landscapes in northeastern Costa Rica that were then used as input for connectivity models. Relative abundance data for the focal species in the three land-cover types were used to generate resistance surfaces for evaluating independent support of each experimentally parameterized resistance surface.

Our primary objectives were to 1) develop cost surfaces that represent local mechanisms or sets of mechanisms that may affect landscape resistances for two amphibian species, 2) evaluate resistance models using an independent dataset for future downstream analyses of gene-flow rates, population-genetic structure, and community structure in this system, 3) examine the relationships among ecological distances derived from Circuitscape models, least-cost paths, and Euclidean distances to determine the level of agreement among these commonly used measures of connectivity, 4) analyze the extent of overlap between predicted movement pathways for the focal species, information useful for multi-species corridor design, and 5) from these analyses, draw 
inferences about land uses and local processes that likely affect connectivity for amphibian populations in tropical agro-landscapes.

\section{METHODS}

Study Area and Species

All fieldwork for this study was conducted between January 2010 and August 2012 in Sarapiquí canton of northeastern Costa Rica. The dominant natural habitat type in the region is tropical lowland wet forest and the climate is characterized by a mean annual temperature of $25^{\circ} \mathrm{C}$ and over $4 \mathrm{~m}$ of annual rainfall (Sanford et al. 1994, Savage 2002). Since the 1950s, much of the forested area has been fragmented and converted to pastures and other types of intensive agriculture (Butterfield 1994, Sesnie et al. 2008). Forest still covers approximately $30 \%$ of the landscape, while pastures are the most prevalent human land use. Other common agricultural schemes include banana, pineapple, and heart-of-palm (palmito) production. We conducted our experiments at $\mathrm{La}$ Selva Biological Station and at replicate sites in the surrounding landscape that each contained areas of adjacent forest, palmito, and pasture (Fig 1). We chose to work in pasture and palmito because these represent two common land uses that differ in vegetation structure and abiotic conditions. Pastures are characterized by thick cover of non-native grasses and scattered remnant trees (Robinson et al. 2013). Palmito consists of monocultures of Bactris gasipaes palms maintained in rows and at heights of approx. 2 $\mathrm{m}$; groundcover usually consists of palm fronds, bare soil and occasional herbaceous cover. 
Our focal species were common leaf litter frogs, Oophaga pumilio and Craugastor bransfordii. Oophaga pumilio in this region has red and blue coloration; the species possesses alkaloids in the skin that function in predator defense (Saporito et al. 2007a). The reproductive strategy of $O$. pumilio involves deposition and fertilization of eggs in the leaf litter where tadpoles hatch and are transported on the back of the female to phytotelm-rearing sites, such as bromeliads (Limerick 1980). The female later returns to rearing sites to deposit unfertilized eggs as food for developing tadpoles (Brust 1993). The species is common and is dependent upon forest resources for reproduction (Donnelly 1989), but does occur to a lesser extent in some disturbed habitats, such as pastures with remnant trees (Kurz et al. 2014, Robinson et al. 2013). Craugastor bransfordii is a small brown frog that forages and reproduces in the leaf litter (Savage and Emmerson 1970). Eggs are deposited in the leaf litter and undergo direct development. Craugastor bransfordii is also very common in forest habitats and can be found at modest abundances in palmito, but is rarely observed in pastures (Kurz et al. 2014). Both species are considered diurnal (Guyer and Donnelly 2005).

\section{Field Experiments and Surveys}

To examine major components of landscape connectivity for amphibians, including habitat-specific desiccation risk and associated survival, resistance of substrates to movement, behavior, and predation risk among land uses, we conducted four experiments. The first experiment was designed to measure water loss and survival of frogs exposed to microclimatic conditions associated with forest, palmito plantations, and pastures. For each trial in the experiment, we placed nine frogs (three in each land use) 
into individual enclosures for a one-hour period. Enclosures were placed at random distances and compass headings from the edge, while ensuring that enclosures within the same land use were placed at least ten meters apart from each other and at least $20 \mathrm{~m}$ from the forest edge. In the study system, vegetation structure in forest is not strongly influenced by distance to the edge and forest-land use transitions tend to be very abrupt (Fig. 1; Schedlbauer et al. 2007). Enclosures were constructed out of light-wire mesh rolled into cylinders measuring $45 \mathrm{~cm}$ tall and $15 \mathrm{~cm}$ in diameter (e.g., Rittenhouse et al. 2008). Grey window screen material was attached to the top of the enclosures using staples, while the bottom end of the enclosure was buried to approximately $5 \mathrm{~cm}$ into the ground. Ground cover (e.g., grass, leaf litter, debris) found directly adjacent to the enclosure was replaced at the bottom of each cage. Frogs were captured 12-24 hours prior to the start of experiments and kept individually in plastic containers with moist leaf litter in shaded, ambient conditions. The mass of all frogs was measured at the beginning and end of the trial in the field using an Acculab PP-62 digital scale and survival was recorded at the end of each trial. Trials were conducted at 4 replicate sites, on 16 different days, during morning and afternoon hours, and under a range of weather conditions to ensure that results are representative of the variation in climatic conditions that typically occurs in the region. We measured temperature and humidity inside each enclosure using ibutton Hygrochron sensors (Maxim Integrated Products).

A second experiment gauged the physical resistance to individual movement offered by common substrates found in each land use. Inside a shade house at La Selva Biological Station, we constructed $2 \times 0.5 \times 0.5 \mathrm{~m}$ experimental arenas from particle board. The bottom of each arena was covered with a plastic sheet and then covered with 
$\mathrm{a} \sim 10 \mathrm{~cm}$-thick layer of substrate collected within four replicate forests, pastures, and palmito plantations. Substrates were collected from the top $10 \mathrm{~cm}$ of soil and included leaf-litter and ground cover (fine debris and plants $<15 \mathrm{~cm}$ tall). Within each replicate land use substrates were collected from 3-4 randomly located points and transported to the shade house in plastic storage containers. For a given set of trials, we collected 15 frogs each for both species from secondary forest, and 5 individuals of each species were randomly assigned to a substrate type. Trials consisted of releasing a frog at one end of an arena and recording the time taken to traverse the length of the arena. A standardized stimulus was applied using a moveable wall. Every time the individual being tested stopped for 3 seconds, the wall was advanced to a point just behind the frog, without touching the frog. This method ensured that motivation was standardized across individuals and treatments (e.g., Stevens et al. 2004). However, a subset of trials was also conducted by naive observers (individuals not familiar with the study) to evaluate the potential for observer bias. Substrates were changed four times over the course of the experiment and all individuals were tested only once. The assignment of substrates to a given arena and the assignment of individual frogs to treatments were randomized.

A third experiment measured behavioral choice between forest substrates and substrates commonly encountered within pastures and palmito. These experiments were conducted in small chambers within a shade house using substrates collected from the upper 5-10 cm of soil (i.e., soil, litter and ground cover) found in randomly-located areas within pasture, palmito plantations, and forests. We used plastic storage containers as choice arenas $(33 \times 24 \times 13 \mathrm{~cm})$. Each experimental arena was divided at the center using a $6 \mathrm{~cm}$ tall partition, and held two substrates on either side of the partition, from 
forest and either palmito or pasture land-uses. Both sides of the arena were sprayed with equal amounts of untreated well water to ensure that frogs were responding to the substrates themselves as opposed to moisture gradients. A strip of cardboard ( $24 \times 6 \mathrm{~cm})$ was placed width-wise on top of the substrates, in the middle of the arena, and used as a release platform. Individuals were randomly assigned to treatments. Cardinal orientation of arenas was alternated among replicate arenas so that there was not a directional bias associated with any given substrate. Before the start of each trial, frogs were placed, facing parallel to the center line of the arena, under a plastic cup on the release platform, for a five-minute acclimation period. The cups were then raised, and individuals were released at the center of the chamber and substrate choice was recorded initially and then every 15 minutes for 75 total minutes. Choice was scored as the substrate a frog was found on, and individuals found on the release platform were recorded as no choice.

We conducted a fourth experiment to test whether predator encounter rates differed by land-cover type and species. To obtain an index of predator encounter rates for each treatment, we employed a tethering experiment, a standard method for assessing predator encounters commonly used in marine ecology studies (Aronson et al. 2001, Hammerschlag et al. 2010). While this method does not provides estimates of actual predation rates, as prey are not able to use their entire suite of anti-predator behaviors, it does provide an estimate of encounter rates, which can reflect habitat-specific predator abundances or differences in prey detection. We conducted trials in four replicate areas that each included a forest remnant, palmito plantation, and pasture (Fig. 1). We established transects within each land-use type, located at least $25 \mathrm{~m}$ from and running parallel to the forest edge. Along each transect we tethered six frogs, three O. pumilio 
and three $C$. bransfordii, alternated at intervals of $10 \mathrm{~m}$ along the transect. The species tethered at the start of a transect was randomized. Frogs were tethered around the waist with $75 \mathrm{~cm}$ of black-sewing thread attached to a small wooden stake inserted into the ground. Individuals were randomly assigned to treatments. Trials were conducted for 16 hrs, from $16: 30 \mathrm{~h}$ to $08: 30 \mathrm{~h}$ to reduce the risk of heat-stress and dehydration. A conservative score of predator encounters was used that included only animals remaining tethered that had visible injuries likely resulting from predation attempts. Any animals missing at the end of a trial were excluded from the dataset. Individuals from all experiments were released at their original capture sites following the trials.

Field survey data were collected in June-August, 2011 at ten sites near La Selva Biological Station in Sarapiquí, each consisting of a forest fragment and adjacent pasture or palmito plot. Detailed methods and results are described in Kurz et al. (In Press). Briefly, $50 \mathrm{~m}$ long transects were established in forest adjacent to pasture, forest adjacent to palmito, pasture and palmito plots and searched for reptiles and amphibians. Transects were searched for $25 \mathrm{~min}$, and half of all transects were searched at night and the other half during the day. Oophaga pumilio and C. bransfordii were the two most commonly encountered species on forest transects.

\section{Statistical analysis of field experiments}

To analyze the effects of temperature and land-use type on water loss and survival we used generalized linear mixed effects models (GLMM) with a binomial distribution (Zuur et al. 2009). Water loss was calculated as the proportional change in mass of each individual measured at the start and end of a trial. These values were arc-sine transformed 
prior to analysis. Survival was coded as a binary response (alive or dead). Site was included as a random effect in the model. Fixed effects included species, sex, SVL (snout-vent length), temperature, and land-use type. A binomial GLMM was used to analyze predator removal probabilities, where predator encounters for each individual (encounter or no encounter) were the binary responses, site was a random effect, and species, land-use type, and total duration of the trial were included as fixed effects.

We analyzed mean travel times in substrate-resistance experiments using a general linear model that included land-use type, species, SVL, and sex as explanatory variables. A stepwise routine was used for variable selection and post-hoc comparisons were made using Tukey's HSD test. Binomial tests were used to analyze choices of substrates between forest and pasture or palmito. All analyses were conducted using the R v.2.15.1 (R Development Core Team, 2012).

\section{Circuitscape and Least-cost path models}

To compare resistance estimates obtained from experimental data to those derived from survey data, we used Circuitscape v3.5 to model landscapes as electrical circuits, movement as current flowing through the circuit, and to generate current maps (McRae and Shah 2009). Current maps represent variation in current densities along multiple pathways that predict net movement probabilities based on multiple random walks (McRae et al. 2008). We first produced resistance surfaces for six-25 $\mathrm{km}^{2}$ landscapes in Sarapiquí, Costa Rica using 30 m resolution land-cover rasters from 2001 (Sesnie et al. 2008). Land cover grids were reclassified by assigning weights to each land-cover type derived from response ratios calculated for experiments and for survey data. Response 
ratios for water loss, survival, predation, and substrate resistance experiments were calculated by dividing the mean responses in palmito and pasture by responses in forest, because greater response ratio values for these experiments are expected to be associated with increased resistance. Conversely, response ratios for survey data and the substrate choice experiment were calculated by dividing responses in forest by those in each land cover type, because we assumed lower resistance of forest habitat and that greater abundances and preferences reflects lower resistance. Forest, palmito, and pasture covered $80-94 \%($ mean $=86.2 \%)$ of the focal landscapes. We assigned cost values to the remaining land cover types on the basis of their structural similarity to measured land cover types (e.g., presence or absence of mid-story and canopy vegetation). Potential error associated with this approach should have negligible influence on the analysis, because unmeasured land uses represent a relatively small area of the focal landscapes, and the weighting scheme was standardized across all landscapes and comparisons.

To evaluate experimentally parameterized resistance surfaces, we generated a total of 72 cost surfaces, representing each [parameter source] x [species] x [landscape] combination, which were converted to ASCII format for input into Circuitscape v3.5 (McRae and Shah 2009). We modeled connectivity between two focal forest fragments in each landscape. Cell values were coded as resistances; higher values indicated greater costs associated with dispersal. Graphs were constructed by connecting focal cells to eight neighboring cells on the basis of average resistance values.

Correlations between map grid cell values were used to assess the level of agreement between experimentally derived resistance estimates and resistance estimates derived from survey data. Grid-cell values corresponding to focal fragments were deleted 
from the datasets prior to analyses to eliminate the influence of fragment size on correlation coefficients; we were solely interested in evaluating landscape resistances surrounding focal fragments. We compared current maps by estimating bootstrap correlations from 1000 bootstrap samples of cell values from each experiment-derived current map. We then modeled the fixed effects of experiment type (e.g., predation risk or desiccation risk, etc.), amount of forest cover on the landscape, and species identity on current map correlations using a GLMM implemented with package glmmPQL in R v.2.15.1 (R Development Core Team, 2012). Landscape was entered as a random effect. Correlation coefficients were squared prior to analysis. A quasibinomial distribution was specified because the response consisted of values ranging between 0 and 1 , and the variable was under-dispersed (i.e., variance was lower than expected, given the mean; Quinn and Keough 2002, Zuur et al. 2009).

We also combined resistance surfaces that represented combinations of local mechanisms. We combined the top two and three local mechanisms that individually had the highest correspondence with survey-derived resistance estimates. A modified metaanalytic weighted mean was used to combine response ratios. We used the inverse of the variance of the map correlations across landscapes for each mechanism to weight effect sizes, because this measure of variance reflects sensitivity to landscape configuration and is not affected by different experimental methods and response types.

To compare resistance distances and accumulated least cost path distances derived from circuit theory and LCPA, respectively, we parameterized cost surfaces for a $1800 \mathrm{~km}^{2}$ landscape using response ratios from survey data, because we considered relative abundances to be our best empirical index of resistance. We generated 20 random 
points on the landscape and modeled pairwise resistance values and accumulated least cost distances among all points for both $O$. pumilio and C. bransfordii. We also calculated Euclidean distances among all points to compare with resistance-derived measures of distance. Significance of associations between each combination of distance measure was assessed using Mantel tests.

Finally, we analyzed overlap between predicted corridors for both species. We modeled potential corridors between two focal forest fragments in six replicate $25 \mathrm{~km}^{2}$ landscapes using the ArcGIS toolkit Linkage Mapper (McRae and Kavanagh 2011). We used survey data to parameterize resistance surfaces used as input for Linkage mapper, which identifies least cost corridors delineated using cost-weighted distance surfaces. We limited the modeling space by designating $500 \mathrm{~m}$ radii bounding circles around each fragment. Modeled corridors were also clipped to a $500 \mathrm{~m}$ maximum width; this is an order of magnitude greater than the typical home range of $O$. pumilio (Donnelly 1989b), and we assume that this width is greater than the typical home range of $C$. bransfordii (see recommendations in Beier et al. 2008). Finally, we calculated the percent overlap of modeled corridors between species to quantify the degree of correspondence between species-specific linkages.

\section{RESULTS}

During microclimate exposure trials, the proportional weight loss for O. pumilio was $0.032 \pm 0.022($ mean $\pm \mathrm{SD})$ in forest, $0.085 \pm 0.06$ in palmito, and $0.109 \pm 0.08$ in pasture. For C. bransfordii, mean proportional change in weight was $0.024 \pm 0.03$ in forest, $0.097 \pm 0.082$ in palmito, and $0.091 \pm 0.091$ in pasture. Temperature was a highly 
significant variable in the GLMM analyzing proportional change in weight, while all other variables were non-significant (Fig 2a; Table 1). When temperature is dropped from the analysis, land cover type is marginally significant at $\alpha=0.05$ (Table S1). Mean temperatures across all trials were $26.8 \pm 1.8$ in forest, $31.3 \pm 4.7$ in palmito and $32.7 \pm$ 5.4 in pasture. All individuals survived one-hour exposure trials in forest. In palmito, $87.5 \%$ of $O$. pumilio individuals and $74.1 \%$ of $C$. bransfordii individuals survived the duration of the trial. In pastures, $75.8 \%$ of O.pumlio and $66.7 \%$ of C. bransfordii survived. Temperature during microclimate exposure trials was a highly significant predictor of survival probability (Fig 2b; Table 1). Survival was also positively associated with SVL; however, all other variables were non-significant.

We conducted a total of 109 and 92 substrate movement trials for $O$. pumilio and C. bransfordii, respectively. For $O$. pumilio, the mean movement times across substrates were $39.4 \pm 17.3 \mathrm{~s}$ in forest, $37.5 \pm 14.1 \mathrm{~s}$ across palmito substrates, and $62.7 \pm 21.7 \mathrm{~s}$ across pasture substrates (Fig 3a). For C. bransfordii, mean travel times were $40.6 \pm 19.6$ $\mathrm{s}$ across forest substrates, $41.0 \pm 14.8 \mathrm{~s}$ for palmito, and $71.2 \pm 36.3 \mathrm{~s}$ for pasture substrates. For trials conducted by naïve observers $(n=30)$, results were similar to those obtained by primary observers (Table S2). So, we included these trials in the final dataset reported here. In the global GLM that included species, sex, SVL, and treatment, treatment was the only significant factor affecting movement times $(P<0.05$; Table 2$)$. Treatment was the only variable retained in the model following stepwise selection. Multiple comparisons showed that there was no significant difference between forest and palmito times $(P=0.999)$, but movement times across pasture substrates were significantly slower than across forest and pasture substrates for both species $(P<0.001)$. 
Binomial tests showed no significant differences in preference for forest, pasture or palmito substrates for either species ( $P>0.05$ for all comparisons; Table $\mathrm{S} 3$ ).

No O. pumilio were killed in forest by predators, whereas $12 \%$ (4 out of 33 ) were killed in palmito, and $6 \%$ in pastures. For C. bransfordii, we recorded predator encounters for $21 \%$ of individuals in forest ( 7 out of 33 ), $18 \%$ in palmito, and $18 \%$ of individuals in pasture. Land cover type and time tethered were not significant factors in the model; however, probability of predator encounter did differ between species (Fig 3b; Table 2).

We analyzed agreement between resistance estimates derived from experimental data and field surveys using bootstrapped correlations of grid cell values. Main effects of the GLMM indicated that map correlation coefficients for mortality, water loss, and movement were significantly greater than those for behavior, which had the lowest correlation with estimates from survey data (Fig 4; Table 3). The main effect of species was also significant, but there was no effect of forest cover on map correlations. We present model results that include interactions between species and experiment type, which were significant for movement and predation experiments (Table 3). However, all main effects that were significant remained so after dropping interaction terms from the model (Table S2).

For $O$. pumilio, there were significant correlations between Euclidean distance and LCPA distances (Fig. 5; Mantel $r=0.636, P=0.001$ ) and between LCPA distances and resistance distance (Mantel $r=0.664, P=0.001$ ), but correlation between resistance distances and Euclidean distances was not significant (Mantel $r-0.021=P=0.495$ ). For C. bransfordii, Euclidean distances were also correlated with LCP distances (Mantel $r=$ 
0.433, $P=0.001$ ), but not resistance distances (Mantel $r=0.094, P=0.278$ ). Resistance distances and LCP distances were strongly correlated (Mantel $r=0.806, P=0.001$ ). The mean overlap between predicted species corridors was $83.5 \% \pm 10.8 \%$, and percent overlap increased with forest cover.

\section{DISCUSSION}

Here we develop multiple resistance surfaces using an experimental approach to derive relative cost values and validate our connectivity models using an independent dataset. We distinguish among local-scale mechanisms that are hypothesized to affect habitat selection and movement rates of migrant amphibians across different land cover types, finding that resistance estimates derived from measurement of desiccation risk and associated mortality were consistent with resistance models obtained from survey data for both species. We also compare pairwise accumulated cost distances and resistance distances with pairwise Euclidean distances among random points on the landscape, as these are three commonly used measures of inter-patch connectivity. These metrics did not exhibit consistent positive relationships, which has implication for their use in connectivity research and choice of connectivity metrics for conservation planning. There was moderate-to-high overlap between individual species corridors, and overlap increased with forest cover. Therefore, it will be even more important to consider species-specific responses to matrix elements when planning corridors in areas with low forest cover. 


\section{Experimental assessment of mechanistic connectivity}

Amphibians, as a group, are of critical conservation concern because one-third of species are threatened with extinction and even common species are experiencing population declines (Adams et al. 2013, Vié et al 2009, Whitfield et al. 2007). Amphibians may be particularly responsive to changes in the amount and configuration of habitat because they typically exhibit limited vagility, small body sizes and high sensitivity to microclimatic variation. Among the local factors that mediate population responses to land use change, migrant mortality may be a key parameter determining connectivity (Eklof et al. 2012, Griffiths et al. 2010), and desiccation and thermal stress are likely important causes of amphibian mortality in human-modified habitats (Rothermel and Luhring 2005, Rittenhouse et al. 2008). We observed higher temperatures in pastures and palmito plantations than in forest that were in turn associated with greater desiccation risk and decreased survival (Fig 2).

Our results suggest that land uses with little vegetation cover and relatively warmer, drier microclimates can represent significant dispersal barriers for amphibian species in Sarapiquí. These results are consistent with previous work that found decreased return rates for individuals displaced $30 \mathrm{~m}$ into pasture in comparison to the same distance into forest, as well as reduced movement performance associated with high temperatures in pastures (Nowakowski et al. 2013). It is possible that individuals may initiate dispersal during heavy rain events or at night to avoid desiccation. However, most distances among forest patches are greater than $200 \mathrm{~m}$ in the study landscape, which almost ensures that for long-distance dispersal to occur, individuals will encounter microclimatic conditions measured during our experiments. Whether dispersal success is 
reduced by increased mortality of migrants or by reduced number of dispersal attempts, altered habitats will likely increase isolation of local populations.

Risk of desiccation and mortality associated with heat stress may contribute to behavioral avoidance of open or dry habitats following forest conversion (Cosentino et al. 2011). For example, in temperate regions, radio-tagged adult Ambystoma maculatum avoided open grasslands adjacent to forests (Rittenhouse and Semlitsch 2006), and juvenile A. maculatum and Anaxyrus americanus oriented toward forest when leaving experimental pools located on forest-field edges. In our study area, previous experiments showed that $O$. pumilio tended to orient towards forest habitat when displaced into pasture, presumably using cues that attenuated at distances greater than 25-50 m (Nowakowski et al. 2013). Given that amphibians likely have limited perceptual ranges, they may use fine-scale information, such as substrate cues, for habitat selection during migrations (Rothermel 2004, Rittenhouse et al. 2004). Janin et al. (2012) found that adult Bufo bufo avoided substrates associated with plowed fields and individuals placed on plowed substrates had higher cortecosterone concentrations than those on forest and meadow substrates. While $C$ bransfordii and $O$. pumilio did not exhibit strong preferences for specific substrates during our experiments, lack of substrate preference does not preclude the possibility that behavior is an important factor mediating connectivity in the study system. It is possible that use of substrate cues is scaledependent (our enclosures were relatively small), or that these species focus on other cues that allow them to select suitable habitats, such as canopy closure, microclimatic variation, or refuge availability. 
Substrate type was an important determinant of movement speeds through experimental arrays. We tested the physical resistance to movement associated with common substrates from each land-use type and found that thick grasses that dominate in pastures resulted in significantly slower movement speeds in comparison to forest and palmito substrates (Fig 3a). Similarly, Semlitsch et al. (2012) found that Plethodon metcalfi individuals tended to move more slowly across grass substrates when compared to other substrates found in anthropogenically-modified habitats. Migrating individuals may experience variation in energetic costs when traveling through different matrix types, Relative difficulty of moving across pasture substrates likely translates to increased energy expenditures and increased time exposed to inhospitable microclimatic conditions. Presumably, higher energetic costs associated with moving across pasture grasses in Sarapiquí could result in lower dispersal success, decreased dispersal distances, or increased avoidance of pastures.

Finally, predator guilds, such as bird, mammal, insect, and arachnid assemblages differ between forest and adjacent human land uses (Daily et al. 2001, Daily et al. 2003). Therefore, predation risk likely differs among land-cover types, contributing to contrast among habitats in risk and suitability perceived by prey species (Heithaus et al. 2009). Both direct and indirect effects of predation may affect the distribution and movement pathways of amphibians. While statistical analysis did not reveal an effect of habitat type on predator encounter rates, possibly due to low power, there appeared to be habitat trends for O. pumilio and there was a significant species effect. For C. bransfordii, frequency of predation was similar across habitats (Fig 3b). However, for O. pumilio, we observed no predation in forest, while there were predator encounters in palmito 
plantations and pastures. We know no other studies that have examined predation risk for amphibians using tethering experiments; however, our results for forest habitat are consistent with experiments that have assessed predation risk for the aposematic $O$. pumilio in comparison with cryptically colored leaf-litter frogs using clay models (Saporito 2007b). We observed predator encounters in anthropogenic habitats for this species; though not statistically distinguishable from the zero encounters recorded in forest, they may reflect the presence of different, possibly naïve, predators.

\section{Connectivity modeling}

Response ratios from our experiments provided estimates of relative costs associated with each land use that were then used to parameterize resistance surfaces. Importantly, our approach provided an objective means for determining the degree of contrast among land uses in terms of cost estimates. The most common approach for parameterizing resistance surfaces has been the use of expert opinion (Keller et al. 2012). While it may be reasonable to predict the rank order of resistances for well-known species and habitats, the relative magnitude of these costs can have a large influence on least cost path and resistance estimates (Rayfield et al. 2010, Koen et al. 2012). Therefore, high sensitivity of models to the magnitude of cost contrast among land uses may make estimates derived from expert opinion unreliable for many applications. It should be noted that, while experiments may provide biologically relevant information about habitat contrasts, cost values derived from experiments will not be free of variance associated with choice of experimental protocols or methods used to translate experimental results (e.g., means or effect sizes) into cost values. 
Current maps generated using habitat-specific desiccation risk and survival information both produced strong correlations with maps generated from relative abundance data (Fig 4). For O. pumilio, but not C. bransfordii, resistance estimates from the predation risk experiment were also highly correlated with estimates from abundance data, which was reflected by the significant interaction between species and predation. We conclude that desiccation risk and mortality risk associated with desiccation should be important predictors of habitat-specific movement rates for these species in the agricultural landscape of Sarapiquí, Costa Rica. While body size and behavioral strategies for avoiding desiccation vary among species and can moderate water loss to an extent (Rittenhouse et al. 2008, Wells 2007), it is likely that physiological mechanisms for maintaining water balance are fairly conserved across species, particularly for species within the same genus (reviewed in Wells 2007). Therefore, in the absence of experimental data, habitat-specific temperature information could serve as a useful index of desiccation risk for studies of landscape resistance to amphibian movement (e.g., Trumbo et al. 2013).

We compared Euclidean, accumulated-least cost, and resistance distances derived from relative-abundance data for both species, because these are among the most commonly used measures for assessing landscape connectivity. There were marked disparities among these three methods, suggesting that choice of connectivity analyses should be carefully considered as they reflect different information content that may or may not be important predictors of animal movement (Adriaensen et al. 2003, McRae et al. 2008). There was moderate agreement between least-cost distances and Euclidean distances, and between least cost distances and resistance distances (Fig 5). However, 
there was not a positive relationship between resistance distances and Euclidean distances. For least-cost path models, pairwise values that deviated most from a linear relationship with Euclidean distances were those that had highest combined rank cost values (Fig 5a), which is consistent with results of Rayfield et al. (2010).

It is important to note the conditions under which these three methods will deviate and determine which is most relevant to a given application. A uniform landscape should produce LCP and resistance distances that result in strong linear relationships with Euclidean distances (McRae et al. 2008). As landscape complexity increases along axes of heterogeneity and contrast among landscape elements, least-cost paths and resistance distances diverge from Euclidean distances (Koen et al. 2012, Rayfield et al. 2010). As the number of movement pathways increases, resistance distance estimates from circuit models decrease as a result of redundancy in the circuit, and LCP distances and resistance distances diverge. Resistance distances and least cost paths have been shown to improve model fit over Euclidean distance in analyses of population genetic structure (e.g., McRae and Beier 2007); however, this is not always the case (Velo-Anton et al. 2013).

\section{Conclusions}

In the study system, $O$. pumilio and $C$. bransfordii exhibited strong responses to microclimatic variation associated with different land uses, and desiccation risk proved to be a potentially important mechanism determining landscape resistance. The focal species are numerically dominant vertebrates in the region (Whitfield et al. 2007, Kurz et al. 2014) and likely fulfill important ecological roles as both predators and prey. Therefore disruption of movement and continued declines of these species could have 
negative consequences for the communities in which they occur. Strategies for maintaining connectivity for these species, and likely for others, will depend on landscape configuration and level of forest cover, as we observed species-specific responses to land uses (e.g., predation risk and relative abundances) and that predicted movement corridors diverged with decreasing forest cover.

The spatial arrangements of land uses in combination with their relative value as habitat are likely key factors affecting ecological processes such as movement paths, and ultimately the structure of populations and communities in human-modified landscapes (Driscoll et al. 2013, Karp et al. 2012, Pope et al. 2000). Scaling up from local-scale mechanisms to landscape-scale patterns of movement and community structure will allow for process-based inference in landscape ecological and genetic studies. A potential limitation of the present study and others that use resistance surfaces is that fine-scale within-habitat variation, such the amount of remnant native vegetation (e.g., individual trees; Robinson et al. 2013), may be important for determining connectivity, but is not likely captured in land-cover data sets developed from $\geq 30 \mathrm{~m}$ resolution sources (e.g., Landsat). Future research should examine connectivity at multiple spatial scales and take advantage of high resolution imagery (e.g., $\leq 1 \mathrm{~m}$ ) for characterizing micro-connectivity within habitat types.

Research focused on local-scale mechanisms that contribute to landscape resistance will help conservation managers identify common factors that impede movement and develop multi-species strategies to maintain landscape connectivity. Analysis of resistance surfaces parameterized using experimental data represents a useful approach for investigating how local costs associated with landscape features may 
contribute to the distribution, abundances and movement of focal organisms. It is likely unavoidable that taxon-specific requirements will need to be considered. However, identification of generalized traits of organisms (e.g., body size and trophic level) and characteristics of landscapes (e.g., contrast and heterogeneity) that together modify resistances can serve as a useful compromise between species-specific and systemindependent approaches to characterizing landscape connectivity.

\section{ACKNOWLEDGMENTS}

We are grateful to Amanda Lee and Darvé Robinson for help in the field, to landowners who allowed us access to their properties, to the Costa Rican government (MINAESINAC) for providing permits, to The Organization for Tropical Studies for logistical support, and to J. Watling and M. Heithaus for helpful comments on the manuscript. AJN was supported by The Organization for Tropical Studies, Florida International University Dissertation Evidence Acquisition and Dissertation Year Fellowships during this study. All experimental protocols received IACUC approval (\#s 09-007, 10-023, \& 12-003). 


\section{LITERATURE CITED}

Adams, M. J., Miller, D. A. W., Muths, E., Corn, P. S., Campbell Grant, E. H., Bailey, L., Fellers, G. M., Fisher, R. N., Sadinski, W. J., Waddle, H., and Walls, S. C. 2013. Trends in amphibian occupancy in the United States. PLOSone: DOI: 10.1371/journal.pone.0064347

Adriaensen, F., J. P. Chardon, G. De Blust, E. Swinnen, S. Villalba, H. Gulinck, E. Matthysen. 2003. The application of 'least-cost' modeling as a functional landscape model. Landscape and Urban Planning 64:233-247.

Aronson, R., K. Heck, and J. Valentine. 2001. Measuring predation with tethering experiments. Marine Ecology Progress Series 214:311-312.

Baguette, M., Blanchet, S., Legrand, D., Stevens, V. M., and Turlure, C. 2012. Individual dispersal, landscape connectivity, and ecological networks. Biological Reviews 88:310-326.

Beier, P., D. R. Majka, and W. D. Spencer. 2008. Forks in the road: choices in procedures for desiging wildland linkages. Conservation Biology 22: 836-851.

Brust, D. G. 1993. Maternal brood care of Dendrobates pumilio: a frog that feeds its young. Journal of Herpetology. 27:96-98.

Butterfield, R. P. 1994. The regional context: land colonization and conservation in Sarapiquí. Pp. 299-306 in McDade, L. A., Bawa, K. S., Hespenheide, H. A. \& Hartshorn, G. S. (eds.). La Selva: ecology and natural history of a neotropical rainforest. University of Chicago Press, Chicago.

Campbell Grant, E. H., Nichols, J. D., Lowe, W. H., and Fagan, W. F. 2010. Use of multiple dispersal pathways facilitates amphibian persistence in stream networks. Proceedings of the National Academy of Sciences 107:6936-6940.

Consentino, B. J., Schooley, R. L., and Phillips, C. A. 2011. Connectivity of $\backslash$ agroecosystems: dispersal costs can vary among crops. Landscape Ecology 26:371-379.

Cushman, S. A., Raphael, M. G., Ruggiero, L. F., Shirk, A. S., Wasserman, T. N., and O’Doherty, E. C. 2011. Limiting factors and landscape connectivity: the American marten in the Rocky Mountains. Landscape Ecology 26:1137-1149.

Daily, G. C., Ehrlich, P. R., and Sánchez-Azofeifa, A. 2001. Countryside biogeography: use of human-dominated habitats by the avifauna of southern Costa Rica. Ecological Applications 11:1-13. 
Daily, G.C., Ceballos, G., Pacheco, J., Suzán, G., Sánchez-Azofeifa, A., 2003.

Countryside biogeography of neotropical mammals: conservation opportunities in agricultural landscapes of Costa Rica. Conservation Biology 17, 1814-1826.

Donnelly, M. A. 1989a. Demographic effects of reproductive resource supplementation in a territorial frog, Dendrobates pumilio. Ecological Monographs 59:207-221.

Donnelly, M. A. 1989b. Effects of reproductive resource supplementation on space-use patterns in Dendrobates pumilio. Oecologia 81:212-218.

Driscoll, D. A., S. C. Banks, P. S. Barton, D. B. Lindenmayer, and A. L. Smith. 2013. Conceptual domain of the matrix in fragmented landscapes. TREE. In Press.

Eklöf, A., Kaneryd, L., and Munger, P. 2012. Climate change in metacommunities: dispersal give double-sided effects on persistence. Phil. Trans. R. Soc. B 367:2945-2954.

FAO. 2009. State of the world's forests. FAO, United Nations, Rome, Italy.

Fahrig, L. 2013. Rethinking patch size and isolation effects: the habitat amount hypothesis. Journal of Biogeography 40:1649-1663.

Felton, A., Knight, E., Wood, J., Zammit, C., Lindenmayer, D., 2010. A meta-analysis of fauna and flora species richness and abundance in plantations and pasture lands. Biological Conservation 143, 545-554.

Fischer, J., and D. B. Lindenmayer. 2007. Landscape modification and habitat fragmentation: a synthesis. Global Ecology and Biogeography 16:265-280.

Frankham, R, Ballou, J. D., and Briscoe, D. A. 2002. Introduction to conservation genetics. Cambridge University Press, Cambridge, UK.

Griffiths, R. A., Sewell, D., and McCrea, R. S. 2010. Dynamics of a declining amphibian metapopulation: survival, dispersal, and the impact of climate. Biological Conservation 143:485-491.

Guyer, C. and Donnelly, M. A. 2005. Amphibians and Reptiles of La Selva, Costa Rica, and the Caribbean Slope: A Comprehensive Guide. University of California Press.

Heithaus, M. R., Wirsing, A. J., Burkholder, D., Thomson, J., and Dill. L. M. 2009. Towards a predictive framework for predator risk effects: the interaction of landscape features and prey escape tactics. Journal of Animal Ecology 78: 556562. 
Hammerschlag, N., M. Heithaus, and J. Serafy. 2010. Influence of predation risk and food supply on nocturnal fish foraging distributions along a mangrove-seagrass ecotone. Marine Ecology Progress Series 414:223-235.

Janin, A., Léna, J., Deblois, S., and Joly, P. 2012. Use of stress-hormone levels and habitat selection to assess functional connectivity of a landscape for an amphibian. Conservation Biology 26:925-951.

Karp, D.S., Rominger, A.J., Zook, J., Ranganathan, J., Ehrlich, P.R., Daily, G.C., 2012. Intensive agriculture erodes $\beta$-diversity at large scales. Ecology Letters 15, $963-$ 970.

Koen, E. L., Bowman, J., and Walpole, A. A. 2012. The effect of cost surface parameterization on landscape resistance estimates. Molecular Ecology Resources 12:686-696.

Kool, J. T., A. Moilanen, E. A. Treml. 2013. Population connectivity: recent advances and new perspectives. Landscape Ecology 28:165-185.

Kupfer, J., Malanson, G. P., \& Franklin, S. B. 2006. Not seeing the ocean for the islands: the mediating influence of matrix-based processes on forest fragmentation effects. Global Ecology \& Biogeography. 15, 8-20.

Kurz DJ, Nowakowski AJ, Tingley MW, Donnelly MA, Wilcove DS. 2014. Forest-land use complementarity modifies community structure of a tropical herpetofauna. Biological Conservation, 170, 246-255.

Limerick, S. 1980. Courtship behavior and oviposition of the poison-arrow frog Dendrobates pumilio. Herpetological 36:69-71.

Manel, S., and Holderegger, R. 2013. Ten years of landscape genetics. TREE. In Press.

McKenzie, V. J.. 2007. Human land use and patterns of parasitism in tropical amphibian hosts. Biological Conservation 137:102-116.

McRae, B. H., and P. Beier. 2007. Circuit theory predicts gene flow in plant and animal populations. Proceedings of the National Academy of Sciences 104:19885-19890.

McRae, B. H., B. G. Dickson, T. H. Keitt, and V. B. Shah. 2008. Using circuit theory to model connectivity in ecology, evolution, and conservation. Ecology 89:27122724.

McRae, B.H. and D.M. Kavanagh. 2011. Linkage Mapper Connectivity Analysis Software. The Nature Conservancy, Seattle WA. Available at: http://www.circuitscape.org/linkagemapper. 
McRae, B.H., and Shah, V.B. 2009. Circuitscape user's guide. The University of California, Santa Barbara. Available at: http://www.circuitscape.org.

Nowakowski, A. J., Otero Jiménez, B., Allen, M., Diaz-Escobar, M., and Donnelly, M. A. 2013. Landscape resistance to movement of the poison frog, Oophaga pumilio, in the lowlands or northeastern Costa Rica. Animal Conservation 16:188-197.

Pope, S. E., Fahrig, L., and Merriam, H. G. 2000. Landscape complementation and metapopulation effects on leopard frog populations. Ecology 81:2498-2508.

Quinn, G. P., and Keough, M. J. 2002. Experimental design and data analysis for biologists. Cambridge University Press, Cambridge UK.

R Development Core Team., 2012. R: A language and environment for statistical computing. R Foundation for Statistical Computing, Vienna, Austria. ISBN 3900051-07-0, URL http://www.R-projectorg/.

Rayfield, B., Fortin, M., and Fall, A. 2010. The sensitivity of least-cost habitat graphs to relative cost surface values. Landscape Ecology 25:519-532.

Rittenhouse, T.A.G., Doyle, M.C., Mank, C.R., Rothermel, B.B., and Semlitsch, R.D. (2004). Substrates cues influence habitat selection by spotted salamanders. Journal of Wildlife Management 68, 1151-1158.

Rittenhouse, T.A.G., \& Semlitsch, R. D. 2006. Grasslands as movement barriers for a forest associated salamander: Migration behavior of adult and juvenile salamanders at a distinct habitat edge. Biological Conservation 131, 14-22.

Rittenhouse, T. A. G., Harper, E. B., Rehard, L. R. \& Semlitsch, R. D. 2008. The role of microhabitats in the disseccation and survival of anurans in recently harvested oak-hickory forest. Copeia 4, 807-814.

Robinson, D., Warmsley, A., Nowakowski, A. J., Reider, K. E., and Donnelly, M. A. 2013. The value of remnant trees in pastures for a neotropical poison frog. Journal of Tropical Ecology 29:345-352.

Rothermel., B. B. 2004. Migratory success of juveniles: a potential constraint on connectivity for pond-breeding amphibians. Ecological Applications 14:15351546 .

Rothermel, B. B., and Luhring, T. M. 2005. Burrow availability and desiccation risk of mole salamanders (Ambystoma talpoideum) in harvested versus unharvested forest stands. Journal of Herpetology 39, 619-626. 
Sanford, R. L. Jr., Paaby, P., Luvall, J. C. \& Phillips, E. 1994. Climate, geomorphology, and aquatic systems. In McDade, L.A.,Bawa, K.S., Hespenheide, H. A. \& Hartshorn, G.S. (Eds). La Selva: ecology and natural history of a neotropical rainforest. The University of Chigago Press, Chicago, IL.

Saporito, R.A., Donnelly, M.A., Norton, R., Garraffo, H.M., Spande, T.F., and Daly, J.W. 2007a Oribatid mites as a major dietary source for alkaloids in poison frogs. Proceedings of the National Academy of Sciences 104: 8885-8890.

Saporito, R. A., Zuercher, R., Roberts, M., Gerow, K. G., and Donnelly, M. A. 2007 b. Experimental evidence of aposematism in the Dendrobatid poison frog, Oophaga pumilio. Copeia 2007:1006-1011.

Savage, J. M., and Emmerson, S. B. 1970. Central American frogs allied to Eleutherodactylus bransfordii (Cope): a problem of polymorphism. Copeia 1970:623-644.

Savage, J. M. (2002). The amphibians and reptiles of Costa Rica: A herpetofauna between two continents, two seas. The University of Chicago Press, Chicago, IL.

Schedlbauer, J. L., Finegan, B, and Kavanagh, K. L. 2007. Rain forest structure at forestpasture edges in northeastern Costa Rica. Biotopica 39:578-584.

Semlitsch, R. D., Ecrement, S., Fuller, A., Hammer, K., Howard, J. Krager, C., Mozeley, J., Ogle, J., Shipman, N., Speier, J., Walker, M., and Walters, B. 2012. Natural and anthropogenic substrates affect movement behavior of the Southern Graycheek Salamander (Plethodon metcalfi). Canadian Journal of Zoology 90:1128-1135.

Sesnie, S. E., Gessler, P. E., Finegan, B. \& Thessler, S. (2008). Integrating Landsat TM and SRTM-DEM derived variables with decision trees for habitat classification and change detection in complex neotropical environments. Remote Sensing of Environment $112,2145-2159$.

Spear, S. F., N. Balkenhol, M. J. Fortin, B. H. Mcrae, and K. Scribner. 2010. Use of resistance surfaces for landscape genetic studies: considerations for parameterizations and analysis. Molecular Ecology 19:3576-3591.

Stevens, V., Pollus, E., Wesselingh, R. A., Schitckzelle, N. \& Baguette, M. (2004). Quantifying functional connectivity: experimental evidence for patch specific resistance in the Natterjack toad (Bufo calamita). Landscape Ecology 19, 829842. 
Stevens, V. M., C. Verkenne, S. V. Andewoestijne, R. A. Wesselingh, and M. Baguette. 2006. Gene flow and functional connectivity in the natterjack toad. Molecular Ecology 15:2333-2344.

Trumbo, D. R., S. F. Spear, J. Baumsteiger, and A. Storfer. 2013. Rangewide landscape genetics of an endemic Pacific northwestern salamander. Molecular Ecology 22, $1250-1266$.

Urban, D., and T. Keitt. 2001. Landscape connectivity: a graph-theoretic perspective. Ecology 82:1205-1218.

Velo-Antón, G., Parra, J. L., Parra-Olea, G., and Zamudio, K. R. 2013. Tracking climate change in a dispersal-limited species: reduced spatial and genetic connectivity in a montane salamander. Molecular Ecology 22:3261-3278.

Vié, J.C., Hilton-Taylor, C. \& Stuart, S.N. (eds.) 2009. Wildlife in a Changing WorldAn Analysis of the 2008 IUCN Red List of Threatened Species. Gland, Switzerland: IUCN.

Watling, J.I., Nowakowski, A.J., Donnelly, M.A., Orrock, J.L., 2011. Meta-analysis reveals the importance of matrix composition for animals in fragmented habitat. Global Ecology and Biogeography 20, 209-217.

Wells, K. D. 2007. The ecology and behavior of amphibians. The University of Chicago Press, Chicago, IL.

Whitfield, S. M., Bell, K. E., Philippi, T., Sasa, M., Bolaños, F., Chaves, G., Savage, J. M. \& Donnelly M. A. (2007). Amphibian and reptile declines over 35 years at La Selva, Costa Rica. Proceedings of the National Academy of Science 104, 83528356.

Zeller, K. A., K. McGarigal, A. R. Whiteley. 2012. Estimating landscape resistance to movement: a review. Landscape Ecology 27:777-797.

Zuur, A. F., Ieno, E. N., Walker, N. J., Saveliev A. Z. \& Smith, G. M. 2009. Mixed effects models and extensions in ecology with R. Springer, New York. 
Table 2.1. GLMM results for analyses of water loss and survival during microclimatic exposure experiments. Significant variables are indicated with asterisks.

\begin{tabular}{lrrrl}
\hline Variable & Estimate & Std. Error & \multicolumn{1}{c}{$\mathbf{z}$} & p-value \\
\hline Water loss GLMM & & & & \\
(Intercept) & -5.764 & 2.506 & -2.300 & $0.021 *$ \\
Species [Op] & 0.096 & 0.391 & 0.245 & 0.807 \\
SVL (mm) & -0.027 & 0.086 & -0.317 & 0.751 \\
Sex [M] & -0.101 & 0.437 & -0.231 & 0.817 \\
Land Cover [Palmito] & 0.010 & 0.575 & 0.017 & 0.987 \\
Land Cover [Pasture] & -0.207 & 0.616 & -0.335 & 0.737 \\
inTemp & 0.166 & 0.050 & 3.342 & $0.001 * * *$ \\
& & & & \\
Survival GLMM & & & & \\
(Intercept) & -31.052 & 2658.590 & -0.012 & 0.991 \\
Species [Op] & -1.073 & 1.000 & -1.074 & 0.283 \\
SVL.(mm) & -0.771 & 0.282 & -2.734 & $0.006 * *$ \\
Sex [M] & 0.454 & 0.928 & 0.489 & 0.625 \\
Land Cover [Palmito] & 14.354 & 2658.585 & 0.005 & 0.996 \\
Land Cover [Pasture] & 14.179 & 2658.585 & 0.005 & 0.996 \\
inTemp & 0.947 & 0.223 & 4.251 & $0.000 * * *$ \\
\hline
\end{tabular}


Table 2.2. Model results for analyses of substrate resistance trials and predator encounters during tethering experiments. Significant variables are indicated with asterisks.

\begin{tabular}{lcccc}
\hline Variable & Es timate & Std. Error & t-value & p-value \\
\hline Substrate resistance Global GLM & & & \\
(Intercept) & 4.006 & 0.373 & 10.734 & $<0.001 * * *$ \\
Sex [M] & -0.095 & 0.077 & -1.235 & 0.218 \\
Species [Op] & -0.024 & 0.069 & -0.351 & 0.726 \\
SVL (mm) & -0.017 & 0.017 & -1.045 & 0.298 \\
Land use [Palmito] & 0.011 & 0.079 & 0.142 & 0.887 \\
Land use [Pasture] & 0.481 & 0.077 & 6.266 & $<0.001 * * *$ \\
& & & & \\
Substrate resistance Final GLM & & & \\
(Intercept) & 3.601 & 0.055 & 65.737 & $<0.001 * * *$ \\
Land use [Palmito] & 0.000 & 0.079 & 0.000 & 1.000 \\
Land use [Pasture] & 0.481 & 0.076 & 6.292 & $<0.001 * * *$ \\
Pre dation GLMM & & & & \\
(Intercept) & -2.479 & 3.942 & -0.629 & 0.530 \\
Species [Op] & -1.271 & 0.504 & -2.524 & $0.012 *$ \\
Land use [Palmito] & 0.324 & 0.562 & 0.576 & 0.564 \\
Land use [Pasture] & 0.167 & 0.569 & 0.294 & 0.769 \\
Time tethered & 0.063 & 0.269 & 0.234 & 0.815 \\
\hline
\end{tabular}


Table 2.3. GLMM results for analysis of factors explaining variation in correlation coefficients between experiment and survey-derived current maps from Circuitscape output. Significant variables are indicated with asterisks.

\begin{tabular}{lrrrc}
\hline Variable & Estimate & Std.Error & t-value & p-value \\
\hline Map correlations GLMM & & & & \\
(Intercept) & -3.181 & 1.029 & -3.091 & $0.003 * *$ \\
Forest cover & 2.771 & 1.815 & 1.526 & 0.202 \\
Experiment[Mort] & 2.348 & 0.286 & 8.198 & $<0.001 * * *$ \\
Experiment[Move] & 0.866 & 0.288 & 3.005 & $0.004 * *$ \\
Experiment[Pred] & 0.236 & 0.305 & 0.772 & 0.444 \\
Experiment[Water] & 1.410 & 0.282 & 4.998 & $<0.001 * * *$ \\
Species[Op] & 1.858 & 0.282 & 6.593 & $<0.001 * * *$ \\
Experiment[Mort]:Species & -0.067 & 0.438 & -0.152 & 0.880 \\
Experiment[Move]:Species & -0.824 & 0.375 & -2.196 & 0.033 \\
Experiment[Pred]:Species & 3.109 & 0.572 & 5.432 & $<0.001 * * *$ \\
Experiment[Water]:Species & -0.167 & 0.387 & -0.432 & 0.668 \\
\hline
\end{tabular}




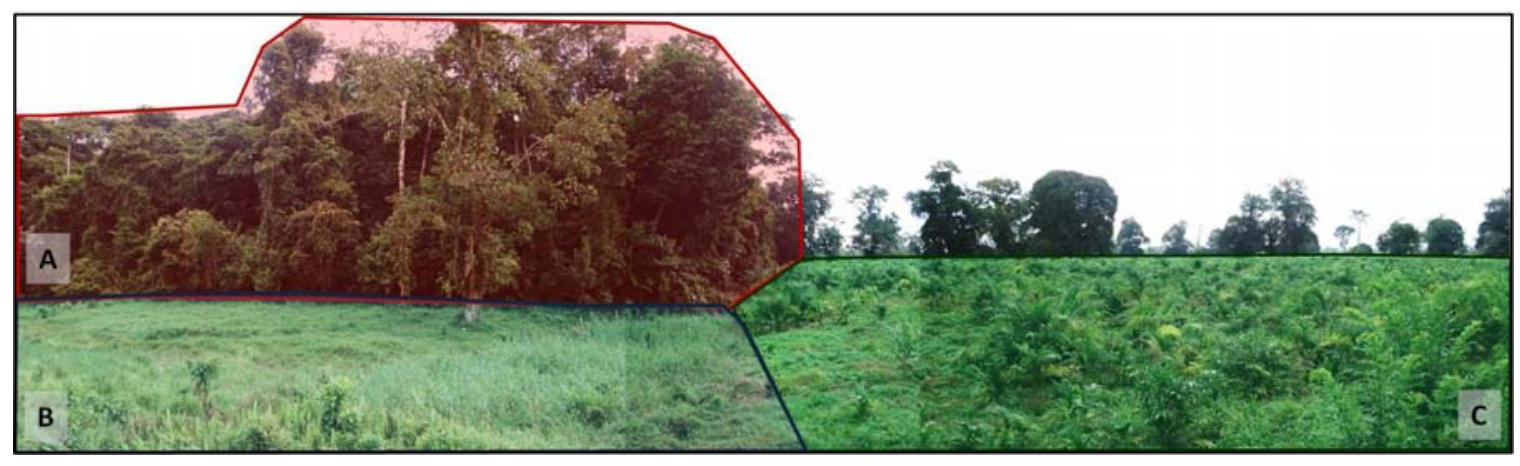

Figure 2.1. A replicate site in Sarapiquí, Costa Rica, consisting of adjacent areas of forest (A), pasture (B), and palmito (C), where microclimatic exposure and predation experiments were conducted, and where substrates were collected for the substrateresistance and choice experiments. 

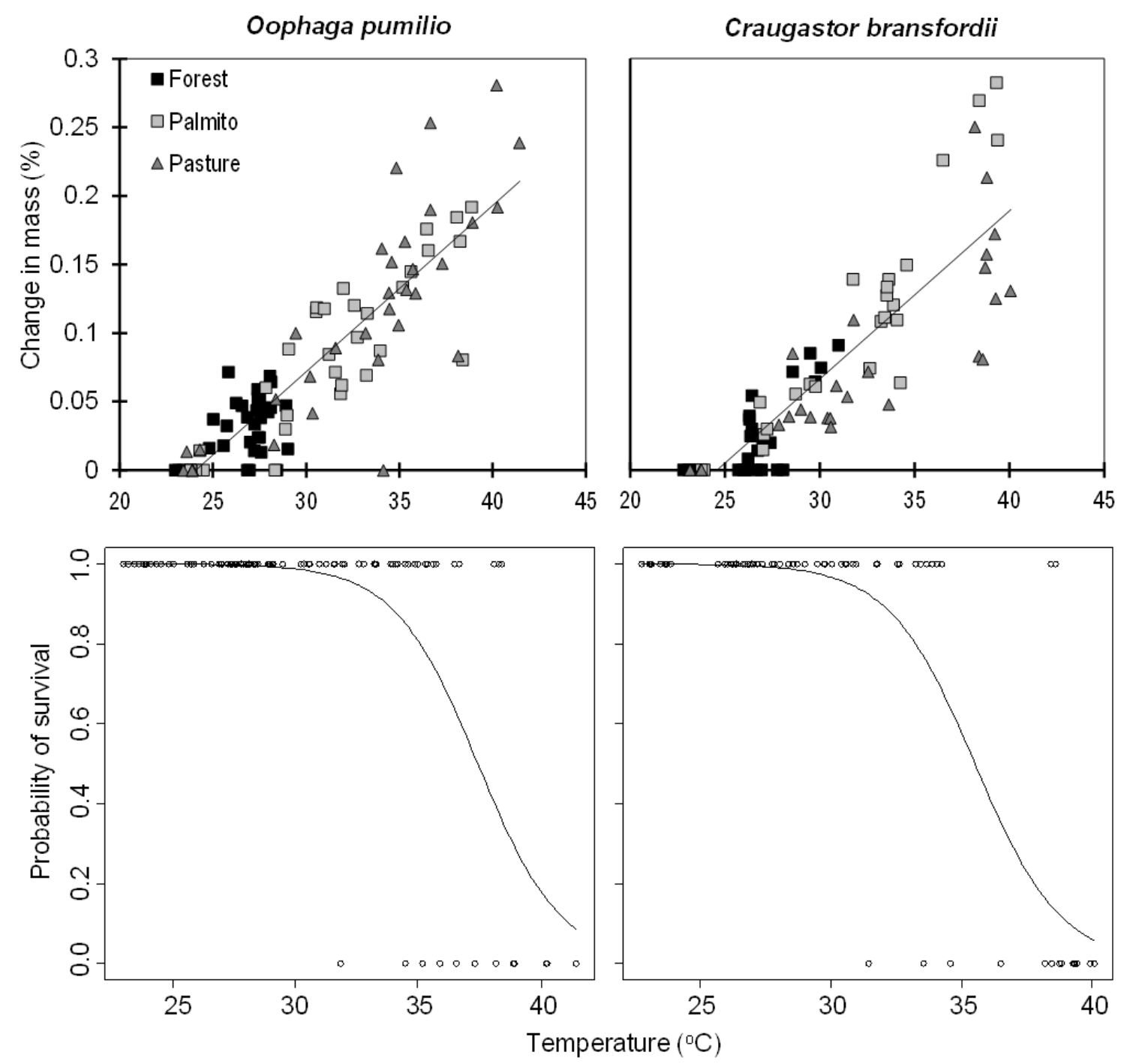

Figure 2.2. Top shows relationships between proportional decrease in mass and temperatures measured in forest, palmito, and pastures during microclimatic exposure experiments. Bottom panels shows the effect of temperature on probability of survival during one-hour trials. 

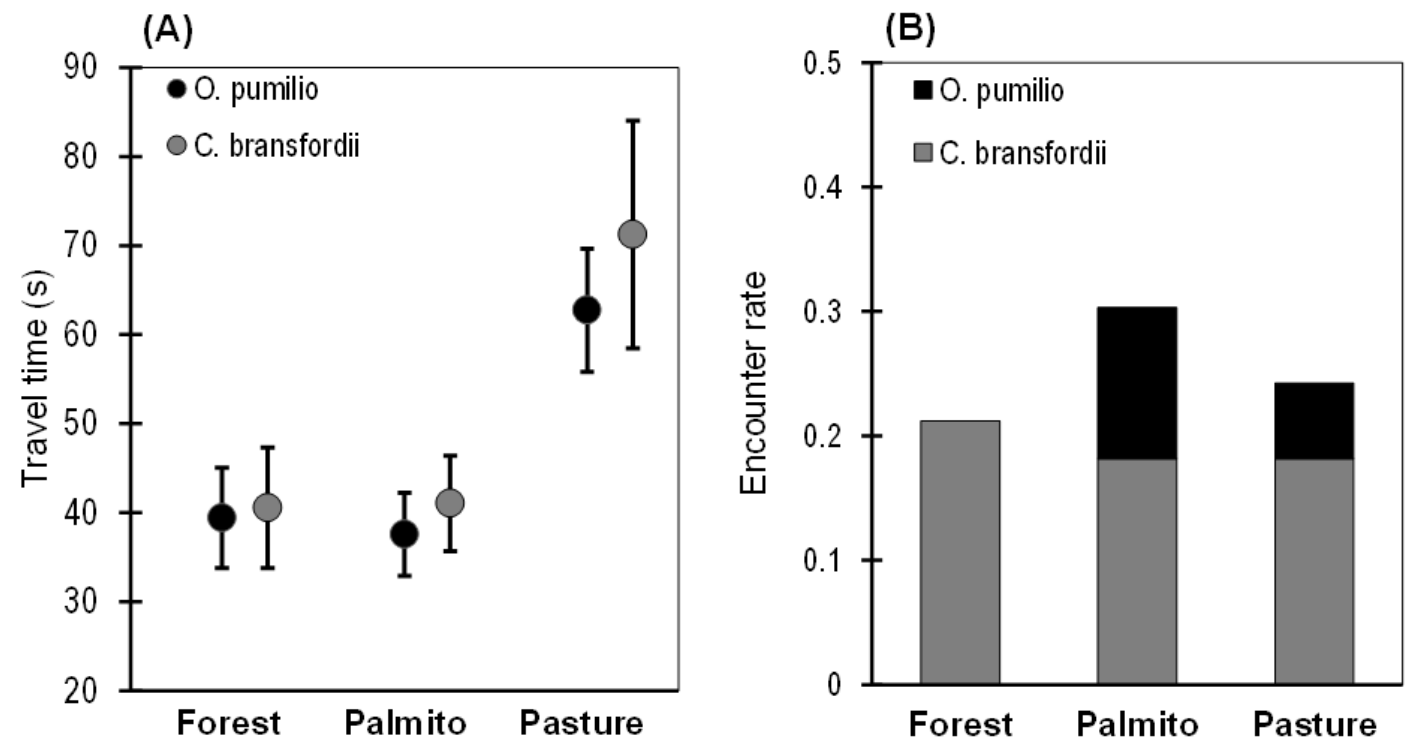

Figure 2.3. Mean travel times for O. pumilio and C. bransfordii across substrates from forest, palmito, and pastures (A). Error bars represent 95\% confidence intervals. Proportion of individuals that encountered predators during tethering experiments (B). 


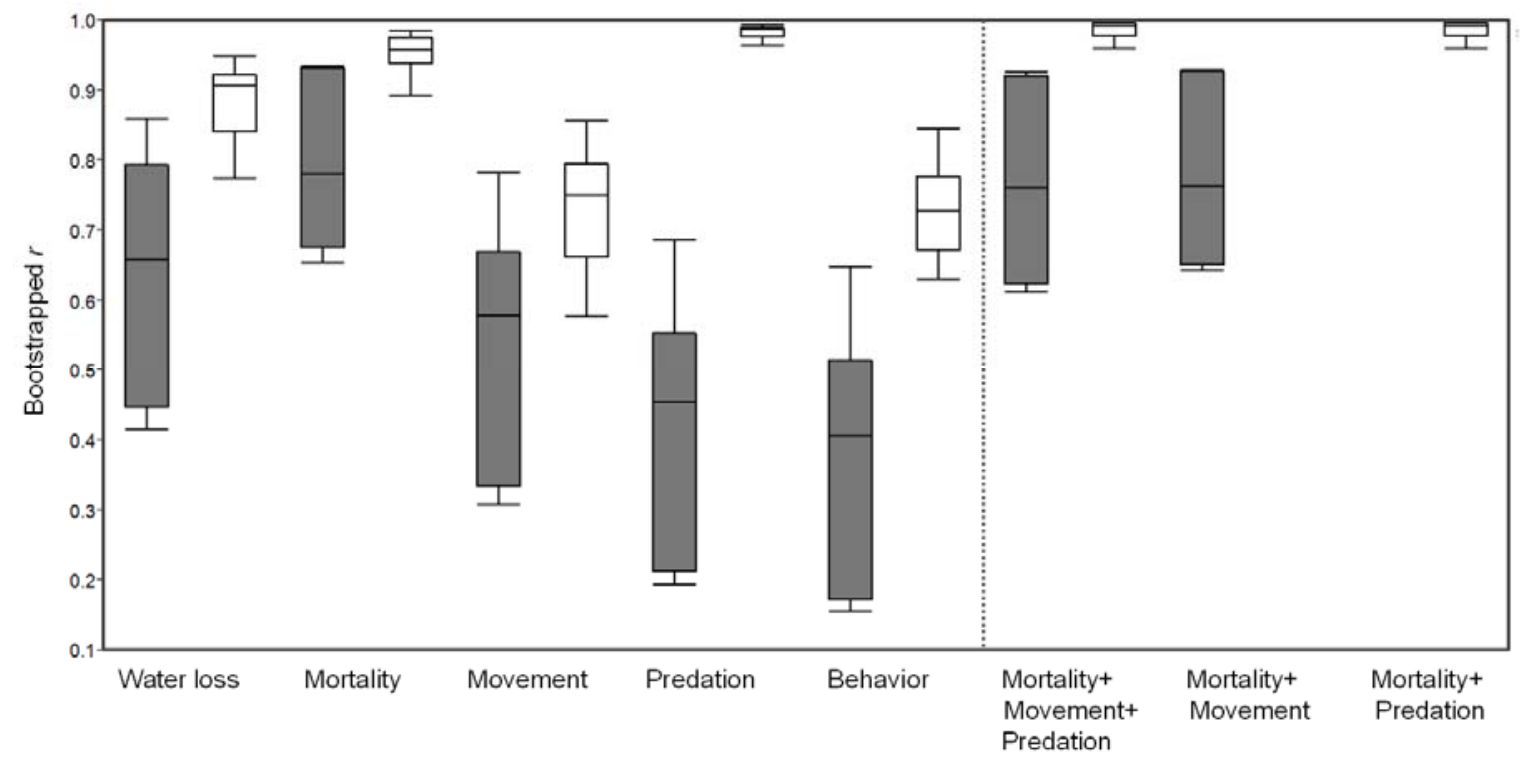

Figure 2.4. Boxplots show median correlation coefficients for map correlations between experimentally parameterized resistance models and estimates derived from survey data for O. pumilio (white bars) and C. bransfordii (grey bars). 

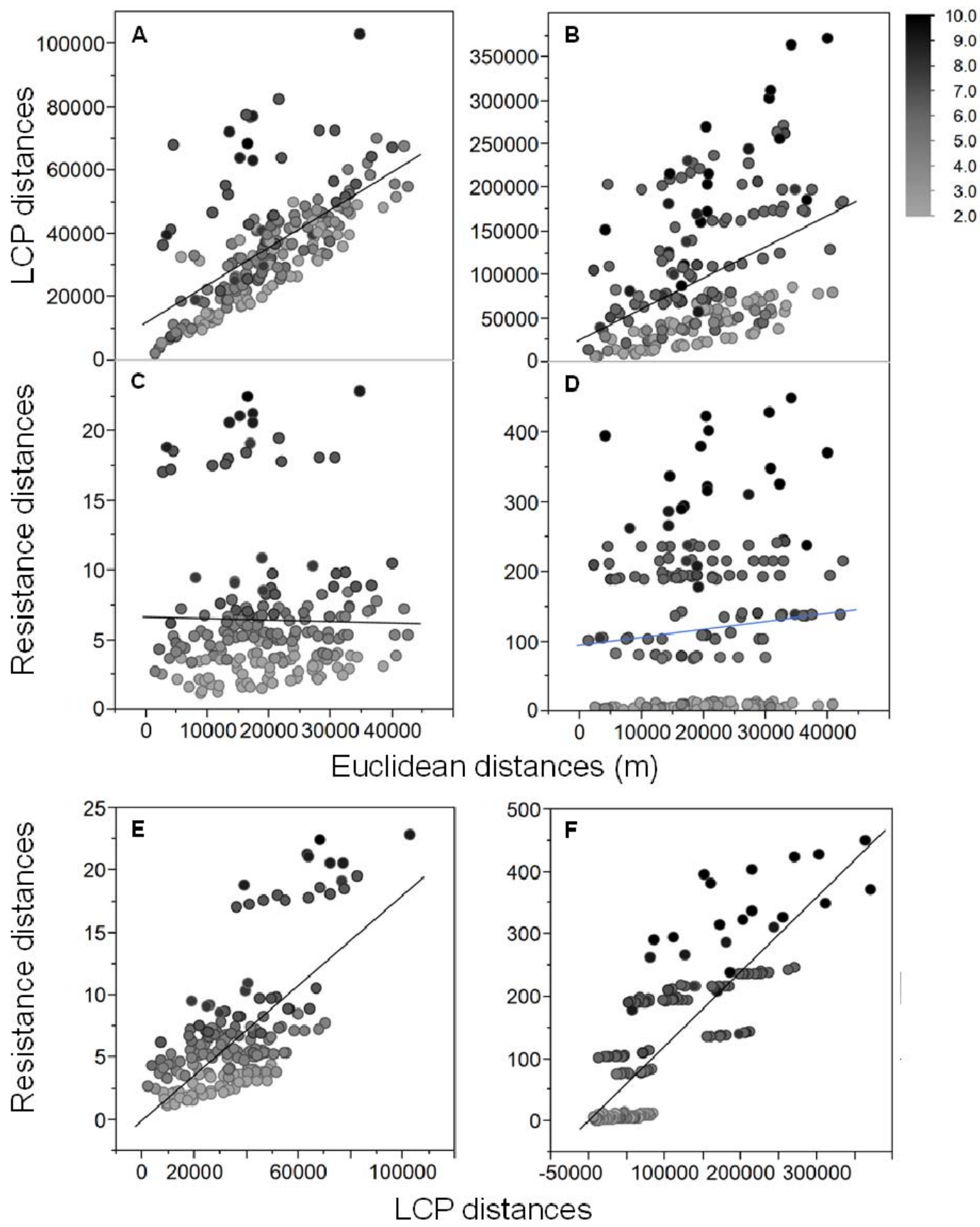

Figure 2.5. Relationships between Euclidean distances and accumulated least-cost distances (A \& B), between Euclidean distances and resistance distances (C \& D), and between accumulated least-cost distances and resistance distances ( $\mathrm{E} \& \mathrm{~F})$ for O. pumilio (A, C, \& E) and C. bransfordii (B, D, \& F). Color gradient represents the sum of ranked 
cost values between start and destination cells. Note that pairwise values with higher combined costs tend to plot above the linear trendline.
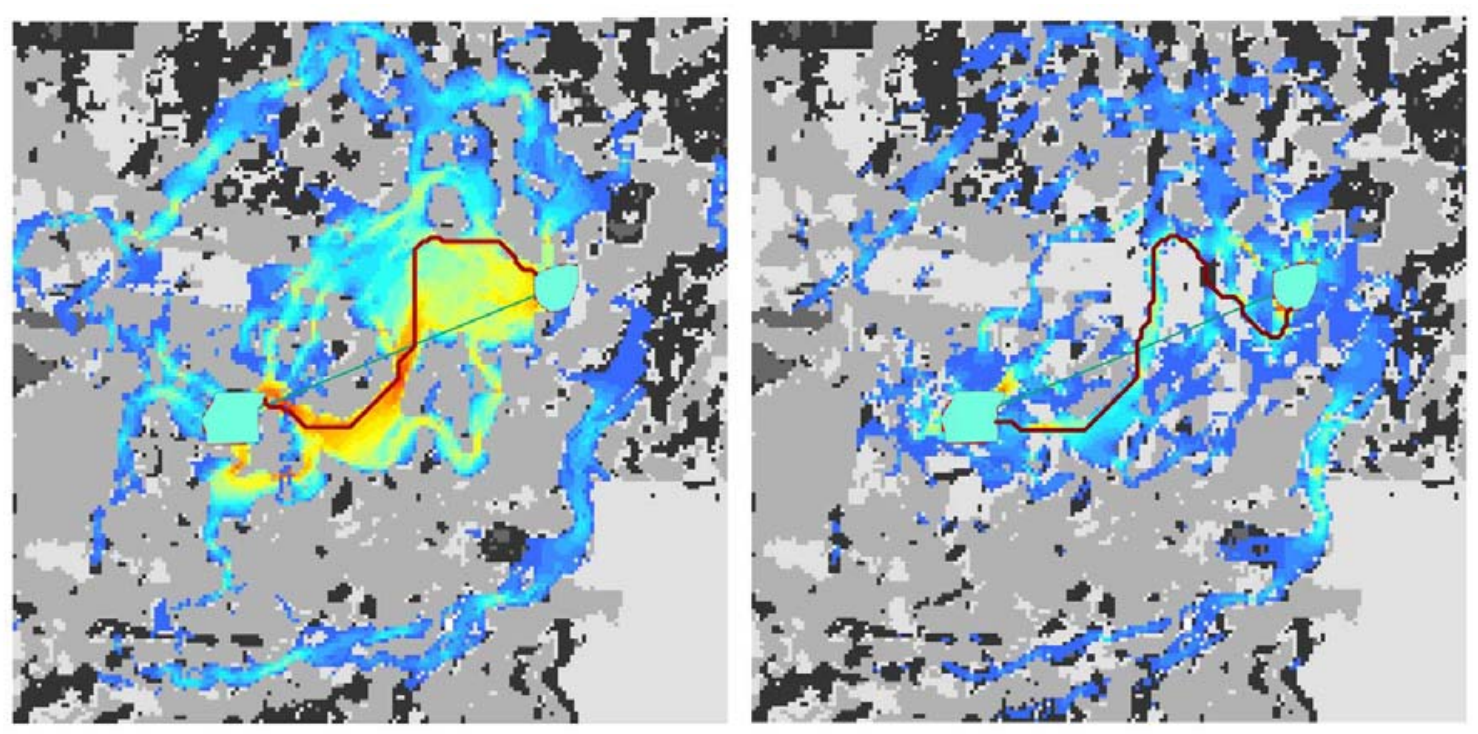

Figure 2.6. One replicate $625 \mathrm{~km}^{2}$ landscape in Sarapiquí, Costa Rica. The dominant land cover types are palmito (light grey), pastures (medium grey), and forest (black). Three measures of connectivity are shown between two forest patches (light blue polygons) for C. bransfordii (left) and O. pumilio (right). Euclidean distances are represented by green lines connecting patches. Least-cost paths based on abundance-derived resistance surfaces are shown in red. Areas of high current density from Circuitscape models are shown in blue, yellow and red, with warm colors associated with highest current densities (analogous to net movement probabilities). Note that multiple pathways highlighted by current maps as opposed to single pathways represented by least-cost paths and Euclidean distances. 


\title{
IV. CHAPTER 3: DISPERSAL COSTS AND ABUNDANCES EXPLAIN GENETIC DIFFERENTIATION OF TWO AMPHIBIANS IN A COMPLEX NEOTROPICAL LANDSCAPE
}

\begin{abstract}
Conversion of forests to agricultural lands often creates breaks in distributions of forest species and can disrupt dispersal. In the tropics, forest conversion is occurring rapidly and threatens persistence of species-rich faunas through reduced population sizes and reduced gene flow through altered habitats. However, there are currently few landscape genetic studies of tropical species. We examine population structure and landscape effects on two amphibian species in an agricultural landscape in Costa Rica. We incorporate data from field surveys and experiments to develop resistance surfaces that represent local mechanisms associated with amphibian dispersal. As lag times can exist between forest conversion and genetic responses, we also evaluated the relative influence of landscape configurations at four different time periods. We found similar levels of population structure and concordance of geographic clusters for both species. However, species exhibited differing responses to landscape features. For Craugastor bransfordii, population differentiation was significantly related to landscape resistances estimated from abundance and experiment data. Model support was highest for experiment-derived resistance surfaces that represented habitat-specific desiccation risk and substrate resistances. Genetic variation was best explained by contemporary landscape configuration, indicating lack of a substantial time lag in population response. For Oophaga pumilio, genetic structure was best explained by geographic isolation and was not related to any other landscape-resistance estimate after controlling for distance.
\end{abstract}


Species-specific responses to landscape features may be attributable to overriding effects of population size on geographic patterns of differentiation for $O$. pumilio but not $C$. bransfordii. In addition, pastures are likely more permeable to O.pumilio gene flow because this species is known to use pastures when remnant vegetation is present, but $C$, bransfordii does not. Ongoing reforestation efforts will likely increase connectivity for both species in the region by maintaining tree cover and reducing area of pastures.

\section{INTRODUCTION}

Anthropogenic land-cover change produces novel environments that affect ecological and evolutionary processes in most terrestrial systems (Hobbs et al. 2009, Barnosky et al. 2012). A critical result of land-cover change is the alteration of animal distributions and movements across landscapes, which creates discontinuities among remnant populations. Anthropogenic features often act as dispersal barriers that can reduce allelic diversity through genetic drift, reduce the spread of adaptive genes, and increase susceptibility to environmental change (Pearman \& Garner 2005, Manel \& Holderegger 2013). As forest loss continues, existing protected areas will prove insufficient to fully mitigate biodiversity loss and are themselves often isolated (Rosenzweig 2003, DeFries et al. 2005, Laurance et al. 2012). Strategies to maintain connectivity of reserve networks will need to incorporate elements of surrounding agricultural landscapes (Daily et al. 2003, DeClerck et al. 2010). By identifying landscape features that impede dispersal as well as idiosyncrasies among species responses, conservation practitioners will be better able to implement plans to facilitate movement of multiple species (Beier et al 2008, Betts et al. 2014). 
Functional connectivity is determined by the combined influence of landscape configuration and species-specific responses to landscapes (Luque et al. 2012). When landscapes are complex, organisms perceive contrasts in habitat quality or risk among alternative pathways that may modify movement behavior and dispersal rates (Baguette et al. 2012). Increased diversity and contrast of land-cover types, may disrupt isolation by distance relationships (Bender \& Fahrig 2005, Heidinger et al. 2013, Benscoter et al., submitted) making it more informative to analyze effective distances that account for species responses to landscape features (McRae \& Beier 2007, Castillo et al. 2014, Soare et al. 2014).). Local scale experiments can be used to estimate effective distances by providing information on species-specific responses to landscape features (Knowlton \& Graham 2010), such as gap crossing behavior (Smith et al. 2013) and habitat-specific survival (Rittenhouse et al. 2008, Hammerschlag et al. 2010). Given time, the cumulative effects of local dispersal risks should scale up to population-level patterns of genetic structure. However, the influence of local processes on genetic structure will ultimately be regulated by other demographic parameters, such as population size and density (Busch et al. 2009, Lowe \& Allendorf 2010).

For amphibians, habitat modification is the dominant threat to global diversity and is particularly concerning in the tropics where rapid forest loss converges upon the world's most species-rich systems (Stuart et al. 2004, Vié et al. 2009, Hansen et al. 2013). Isolating effects of landscape change may be pronounced (Jenkins et al. 2010) and manifest quickly in amphibian populations, because of limited vagility (Smith \& Green 2005), short generation times, and metabolic constraints on movement (Wells 2007). Ectothermy and highly permeable skin limit activity and likely increase susceptibility to 
microclimatic variation associated with landscape change. Studies have reported that amphibians exhibit higher rates of water loss (Rothermel \& Luhring 2005, Consentino et al. 2011), mortality (Rothermel \& Semlitsch 2006), and behavioral avoidance in land uses with little or no canopy cover in temperate zones (Rittenhouse \& Semlitsch 2006). However, tropical ectotherms may be more sensitive to altered microclimates than temperate species (Deutsch et al. 2008, Huey et al. 2009), as ambient forest temperatures are near physiological thermal maxima for some frog species, particularly at lower elevations (Catenazzi et al. 2013).

Landscape genetics provides an informative means to evaluate connectivity (Manel \& Holderregger 2013) by combining variable markers with remotely sensed data. Recent studies demonstrated the effects of anthropogenic habitat modifications, such as roads (Short Bull et al. 2011), agricultural and urban land uses (Goldberg \& Waits 2010), and climate change (Wasserman et al. 2012, Velo-Antón et al. 2013) on genetic variation. Empirical and simulation studies show fine scale landscape effects can be detected after only a few generations, depending on the permeability of introduced barriers (Zellmer \& Knowles 2009, Landguth et al. 2010). However, it is important to consider time lags between landscape change and population responses, as large populations will likely respond more slowly to loss of connectivity (Anderson et al. 2010). Among recent advances in genetic connectivity analysis, circuit theory models have become widely used to estimate effective distances (McRae et al. 2008) and provide an advantage over other methods by accounting for multiple pathways among sites.

A key component of the circuit model framework is the resistance surface which simultaneously represents the spatial configuration of landscape elements (e.g., land use 
types) and hypothesized or empirical dispersal costs associated with landscape features (Spear et al. 2010). The majority of studies to date have relied on expert opinion or model fitting procedures to determine cost values (Spear et al. 2010, Zeller et al. 2012). However, resistance estimates are highly sensitive to the magnitude of contrast among cost values assigned to landscape features, and expert-assigned values may not reflect relevant levels of contrasts (Rayfield et al. 2010, Koen et al. 2012). Model-fitting approaches allow for identification of dispersal barriers, but do not facilitate a priori hypothesis testing or mechanistic insights. Other studies have used field surveys or movement data (e.g., from mark-recapture or radio telemetry) to parameterize resistance surfaces. However, surprisingly few studies have used experiments to derive cost surfaces, despite the potential to evaluate different mechanism associated with landscape resistance (Stevens et al. 2006).

Here we examine landscape effects on population structure of two dominant amphibian species in an agricultural landscape in Costa Rica. We used independent datasets from field surveys and experiments to derive resistance surfaces that reflect biologically relevant levels of habitat contrast for our two focal species. Field surveys generated relative abundance data in three prevalent land-cover types (Kurz et al. 2014). Experiments were designed to provide indices of habitat-specific desiccation risk and associated survival, movement performance, and predator encounter rates. In addition, we used land cover data from multiple time periods to examine effects of past and present landscape configuration on population structure.

Our primary objectives were to, 1) compare effects of resistance distances with simple isolation by distance models, 2) evaluate relative model support for resistance 
distances derived from different field experiments, 3) determine if strength of landscapegenetic relationships vary across time (i.e., landscape configurations associated with different time periods), and 4) to compare level of population structure and responses to landscape models between the two focal species. We expected, a priori, that 1) resistances derived from empirical costs would be more informative than Euclidean distances, as landscape modification has occurred for over half a century in the study region. 2) landscape-genetic correlations would be strongest for desiccation risk-derived cost surfaces as indicated by model validation (Nowakowski et al., submitted), 3) the strength of landscape-genetic correlations would be greater for older landscape configurations, reflecting time lags, and 4) that litter frogs would exhibit stronger population subdivision and responses to landscape change, as studies of other directdeveloping species indicate limited dispersal capabilities in this group (e.g., Elmer et al. 2007).

\section{METHODS}

\section{Study system and field sampling}

Our study took place in the Caribbean lowland region of northeastern Costa Rica. Wet tropical lowland forest is the dominant natural vegetation type in this system and is part of a biogeographic region that extends along the Atlantic versant from Mexico to Panama. The area receives about $4 \mathrm{~m}$ of rain annually and has a mean annual temperature of $25^{\circ} \mathrm{C}$ (Sanford et al. 1994, Savage 2002). The study landscape is a heterogeneous mosaic of forest, pastures, and cultivated lands. Approximately $40 \%$ of the landscape remains forested (about 12\% of which is secondary regrowth); though, most forest is 
comprised of fragmented patches and riparian zones (Fig 1; Sesnie et al. 2008, Fagan et al. 2013). Beginning in the 1950's, expansion of cattle ranching caused rapid deforestation for the establishment of pasture lands (Butterfield 1994). However, loss of mature forest has slowed following implementation of a national ban on forest clearing (Morse et al. 2009, Fagan et al. 2013). While pastures are the dominant land use, covering $40 \%$ of the land area, agricultural crops, such as banana, pineapple, and heartof-palm, have expanded in recent decades to cover about $10 \%$ of the landscape (Fagan et al. 2013).

Our study focuses on the two dominant amphibian species in the area, Oophaga pumilio and Craugastor bransfordii. Oophaga pumilio is a brightly colored poison frog that contains alkaloids in its skin, which are sequestered from arthropods in its diet (Saporito et al. 2007). The species is dependent upon forest resources for reproduction, such as leaf-litter ovaposition sites and tadpole rearing sites in phytotelmata (Donnelly 1989). Craugastor bransfordii is a cryptically-colored frog that also breeds in the leaf litter. However, this species does not have a free-living tadpole stage. Both species reach high abundances in forest, but exhibit different responses to landscape change outside of forests (Kurz et al. 2014). Poison frogs are known to occur in pastures, where occupancy and abundances are associated with the presence of individual-remnant trees (Nowakowski, unpubl. data, Robinson et al. 2013), but were rarely observed in cultivated areas (Kurz et al. 2014). In contrast, C. bransfordii reach moderate abundances in heartof palm plantations, but are nearly absent in pastures. Population declines were recorded for both species over a 35 year period at a protected area within the study landscape (Whitfield et al. 2007). 
We sampled amphibians at 17 forest remnants in northeastern Costa Rica. As part of a concurrent study to characterize species richness and composition, we conducted visual encounter surveys along 50 x $4 \mathrm{~m}$ transects (e.g., von May et al. 2010). In each remnant, 26 transects were randomly located and searched at night, between 18:30 and 01:00 hrs. Randomized transect placement increases the likeliness that sampled individuals are representative of the genetic variation that occurs within sites. However, we also augmented sample sizes with individuals encountered outside of transects. Toe clips were collected from focal species and stored in 95\% ethanol and frozen.

\section{Microsatellite genotyping and summary statistics}

Tissue was digested in lysis buffer and proteinase $\mathrm{K}$, and standard phenolchloroform methods were used to extract DNA (Sambrook \& Russell 2001). Template DNA was diluted to $20 \mathrm{ng} / \mu 1$, and PCR reactions were run with multiplexed sets of 2-4 fluorescently labelled (6-FAM and HEX) primer pairs. We genotyped individuals at 11 loci for O.pumilio (Oop_B9, Oop_B8, Oop_E3, Oop_G5, Oop_H5, Oop_O1, Oop_F1, Dpum14, Dpum24, Dpum63, and Dpum44; Hauswaldt et al. 2009, Wang \& Summers 2009) and 10 loci for C. bransfordii (Cbra_2, Cbra_16, Cbra_18, Cbra_28, Cbra_38, Cbra_48, Cbra_53, Cbra_61, Cbra_64, Cbra_71; Nowakowski et al., submitted). We used $20 \mu 1$ reaction volumes for PCR amplifications that consisted of $40 \mathrm{ng}$ of template DNA, $10 \mathrm{mM}$ Tris- $\mathrm{HCl}, 50 \mathrm{mM} \mathrm{KCl}, 0.5 \mathrm{mg} / \mathrm{ml} \mathrm{BSA}, 1.5 \mathrm{mM}$ of $\mathrm{MgCl} 2,0.2 \mathrm{mM}$ of each dNTP, and NEB Taq polymerase (1U). Amplicon sizes were determined using an ABI 3130XL and GeneScan 4.1 (Applied Biosystems). We scored raw alleles using 
program GENEMAPPER v.X (Applied Biosystems), and binned alleles using FlexiBin (Amos et al. 2007).

We summarized allele frequencies, heterozygosity, and tested for significant linkage disequilibrium (LD) and deviations from Hardy-Weinberg equilibrium (HWE) using program Arlequin v3.5 (Excoffier \& Lischer 2010). We specified 1,000,000 Markov chain steps with a 100,000 step burnin for performing exact tests of HWE and 1000 permutations for tests of LD and applied Bonferroni corrections (Rice 1989). Null allele frequencies were estimated using MICROCHECKER v2.2.3 (van Oosterhout et al. 2004).

Analyses of population genetic structure Population differentiation and population size:

We characterized genetic differentiation between pairs of sample sites using two measures, $F_{\mathrm{ST}}$ and Jost's $D$. Values of $F_{\mathrm{ST}}$ are known to be dependent upon within population diversity such that for multi-allelic markers, high expected heterozyosity can result in low maximum $F_{\mathrm{ST}}$ values (e.g., $\max F_{\mathrm{ST}}=0.1$; Meirmans $\&$ Hedrick 2011). However, interpretation of values is facilitated by well-understood relationships among drift, migration, and population size for $F_{\mathrm{ST}}$ measures of differentiation. On the other hand, $D$ better reflect differentiation of allele frequencies among populations than $F_{\mathrm{ST}}$ and maximum values are not restricted by within population heterozygosity (Jost 2008; Meirmans \& Hedrick 2011). However, evolutionary interpretations of $D$ are currently less well established than for $F_{\mathrm{ST}}$ measures (Whitlock 2011). 
Because rate of genetic drift and patterns of differentiation are influenced by effective population size $\left(\mathrm{N}_{\mathrm{e}}\right)$, we estimated $\mathrm{N}_{\mathrm{e}}$ for each site using the linkage disequilibrium method implemented in program LDNe (Waples \& Do 2008). We specified a random mating system within populations and excluded rare alleles with frequencies $<0.01$. Influence of spatial variation in $\mathrm{N}_{\mathrm{e}}$ on patterns of differentiation was assessed using linear regression. We also analyzed associations between differentiation and relative abundances measured along transects. While theory dictates that $\mathrm{N}_{\mathrm{e}}$ affects differentiation (Franham et al. 2002), $\mathrm{N}_{\mathrm{e}}$ estimates are often imprecise (e.g., Richardson 2012) and sensitive to model parameters; abundances should co-vary with $\mathrm{N}_{\mathrm{e}}$ to the extent that local populations conform to idealized population structures. In all but one site, where fewer than 30 O. pumilio were encountered, relative abundances recorded on transects are independent of sample sizes used in genetic analyses. Sample sizes for genetic analyses were standardized at 30-35 samples per site per species and any variation in $n$ across sites is largely attributable to genotyping completeness.

\section{Bayesian clustering:}

To compare the level of population structure between species represented as the number and geographic locations of genetic demes, we used a Bayesian clustering model implemented in program STRUCTURE (Pritchard et al. 2000). The STRUCTURE model determines support for a given number of genetic clusters $(\mathrm{K})$ by estimating the probability of the multi-locus genotype data, given a specified number of clusters, $\operatorname{Pr}(\mathrm{X} \mid \mathrm{K})$. Individuals are assigned to clusters so as to minimize linkage disequilibrium and deviations from HWE. 
On the basis of exploratory analyses where $\mathrm{K}$ was set to all values $\leq$ total number of sample sites, we focused replicate model runs on $\mathrm{K}=1-10$ for $O$. pumilio and $\mathrm{K}=1-9$ for C.bransfordii. For each value of K, 6 replicate models were run with a 200,000 step burnin period and 500.000 MCMC repetitions following burnin. We specified models that allowed for admixture, as local populations often have mixed ancestry, and correlated-allele frequencies. We used sampling location priors, which are useful for improving population assignment when data indicate weak to moderate population structure; location information typically improves resolution, but does not generate artificial structure in the data (Hubisz et al. 2009, Pritchard et al. 2010). Model support for the number of distinct genetic clusters $(\mathrm{K})$ was determined as the maximum value of $\ln \operatorname{Pr}(\mathrm{X} \mid \mathrm{K})$ before asymptote for multiple possible $\mathrm{K}$ values using program STRUCTURE HARVESTER (Earl \& von Holdt 2011). Replicate runs were aligned and averaged using CLUMP (Jakobsson \& Rosenberg 2007) and $Q$-plots were constructed using program DISTRUCT (Rosenberg 2004)

\section{Resistance distance-genetic distance relationships} Resistance surfaces

We evaluated landscape effects on pairwise population differentiation using experiment and field survey-derived resistance surfaces. Cost surfaces were created by reclassifying cell values of land cover datasets developed from 1986, 2001, and 2011 Landsat images (Fagan et al. 2013). Empirical costs were assigned to forests, pastures, and palmito land cover types, which represent approximately $86 \%$ of the study landscape. We clipped the land cover datasets to the extent of our $2,500 \mathrm{~km}^{2}$ study area. 
For field-survey derived resistance surfaces, we used relative abundance data for the two focal species collected along 400 transects surveyed in forest, pasture, and palmito plots in Sarapiquí, Costa Rica (Kurz et al. 2014). Ten sites were surveyed in 2012 and each site included a forest plot and either a pasture or palmito plot adjacent. Four habitat categories were sampled in total, forest adjacent to pasture, pasture, forest adjacent to palmito, and palmito, with 100 transects surveyed in each category. Complete details on sampling and results are reported in Kurz et al. (2014).

For experiment-derived resistance surfaces, we used data from three separate field experiments that measured 1) desiccation risk and associated mortality in forest, pasture, and palmito, 2) ease of movement across common substrates associated with each land use, and 3) predator encounter rates in focal land uses. Briefly, desiccation risk and mortality were measured by placing frogs in individual enclosures within each land-use type thereby exposing them to habitat-specific microclimatic conditions. Survival and change-in-mass as an index of water loss were recorded over one-hour trials conducted on multiple days and under a range of weather conditions. Substrate resistance was measured as the time taken by individuals to traverse $1.8 \mathrm{~m}$ runs containing land-use specific substrates (e.g., forest leaf litter and pasture grasses). We used tethering experiments to record the number of predation events in each land use. Tethering experiments are commonly used in marine-ecology studies and can be used to provide an index of habitat-specific predator encounter rates (Aronson et al. 2001, Hammerschlag et al. 2010). Complete details on experimental approach, resistance surface parameterization, and model validation are reported in Nowakowski et al. (unpubl data). These empirical datasets allowed us to assign resistance values that reflect biologically 
relevant levels of contrast among landscape elements and to make inferences about the importance of local mechanisms in explaining landscape scale patterns of population structure.

Experiments were translated to cost surfaces as follows: All forested cells were assigned a resistance value of 1 , assuming low resistances of forest in relation to other land uses. Cost values for pastures and palmito were calculated as the response ratios from experimental results and survey data. For example, the cost value $(\mathrm{C})$ for pastures derived from abundance data were calculated as $\mathrm{C}_{\mathrm{p}}=$ total abundance in forest / total abundance in pasture. Therefore lower abundances relative to forest are assumed to reflect greater resistances of pastures. Conversely, $\mathrm{C}_{\mathrm{p}}$ derived from water loss experiments was calculated as $\mathrm{C}_{\mathrm{p}}=$ percent weight loss in pasture / percent weight loss in forest, as greater desiccation risk is assumed to be associated with higher resistances. We assigned costs to other land uses, such as banana and tree plantations, on the basis of structural similarity to measured lands uses (e.g., the presence or absence of overstory or midstory vegetation strata). Rivers were assigned resistances equal to the average resistances for forest, palmito, and pasture. Our approach for assigning costs to unmeasured land uses should have negligible influence on the analyses, as these features only represent $16 \%$ of the study landscape and values were standardized across all resistance surfaces. Experiment-derived resistance surfaces were evaluated for the 2011 landscape only.

To evaluate changes in the strength of landscape-genetic responses across time we produced resistance surfaces for four time periods, pre-fragmentation (e.g., 1940’s), 1986, 2001, and 2011. Pre-fragmentation surfaces consisted of a forested landscape with 
resistances assigned to forest and rivers as above. We also accounted for mountains occurring to the south by assigning infinite resistance to areas above the known elevation limits of each species. For 1986, 2001, and 2011 time periods we used classified land cover data from Fagan et al. (2013) and assigned costs using relative abundance data as described above. We used abundances for analyses of temporal landscape signatures, because they represent our best independent measure of resistance - abundances likely reflect the combined influence of multiple mechanisms underlying connectivity (e.g., habitat specific survival and behavior). We produced additional surfaces for each year that accounted for elevation limits to determine if inclusion of mountain features improved model fit.

Our simplest landscape models consisted of pairwise geographic distances and isolation by resistance (IBR) values. We generated IBR distances by creating a uniform landscape grid with all cells equal to 1 for input into CIRCUITSCAPE. The IBR distances are generally correlated with geographic distances, but not perfectly, as resistances distances reflect diffuse paths and are influenced by size of source and destination patches (McRae et al. 2008). One reason to use IBR is that the model assumes a finite landscape (Lee-Yaw et al.2009). On the other hand, geographic distances represent the purely spatial component of the landscape (i.e., the arrangement of sample sites). Both geographic distances and IBR models contain no information about landscape features and can be used as null models for evaluating support for more complex landscape models. 


\section{Circuitescape modeling}

We used CIRCUITSCAPE to estimate landscape resistances among sample sites (McRae \& Shah 2009). CIRCUITSCAPE combines graph theory and circuit theory to model connectivity by constructing graphs that connect focal nodes representing populations or sample sites (McRae et al. 2008). Graph edges are replaced by resistors to create networks analogous to electrical circuits where resistances among focal nodes are a function of cost surface grids used as input. We used pairwise resistance distances output by CIRCUITSCAPE as a connectivity measure, which reflects the combined resistance of all resistors and the redundancy of pathways. Allowing for multiple connections between pairs of nodes is more realistic and may improve performance over approaches that consider only individual movement pathways, such as least-cost path analyses (McRae \& Beier 2007).

In total, we generated 9 resistance surfaces for each species, abundance parameterized land cover for pre-fragmentation, 1986, 2001, and 2011 periods, experiment-derived surfaces for water loss, survival, substrate resistance, and predation responses, and an IBR surface, which were converted to ASCII format and used as input for CIRCUITSCAPE. We modeled connectivity among 15 and 17 focal regions (forest remnants) for $O$. pumilio and $C$. bransfordii, respectively. Cost surface cells were coded as resistances and spatial graphs were constructed by connecting eight cell neighbors using average resistance values. 


\section{Partial Mantel tests}

We performed two sets of analyses using a series of partial Mantel tests to 1) evaluate the relative support for different experimentally measured mechanisms underlying observed genetic connectivity and 2) to compare historic versus contemporary landscape signatures on observed population differentiation. Our analyses follow the general approach outlined by Cushman \& Landguth (2010); support for or exclusion of successively complex landscape models (uniform landscape -> pre-fragmentation landscape -> agricultural landscapes) was determined while controlling for alternative landscape surfaces. Though, for certain comparisons, such as among years and between desiccation risk and associated mortality, our aim was not to exclude alternative resistance surfaces (aside from geographic distance), as they are non-independent, but to evaluate relative strength of correlations for each. We chose to use partial Mantel tests because this approach is suited for evaluating hypotheses expressed in terms of distances (Legendre and Fortin 2010), and data manipulations needed to fit non-independent distance values into a parametric framework are often cumbersome. While partial Mantel tests in a causal modeling framework have low Type II error rate, they are prone to elevated Type I error, particularly when alternative resistance models are correlated (Cushman and Landguth 2010, Cushman et al. 2013). Here, we focus on relative support of alternative models indicated by diagnostic statistics, which has been shown to reduce Type I error (Cushman et al. 2013). 


\section{RESULTS}

\section{Marker screening and summary statistics}

We assembled complete multi-locus genotypes (no missing data) for a total of 512 O. pumilio individuals and 513 C. bransfordii individuals. For O.pumilio, we excluded loci Oop_H5 and Dpum_44 from analyses because they exhibited high rates of nonamplification $(>0.05)$ and occasional extra alleles, possibly attributable to null alleles and insertions, respectively. Across the remaining 9 loci, we detected significant deviation from HWE in only 1 test (of 135) after Bonferroni correction. Significant LD was found for one pair of loci in one population. For C. bransfordii, departure from HWE was found in 39 (of 170) tests. Most loci did not exhibit consistent deviations from HWE.

However, Cbra_71 was out of HWE in all 17 populations. This is most likely attributable to high frequency of null alleles at this locus (NA>0.2). We excluded Cbra_71 from downstream analyses, but included two loci that had null alleles at lower frequencies (Cbra_48 and Cbra_61; NA $<0.2$. Simulations studies show that loci with null allele frequencies $\leq 0.2$ have little effect on STRUCTURE model performance (Carlsson 2008) and do not significantly bias estimation of $F_{\mathrm{ST}}$ when differentiation is weak (Chapuis and Estoup 2006), but exclusion of loci reduces statistical power. There was no pervasive pattern of LD across populations for C. bransfordii (mean of 0.76 linked pairs of loci per population). Genetic diversity was generally high for both species. For $O$. pumilio, total number of alleles per locus ranged from 6-24. Across all loci and sites, mean allelic richness (AR) was $11.1 \pm 1.2($ mean $\pm \mathrm{SD})$, and mean observed heterozygosity $\left(\mathrm{H}_{\mathrm{o}}\right)$ was $0.81 \pm 0.04$. For $C$. bransfordii, total alleles per locus ranged from 23-41, AR was $16.3 \pm$ 0.96 , and $\mathrm{H}_{\mathrm{o}}$ was $0.81 \pm 0.03$. 


\section{Population genetic structure}

Population differentiation and population size:

Mean pairwise estimates of $F_{\mathrm{ST}}$ were $0.029 \pm 0.017$ (mean $\pm \mathrm{SD}$ ) ranging from 0.0-0.07 and mean estimates of $D$ were $0.075 \pm 0.049$ with a range of $0.00-0.2$ for $O$. pumilio. For $C$. bransfordii, mean $F_{\mathrm{ST}}$ was $0.020 \pm 0.007$ (range: $0.004-0.044$ ) and mean $D$ was $0.166 \pm 0.068$ (range: $0.011-0.375$ ). The majority of pairwise $F_{\mathrm{ST}}$ values were significantly greater than zero (O.pumilio: 90 of 105; C. bransforii: 128 of 136) after Bonferroni correction for multiple tests. Effective population size varied considerably across sites for both species; we did not compute summary statistics as point estimates and confidence limits included infinity for multiple populations (Table S2). Therefore, we binned $\mathrm{N}_{\mathrm{e}}$ estimates and converted them to ranks for further analyses. Mean pairwise $F_{\text {ST }}$ estimates were negatively associated with local relative abundances $\left(\right.$ Fig $1 ; \mathrm{R}^{2}=$ $0.409, P=0.010)$ and ranked $\mathrm{N}_{\mathrm{e}}$ estimates $\left(\mathrm{R}^{2}=0.251, P=0.057\right)$ for O.pumilio indicating lower differentiation among pairs of large populations. Mean pairwise $F_{\mathrm{ST}}$ was not correlated with relative abundances $\left(\mathrm{R}^{2}=0.000, P=0.990\right)$ or rank estimates of $\mathrm{N}_{\mathrm{e}}$ $\left(\mathrm{R}^{2} 0.097, P=0.222\right)$ for $C$. bransfordii.

\section{Bayesian clustering:}

The highest values of $\ln \mathrm{P}(\mathrm{X} \mid \mathrm{K})$ supported $\mathrm{K}=5$ genetic clusters for $O$. pumilio and $\mathrm{K}=4$ clusters for $C$. bransfordii (Fig 2; Fig S3). Geographic patterns of population clustering were generally concordant between species, and genetic clusters tended to correspond to the spatial scale associated with groups of neighboring sites rather than individual sites. For poison frogs, sites located in the southeastern part of the landscape 
( second cluster, and sites in the southwestern part of the landscape (m, n, \& o) were grouped into a third cluster. Several other sites $(\mathrm{j}, \mathrm{k}$, and $\mathrm{l})$ were largely admixed between the second and third clusters, and individuals at two sites ( $p$ and $q$ ) located in the northeast, were assigned to two distinct clusters. Most $O$. pumilio individuals were strongly assigned to a given population (i.e., little admixture). Litter frogs, on the other hand, exhibited higher levels of admixed ancestry at the site level. A distinct cluster was formed by site c, while individuals were strongly assigned to three multi-site clusters identified in the southeast ( sites $\mathrm{d}, \mathrm{e}, \mathrm{f}$ ), northwest (at $\mathrm{g}, \mathrm{h}$ ), and southwestern $(\mathrm{l}, \mathrm{m}, \mathrm{n}, \mathrm{\&}$ o) parts of the landscape. Individual ancestry at remaining sites was largely admixed.

\section{Resistance distance-genetic distance relationships}

Poison frogs exhibited a strong and significant isolation by distance relationship for all metrics of genetic differentiation (Fig 1; Table 1). For O. pumilio, there were no significant associations with pre-fragmentation landscape features or for modified landscapes at any year or using any measure of resistance after controlling for geographic distances. Isolation-by-distance relationships remained significant in most cases after controlling for resistance surfaces (Table 1). In contrast, litter frogs exhibited significant, but weaker isolation by distance effects (Mantel $r=0.360, P=<0.0001$ ). There were also significant effects of landscape features on population differentiation (Table 1). For analyses of lag times, we found large partial correlation coefficients for contemporary (2011) and more recent (2001) landscape configurations (Fig 3; Table 1). In analyses of experiment-derived resistance distances, there was model support for all four experiment- 
derived resistances for litter frogs. However, averaged across tests using each combination of genetic distance and null landscape model, partial Mantel $r$ statistics were highest for desiccation-risk and substrate resistance models (Fig 4; Table 1). Mean partial Mantel $\mathrm{r}$ was lowest for predation models and did not differ from zero. Model validation using abundance data also showed low support for predation as a determinant of resistances (Fig 4; Nowakowski et al., unpbul).

\section{DISCUSSION}

The lowland-Atlantic forests of Costa Rica support remarkably diverse assemblages of amphibians (Savage 2002). Much of this forest has already been fragmented and converted to pastoral and agricultural land uses, a common scenario throughout the neotropics (FAO 2009). While loss of mature forest has slowed in the study region, ongoing homogenization and intensification of cultivated lands will continue to have consequences for maintenance of biodiversity on the landscape (Karp et al. 2012, Kurz et al. 2014). The persistence of communities in remnant forests will likely depend on the exchange of migrants with adjacent populations to counteract loss of genetic diversity associated with isolation and drift. Strategies to maintain connectivity will need to identify landscape features that impede dispersal. In this study, we observed similar levels of population structure for two common amphibian species experiencing declines in Sarapiquí. However, the focal species exhibited differential responses to landscape structure that may be attributable to demography or differences in tolerances to landscape change. Taking into account species-specific responses to landscape features, we discuss recommendations to increase connectivity for both species in the region. 


\section{Population structure and dispersal limitation}

Overall levels of differentiation for both species indicated weak, but significant divergence among most sampling locations according to $F_{\mathrm{ST}}$ estimates. However, within population levels of $H_{\mathrm{e}}$ were high, which can restrict maximum values of $F_{\mathrm{ST}}$ (Meirmans $\&$ Hedrick 2011). We used an alternative measure of genetic distance, $D$, that indicated higher levels of differentiation for both species and a greater range of values than for $F_{\mathrm{ST}}$. For O. pumilio, levels of population differentiation are comparable to those reported in a previous study conducted at a larger spatial scale, in which the shortest inter-site distances overlap with our longest inter-site distances (Wang \& Summer 2010). Assignment methods suggest that spatial delineation of clusters is similar between species and that both species were largely structured at the scale of multiple-adjacent sites rather than individual sample sites. Both assignment methods and estimates of population structure indicate similar levels of dispersal limitation for each species.

We know of no direct measurements of dispersal distances for our study species. Oophaga pumilio are known to maintain small home ranges on the order of 10-30 $\mathrm{m}^{2}$ (Donnelly 1989b). What little research exists for direct-developing eleutherodactyline frogs suggest that this group is characterized by small home ranges and limited dispersal (Elmer et al. 2007). However, the average maximum dispersal distance for anurans from existing literature (e.g., mark-recapture or radio telemetry studies; reviewed in Smith \& Green 2005) is $2923 \mathrm{~m}(\mathrm{SD}=5930 \mathrm{~m})$. While it is important to note that substantial variation exists among species, this value is similar to the mean distance among sites within multi-site genetic clusters reported here (O. pumilio, $4029 \mathrm{~m}$; C. bransfordii, 2393 
$\mathrm{m})$. Landscape genetic studies of amphibians in temperate zones have described population structure at similar spatial scales reported here and genetically delineated demes in those studies have also included multiple habitat patches or breeding sites (Funk et al. 2005, Zamudio \& Wieczorek 2007).

\section{Landscape-genetic correlations}

Both species exhibited significant isolation-by-distance relationships (IBD), but IBD was much stronger for poison frogs than for litter frogs (Fig 1). A recent metaanalysis found that ectotherms often exhibit strong IBD relationships, possibly because of metabolic and size constraints on dispersal (Jenkins et al. 2010). IBD is the simplest landscape model as it includes no information on landscape features, but provides a null model for evaluating the importance of landscape structure. We analyzed the influence of increasingly complex landscapes on population differentiation, from a uniform landscape, to dynamic landscapes with multiple land uses. Contemporary landscape effects on population structure were detected for C. bransfordii using empirically-derived resistance surfaces. Support was greatest for abundance-derived and three mechanistically-derived models. In contrast, genetic variation for $O$. pumilio was best explained by distances among sample sites. No other resistance surfaces explained significant variation in genetic structure for poison frogs after controlling for geographic distance.

We assumed that survey-derived resistance surfaces provided a "best" independent estimate of landscape resistance, as abundances likely reflect the cumulative effects of habitat-specific resource availability and mortality risks (i.e., habitat quality). Ultimately, landscape connectivity can be equated to habitat quality for dispersing 
individuals. For litter frogs, resistance distances derived from abundances were a strong predictor of genetic variation among sites after controlling for geographic distances. Support for the abundance model indicates that resistance to gene flow is lowest for litter frogs through forest, intermediate through palmito plantations (and similar land uses) and highest through pastures. Contrary to our expectations, we did not find evidence of a time lag between landscape state and observed population structure. Model support was greatest for the contemporary landscape and effect sizes increased from 1986 to 2011

(Fig 3). Lack of a substantial lag time is in agreement with both recent empirical (Zellmer \& Knowles 2009) and simulation (Landguth et al. 2010) studies that found that contemporary landscape effects on populations were not only detectable, but stronger than historical landscape conditions.

Landscape resistance is a composite of multiple local processes that scale up to determine rates of gene flow. In analyses of litter frog data, model support for a specific local mechanism was greatest for substrate resistance, measured as the speed that individuals moved across common substrates found in each land use. Movement speeds likely reflect the difficulty, and by extension energetic costs, associated with moving across substrates in each habitat. Our results suggest that substrate resistance and responses to local microclimates may be relatively important processes underlying landscape resistance for litter frogs. However, significant support for experiment-derived resistance surfaces was not consistent across alternative analyses; we therefore interpret these results with caution.

Agreement among survey data, field experiments, and population genetic analyses indicates that pastures represent significant dispersal barriers for litter frog populations, 
Pastures a long-standing and widespread landscape features in Sarapiquí that are characterized by ground cover of thick non-native grasses and few scattered shrubs and remnant trees. Maximum daytime temperatures in pastures can exceed those in forests by as much as $10^{\circ} \mathrm{C}$, and remnant vegetation provides limited refugia from microclimatic conditions (Robinson et al. 2013). Because pastures generally support low diversities and low abundances of amphibians (Kurz et al. 2014), the land use may create strong population discontinuities for other species in the area and elsewhere in Mesoamerica.

Lack of a significant landscape effect on population structure for O. pumilio may be explained by the influence of geographic variation in population size on differentiation and the species' ability to use pastures as habitat. Large populations should take longer to respond to new dispersal barriers, because they lose alleles more slowly through genetic drift (Frankham et al. 2002). Relative abundance data and Ne estimates signify large poison frog population sizes at our study sites. We also observed a significant negative association between relative abundances and average $F_{\mathrm{ST}}$ for poison frogs, indicating a possible overriding effect of population size on differentiation. Strong IBD in O. pumlio may reflect large and semi-continuous pre-fragmentation populations that were structured by isolation gradients arising from moderate dispersal and neighbor breeding (Kimura \& Weiss 1964). Following forest conversion, population sizes and dispersal of poison frogs in areas converted to pastures may have been reduced, but not as drastically as for $C$. bransfordii. The presence of poison frogs in pastures, albeit at lower abundances compared to forest (Kurz et al. 2014) supports the conclusion that pastures are not complete dispersal barriers to this species. 
Use of pastures by poison frogs may not only facilitate movement among forest fragments, but pastures also provide habitat where large-remnant trees are present (Robinson et al. 2013). Use of trees in pastures as small habitat patches may extend populations of poison frogs from the forest boundaries allowing for greater genetic continuity among fragments. Relative abundance data suggest that palmito plantations likely provide greater resistance to poison frog movement than pasture; however, palmito and similar land uses represent a smaller proportion of the landscape than pastures and are typically more dynamic in space and time. In contrast, survey data show that pastures are largely uninhabited by litter frogs (Kurz et al. 2014) and therefore likely create large gaps in population distributions on the landscape. Population sizes were also large for $C$ bransfordii, but we did not find an effect of $\mathrm{N}_{\mathrm{e}}$ or relative abundances on levels of population differentiation.

\section{Methodological considerations}

We note two methodological considerations from this study and similar studies of landscape resistance. First, caution should be used when selecting measures of genetic differentiation and null landscape models as different combinations of each can result in varying levels of model support. It is probably best to evaluate consistency of multiple measures or explicitly state the advantage of a given method for a particular use. Here, we base inferences on the level of agreement among all combinations of null models and measures of differentiation, as strong landscape effects should be apparent across most analytical approaches. In addition, we argue that using Euclidean distances is a more 
appropriate null model than IBR for testing for effects of landscape features when the objective is to control solely for the spatial arrangement of sample sites.

Second, when evaluating connectivity using resistance surfaces or other methods that employ raster data, it is important to consider limitations associated with data resolution. For example, we are aware of the possible importance of remnant trees as habitat in pastures for poison frogs (Robinson et al. 2013). However, single trees or small clusters of trees are not represented by our land cover data at $30 \mathrm{~m}$ resolution. Therefore, missing information on variation in habitat quality among different pasture areas could underlie the lack of landscape effect on poison frog populations. The importance of remnant vegetation and other features, such as live fences and hedgerows, are known to modify habitat quality of agricultural land uses for multiple taxa (Felton et al. 2010, Fischer et al. 2010). Future studies should make use of field data, existing species information, and high resolution imagery to investigate the importance of microhabitat variation to landscape resistances.

\section{Maintaining connectivity for frogs in an agricultural landscape}

There are ongoing conservation measures within the study region that could provide mechanisms for increasing connectivity of amphibian populations; these include the management of protected areas and biological corridors (Sanchez-Azofeifa et al. 2003, Fagan et al. 2013), as well as environmental service payment programs (ESPs; Morse et al. 2009). Environmental service payment programs active in Sarapiquí provide incentives to landowners for conversion to and maintenance of native forest regrowth and exotic timber plantations. These programs have contributed to increased cover of native 
reforestations in the region (Fagan et al. 2013). While much of the area remains forested, most forest occurs as small fragments or as linear riparian zones. Typical distances between forest patches in the study system range 100-400 m, which may represent substantial expanses of open habitat to cross for small frogs (Nowakowski et al. 2013). Incentive programs could be used to increase conversion of pastures to secondary forest regrowth, which would reduce distances among forest patches for $O$. pumlio and minimize the amount of pastures lands that occur between forested habitats, thereby increasing connectivity for $C$. bransfordii. In addition, incentives could be used to increase retention of remnant trees and allow for limited recruitment in pastures that could provide conservation benefits in these anthropogenically influenced landscapes.

\section{Conclusions}

Tropical species are underrepresented in the landscape genetics literature (Storfer et al. 2010, Emel \& Storfer 2012), despite high levels of diversity and disproportionate numbers of threatened species (Vié et al. 2008). We present a comparative study of two dominant Neotropical amphibians that identifies similarities between species in the scale and level of population structure, but divergent responses to contemporary landscape change. We link dispersal costs measured with survey data and experiments to landscape scale patterns of genetic structure through resistance models. Our results support continuities between local process and landscape patterns for one species, and a potential overriding effect of population size on differentiation for the other. We conclude that when possible, the use of empirically-derived resistance surfaces will allow for clearer interpretation of processes underlying landscape connectivity compared to use of expert 
opinion and model fitting methods. While our focal species are not equally affected by prevalent land uses, ongoing conversion of pastures to secondary forest and tree plantations should improve connectivity for both species by simultaneously increasing forest cover and decreasing extent of pastures on the landscape.

\section{ACKNOWLEDGMENTS}

We thank M. Veiman for help in the field and lab, members of the DeWoody lab for feedback and assistance,to the Costa Rican government (MINAE-SINAC) for permits, to The Organization for Tropical Studies for logistical support, and to J. Watling for helpful comments on the manuscript. AJN was supported by Florida International University Dissertation Evidence Acquisition and Dissertation Year Fellowships during this study. All experimental protocols received IACUC approval (\#s 09-007, 10-023, \& 12-003). 


\section{LITERATURE CITED}

Amos W, Hoffman JI, Frodsham A, Zhang L, Best S, Hill VS (2007) Automated binning of Microsatellite alleles: problems and solutions. Molecular Ecology Notes, 7, 1014.

Anderson CD, Epperson BK, Fortin MJ, Hoderegger R, James PMA, Rosenberg MS, Scribner KT, Spear S (2010) Considering spatial and temporal scale in landscapegenetic studies of gene flow. Molecular Ecology, 19, 3565-3575.

Aronson R, Heck K, Valentine J (2001) Measuring predation with tethering experiments. Marine Ecology Progress Series, 214, 311-312.

Baguette M, Blanchet S, Legrand D, Stevens VM, Turlure C (2012) Individual dispersal, landscape connectivity, and ecological networks. Biological Reviews, 88, 310326.

Barnosky AD, Hadly EA, Bascompte J, Berlow EL, Brown JH, Fortelius M, Getz WM, Harte J, Hastings, A, Marquet PA, Martinez ND, Mooers A, Roopnarine P, Vermeij G, Williams JW, Gillespie RG, Kitzes J, Marshall C, Matzke N, Mindell DP, Revilla E, Smith AB (2012) Approaching a state-shift in Earth's biosphere. Nature, 486, 52-58.

Beier P, Majka DR, Spencer WD (2008) Forks in the road: choices in procedures for designing wildland linkages. Conservation Biology 22: 836-851.

Bender DJ, Fahrig L (2005) Matrix structure obscures the relationship between interpatch movement and patch size and isolation. Ecology 86, 1023-1033.

Betts MG, Fahrig L, Hadley AS, Halstead KE, Robinson WD, Bowman J, Wiens JA, Lindenmayer DB (In Press) A species-centered approach for uncovering generalities in organism responses to habitat loss and fragmentation. Ecography

Busch JD, Waser PM, DeWoody JA (2009) The influence of density and sex on patterns of fine-scale genetic structure. Evolution, 63, 2302-2314.

Consentino BJ, Schooley RL, Phillips C A (2011) Connectivity of agroecosystems: dispersal costs can vary among crops. Landscape Ecology, 26, 371-379.

Cushman SA, Landguth EL (2010) Spurious correlations and inference in landscape genetics. Molecular Ecology, 19, 3592-3602.

Cushman SA, Wasserman TN, Landguth EL, Shirk AJ (2013) Re-evaluating causal modeling with Mantel tests in landscape genetics. Diversity, 5, 51-72. 
Castillo JA, Epps CW, Davis AR, Cushman SA (2014) Landscape effects on gene flow for a climate-sensitive montane species, the American pika. Molecular Ecology, 23, 843-856.

Catenazzi A, Lehr E, Vredenburg VT (2013) Thermal physiology, disease, and amphibian declines on the eastern slopes of the Andes. Conservation Biology, 28, $509-517$

Daily GC, Ceballos G, Pacheco J, Suzán G, Sánchez-Azofeifa A (2003) Countryside biogeography of neotropical mammals: conservation opportunities in agricultural landscapes of Costa Rica. Conservation Biology, 17, 1814-1826.

DeClerck FAJ, Chazdon R, Holl KD, Milder JC, Finegan B, Martinez-Salinas A, Imbach P, Canet L, Ramos Z (2010) Biodiversity conservation in human-modified landscapes of Mesoamerica: past, present and future. Biological Conservation, 143, 2301-2313.

DeFries R, Hansen A, Newton AC, Hansen MC (2005) Increasing isolation of protected areas in tropical forests over the past twenty years. Ecological Applications, 15, $19-26$.

Deutsch CA, Tewksbury JJ, Huey RB, Sheldon KS, Ghalambor CK, Haak DC, Martin PR (2008) Impacts of climate warming on terrestrial ectotherms across latitude. Proceedings of the National Academy of Sciences 105 6668-6672.

Donnelly MA (1989a) Demographic effects of reproductive resource supplementation in a territorial frog, Dendrobates pumilio. Ecological Monographs, 59, 207-221.

Donnelly M (1989b) Effects of reproductive resource supplementation on space-use patterns in Dendrobates pumilio. Oecologia, 81, 212-218.

Earl DA, vonHoldt BM (2012) STRUCTURE HARVESTER: a website and program for visualizing STRUCTURE output and implementing the Evanno method. Conservation Genetics Resources, 4, 359-361.

Elmer KR, Dávila JA, Lougheed SC (2007) Applying new inter-individual approaches to assess fine-scale population genetic diversity in a neoptropical frog, Eleutherodactylus ockendeni. Heredity, 99, 506-615.

Emel SL, Storfer A (2012) A decade of amphibian population genetic studies: synthesis and recommendations. Conservation Genetics, 13, 1685-1689.

Excoffier L, Lischer HEL (2010) Arlequin suite ver 3.5: A new series of programs to perform population genetics analyses under Linux and Windows. Molecular Ecology Resources, 10, 564-567. 
Fagan ME, DeFries RS, Sesnie SE, Arroyo JP, Walker W, Soto C,, Chazdon RL, Sanchum A (2013) Land cover dynamics following a deforestation ban in northern Costa Rica. Environmental Research Letters, 8, 034017.

FAO (2009) State of the world's forests. FAO, United Nations, Rome, Italy.

Felton A, Knight E, Wood J, Zammit C, Lindenmayer D (2010) A meta-analysis of fauna and flora species richness and abundance in plantations and pasture lands. Biological Conservation, 143, 545-554.

Fischer J, Stott J, Law BS (2010) The disproportionate value of scattered trees. Biological Conservation, 143, 1564-1567.

Funk WC, Blouin MS, Corn PS, Maxell BA, Pilliod DS, Amish S, Allendorf FW (2005b) Population structure of Columbia spotted frogs (Rana luteiventris) is strongly affected by the landscape. Molecular Ecology, 14, 483-496.

Frankam R, Ballou JD, Briscoe DA (2002) Introduction to Conservation Genetics. Cambridge University Press, Cambridge.

Goldberg CS, Waits LP (2010) Comparative landscape genetics of two pond-breeding amphibian species in a highly modified agricultural landscape. Molecular Ecology, 19, 3650-3663.

Hammerschlag N, Heithaus M, Serafy J (2010) Influence of predation risk and food supply on nocturnal fish foraging distributions along a mangrove-seagrass ecotone. Marine Ecology Progress Series, 414, 223-235.

Hansen MC, Potapov PV, Moore R, Hancher M, Turubanova SA, Tyukavina A, Thau D, Stehman SV, Goetz SJ, Loveland TR, Kommareddy A, Egorov A, Chini L, Justice CO, Townsend JRG (2013) High-resolution global maps of $21^{\text {st }}$-century forest cover change. Science, 342, 850-853.

Hauswaldt JS, Ludewig AK, Hagemann S, Prohl H, Vences M (2009) Ten microsatellite loci for the strawberry poison frog (Oophaga pumilio). Conservation Genetics, 10, 1935-1937.

Heidinger IMM, Hein S, Felhaar H, Poethke HJ (2013) The genetic structure of populations of Metrioptera bicolor in a spatially structured landscape: effects of dispersal barriers and geographic distance. Conservation Genetics, 14, 299-311.

Huey RB, Deutsch CA, Tewksbury JJ, Vitt LJ, Hertz PE, Álvarez Pérez HJ, Garland T (2009) Why tropical forest lizards are vulnerable to climate warming. Proceedings of Royal Society B:Biological Sciences, 276, 1939-1948. 
Jenkins DG, Carey M, Czerniewska J, Fletcher J, Hether T, Jones A, Knight S, Knox J, Long T, Mannino M, McGuire M, Riffle A, Segelsky S, Shappell L, Sterner A, Strickler T, Tursi R (2010) A meta-analysis of isolation by distance: relic or reference standard for landscape genetics? Ecography, 33, 315-320.

Jost L (2008) $G_{\mathrm{ST}}$ and its relatives do not measure differentiation. Molecular Ecology, 17, 4015-4026.

Karp DS, Rominger AJ, Zook J, Ranganathan J, Ehrlich PR, Daily GC (2012) Intensive agriculture erodes $\beta$-diversity at large scales. Ecology Letters, 15, 963-970.

Kimura M, Weiss GH (1964) The stepping stone model of population structure and the decrease of genetic correlation with distance. Genetics, 49, 561-576.

Knowlton JL, Graham CH (2010) Using behavioral landscape ecology to predict species' responses to land-use and climate change. Biological Conservation, 143, 1342-1354.

Koen EL, Bowman J, Walpole AA (2012) The effect of cost surface parameterization on landscape resistance estimates. Molecular Ecology Resources, 12, 686-696.

Kurz DJ, Nowakowski AJ, Tingley MW, Donnelly MA, Wilcove DS (2014) Forest-land use complementarity modifies community structure of a tropical herpetofauna. Biological Conservation, 170, 246-255.

Landguth EL, Cushman SA, Schwartz MK, McKelvey KS, Murphy M, Luikart G (2010) Quantifying the lag time to detect barriers in landscape genetics. Molecular Ecology, 19, 4179-4191.

Laurance WF, Useche DC, Rendeiro J, Kalka M, Bradshaw CJA, Sloan SP, Laurance SG, Campbell M, Abernethy K, Alvarez P, Arroyo-Rodriguez V, Ashton P, Benítez-Malvido J, Blom A, Bobo KS, Cannon CH, Cao M, Carroll R, Chapman C, Coates R, Cords M, Danielsen F, De Dijn B, Dinerstein E, Donnelly MA, et al. (2012) Averting biodiversity collapse in tropical forest protected areas. Nature, 489, 290-294.

Lee-Yaw J, Davidson A, McRae B, Green DM (2009) Do landscape processes predict phylogenetic patterns in the wood frog? Molecular Ecology, 18, 1863-1974.

Legendre P, Fortin MJ (2010) Comparison of the Mantel test and alternative approaches for detecting complex multivariate relationships in the spatial analysis of genetics data. Molecular Ecology Resources, 10, 831-844. 
Lowe WH, Allendrorf FW (2010) What can genetics tell us about population connectivity? Molecular Ecology, 19, 3038-3051.

Luque S, Saura S, Fortin MJ (2012) Landscape connectivity analysis for conservation: insights From combining new methods with ecological and genetic data. Landscape Ecology, 27, 153-157.

Manel S, and Holderegger R (2013) Ten years of landscape genetics. Trends in Ecology and Evolution, 28:614-621.

Mattias J, Rosenberg NA (2007) CLUMPP: a cluster matching and permutation program for dealing with label switching and multimodality in analysis of population structure. Bioinformatics, 23, 1801-1806.

McRae BH (2006) Isolation by resistance. Evolution, 60, 1551-1561.

McRae BH, Beier P (2007) Circuit theory predicts gene flow in plant and animal populations. Proceedings of the National Academy of Sciences, 104, 1988519890.

McRae BH, Dickson BG, Keitt TH, Shah VB (2008) Using circuit theory to model connectivity in ecology, evolution, and conservation. Ecology, 89, 2712-2724.

McRae BH, Shah VB (2009) Circuitscape user's guide. The University of California, Santa Barbara. Available at: http://www.circuitscape.org.

Meirmans PG, Hedrick PW (2011) Assessing population structure: $F_{\mathrm{ST}}$ and related measures. Molecular Ecology Resources, 11, 5-18.

Morse W, Schedlbauer J, Sesnie S, Finegan B, Harvey C, Hollenhorst S, Kavanagh K, Stoian D, Wulfhorst JD (2009) Consequences of environmental service payments for forest retention and recruitment in a Costa Rican Biological Corridor. Ecology and Society, 14, 1-20.

Nowakowski AJ, Otero Jiménez B, Allen M, Diaz-Escobar M, Donnelly MA (2013) Landscape resistance to movement of the poison frog, Oophaga pumilio, in the lowlands or northeastern Costa Rica. Animal Conservation, 16, 188-197.

Pearman PB, Garner TWJ (2005) Susceptibility of Italian agile frog populations to an emerging strain of Ranavirus parallels population genetic diversity. Ecology Letters, 8, 401-408.

Pritchard JK, Stephens M, Donnelly P (2000) Inference of population structure using multi-locus genotype data. Genetics, 155, 945-959. 
Rayfield B, Fortin M, Fall A (2010) The sensitivity of least-cost habitat graphs to relative cost surface values. Landscape Ecology, 25, 519-532.

Rittenhouse TAG, Harper EB, Rehard LR, Semlitsch RD (2008) The role of microhabitats in the desiccation and survival of anurans in recently harvested oak-hickory forest. Copeia 4, 807-814.

Rittenhouse TAG, Semlitsch RD (2006) Grasslands as movement barriers for a forest associated salamander: Migration behavior of adult and juvenile salamanders at a distinct habitat edge. Biological Conservation, 131, 14-22.

Robinson D, Warmsley A, Nowakowski A J, Reider KE, Donnelly MA (2013) The value of remnant trees in pastures for a neotropical poison frog. Journal of Tropical Ecology, 29, 345-352.

Rosenberg NA (2004) DISTRUCT: a program for the graphical display of population structure. Molecular Ecology Notes, 4, 137-138.

Rosenzweig ML (2003) Reconciliation ecology and the future of species diversity. Oryx, 37:195-205.

Rothermel BB, Luhring TM (2005) Burrow availability and desiccation risk of mole salamanders (Ambystoma talpoideum) in harvested versus unharvested forest stands. Journal of Herpetology, 39, 619-626.

Rothermel BB, Semlitsch RD (2006) Consequences of forest fragmentation for juvenile survival in spotted (Ambystoma maculatum) and marbled (Ambystoma opacum) salamanders. Canadian Journal of Zoology, 84, 797-807.

Sambrook J, Russell DW (2001) Molecular Cloning: a Laboratory Manual. Cold Spring Harbor Laboratory Press, New York.

Sánchez-Azofeifa GA, Daily GC, Pfaff ASP, Busch C (2003) Integrity and isolation of Costa Rica's national parks and biological reserves: examining the dynamics of land-cover change. Biological Conservation, 109, 123-135.

Sanford RL Jr, Paaby P, Luvall JC, Phillips E (1994) Climate, geomorphology, and aquatic systems. In McDade L.A, Bawa KS, Hespenheide HA, Hartshorn GS (Eds). La Selva: ecology and natural history of a neotropical rainforest. The University of Chigago Press, Chicago, IL.

Saporito RA, Donnelly MA, Norton R, Garraffo HM, Spande TF, Daly JW (2007) Oribatid mites as a major dietary source for alkaloids in poison frogs. Proceedings of the National Academy of Sciences, 104, 8885-8890. 
Savage JM (2002) The amphibians and reptiles of Costa Rica: A herpetofauna between two continents, two seas. The University of Chicago Press, Chicago, IL.

Sesnie SE, Gessler PE, Finegan B, Thessler S (2008) Integrating Landsat TM and SRTMDEM derived variables with decision trees for habitat classification and change detection in complex neotropical environments. Remote Sensing of Environment, 112, 2145-2159.

Short Bull RA, Cushman SA, Mace R, Chilton T, Kendall KC, Landguth EL, Schwartz MK, McKelvey K, Allendorf FW, Luikart G (2011) Why replication is important in landscape genetics: American black bear in the Rocky Mountains. Molecular Ecology, 20, 1092-1107.

Smith AM, Green DM (2005) Dispersal and the metapopulation paradigm in amphibian ecology and conservation: are all amphibian populations metapopulations?

Ecography, 28, 10-128.

Soare TW, Kumar A, Naish KA, O`Donnelly S (2014) Genetic evidence for landscape effects on dispersal in the army ant Eciton burchellii. Molecular Ecology, 23, 96109.

Spear SF, Balkenhol N, Fortin MJ, Mcrae BH, Scribner K (2010) Use of resistance surfaces for landscape genetic studies: considerations for parameterizations and analysis. Molecular Ecology, 19, 3576-3591.

Stevens VM, Verkenne C, Andewoestijne SV, Wesselingh RA, Baguette M (2006) Gene flow and functional connectivity in the natterjack toad. Molecular Ecology, 15, 2333-2344.

Storfer A, Murphy MA, Spear SF, Holderegger R, Waits LP (2010) Landscape genetics: where are we now? Molecular Ecology, 19, 3496-3514.

Stuart SN, Chanson JS, Cox NA, Young BE, Rodrigues ASL, Fischman DL, Walker RW (2004) Science, 306, 1783-1786.

Van Oosterhout C, Hutchinson WF, Wills DPM, Shipley P (2004) MICRO-CHECKER: software for identifying and correcting genotyping errors in microsatellite data. Molecular Ecology Notes, 4, 535-538.

Velo-Antón G, Parra JL, Parra-Olea G, Zamudio KR (2013) Tracking climate change in a dispersal-limited species: reduced spatial and genetic connectivity in a montane salamander. Molecular Ecology, 22, 3261-3278. 
Vié JC, Hilton-Taylor C, Stuart SN (eds.) (2009) Wildlife in a Changing World- An Analysis of the 2008 IUCN Red List of Threatened Species. Gland, Switzerland: IUCN.

von May R, Jacobs JM Santa-Cruz R, Valdivia J, Huaman JM, Donnelly MA (2010) Amphibian community structure as a function of forest type in Amazonian Peru. Journal of Tropical Ecology, 26, 509-519.

Wang IJ, Savage WK, Shaffer HB (2009) Landscape genetics and least-cost path analysis reveal unexpected dispersal routes in the California tiger salamander (Ambystoma californiense). Molecular Ecology, 18, 1365-1374.

Wang IJ, Summers K (2009) Highly polymorphic microsatellite markers for the highly Polymorphic strawberry poison-dart frog and some of its congeners. Conservation Genetics, 10, 2033-2036.

Wang IJ, Summers K (2010) Genetic structure is correlated with phenotypic divergence rather than geographic isolation in the highly polymorphic strawberry poison-dart frog. Molecular Ecology, 19, 447-458.

Wasserman TN, Cushman SA, Shirk AS, Landguth EL, Littell JS (2012) Simulating the effects of climate change on population connectivity of American marten (Martes americana) in the northern Rocky Mountains, USA. Landscape Ecology, 27, 211225.

Wells KD (2007) The ecology and behavior of amphibians. The University of Chicago Press, Chicago, IL.

Whitfield SM, Bell KE, Philippi T, Sasa M, Bolaños F, Chaves G, Savage JM, Donnelly MA (2007) Amphibian and reptile declines over 35 years at La Selva, Costa Rica. Proceedings of the National Academy of Science, 104, 8352-8356.

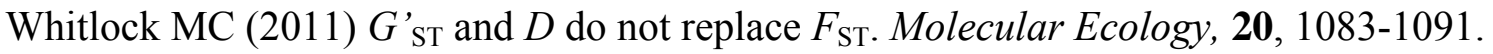

Zamudio KR, Wieczorek AM (2007) Fine-scale spatial genetic structure and dispersal among spotted salamander (Ambystoma maculatum) breeding populations. Molecular Ecology, 16, 257-274.

Zeller KA, McGarigal K, Whiteley AR (2012) Estimating landscape resistance to movement: a review. Landscape Ecology, 27, 777-797.

Zellmer AJ, Knowles LL (2009) Disentangling the effects of historic vs. contemporary landscape structure on population genetic divergence. Molecular Ecology, 18, 3593-3602. 
Table 3.1. Mantel r, 95\% CI, and P values for analyses of genetic distances and resistance

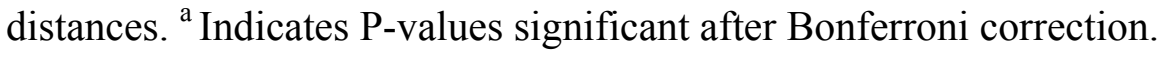

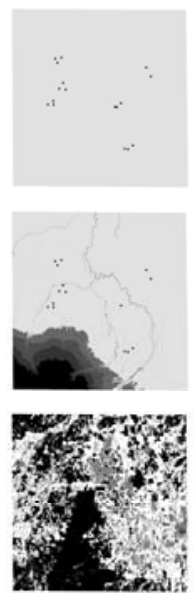

\begin{tabular}{|c|c|c|c|c|c|c|}
\hline \multirow{2}{*}{$\begin{array}{l}D_{\text {est }} \\
\text { Model }\end{array}$} & \multicolumn{2}{|c|}{ O. pumilio } & \multicolumn{4}{|c|}{ C. bransfordii } \\
\hline & Mantel r & $95 \%$ CI & $P$-value & Mantel r & $95 \%$ CI & $P$-value \\
\hline IBD (logGeoDist) & 0.6726 & 0.183 & $<0.0001^{\mathrm{a}} * *$ & 0.4069 & 0.14 & $<0.0001^{\mathrm{a}}$ \\
\hline \multicolumn{7}{|l|}{ Pre-fragmentation } \\
\hline Pre-frag|Dist & 0.0252 & 0.253 & 0.4528 & 0.3276 & 0.263 & 0.0188 \\
\hline Dist|Pre-frag & 0.2858 & 0.273 & 0.0428 & -0.1963 & 0.249 & 0.8997 \\
\hline \multicolumn{7}{|l|}{ Abundance } \\
\hline abun_2011|Dist & 0.1158 & 0.278 & 0.2465 & 0.6038 & 0.319 & $<0.0001^{{ }^{a}} *$ \\
\hline abun_2001|Dist & 0.113 & 0.278 & 0.2493 & 0.4298 & 0.318 & 0.0101 \\
\hline abun_1986|Dist & -0.0856 & 0.291 & 0.6623 & 0.1622 & 0.337 & 0.1891 \\
\hline Dist|abun_2011 & 0.4647 & 0.191 & $<0.0001^{\mathrm{a}_{* *}}$ & 0.1800 & 0.149 & 0.0246 \\
\hline abun_2011|Pre-frag & 0.1086 & 0.259 & 0.2605 & 0.5683 & 0.311 & $0.0002^{a} *$ \\
\hline Experiments 2011 & & & & & & \\
\hline Survival|Dist & 0.1416 & 0.281 & 0.2095 & 0.5198 & 0.305 & $0.0008^{a} *$ \\
\hline Dist|Survival & 0.4786 & 0.192 & $<0.0001^{{ }^{a}} * *$ & 0.0424 & 0.177 & 0.3549 \\
\hline Water loss $\mid$ Dist & 0.1222 & 0.28 & 0.2507 & 0.5525 & 0.311 & $0.0004^{\mathrm{a}} *$ \\
\hline Dist|Water loss & 0.3163 & 0.226 & 0.0104 & -0.2485 & 0.246 & 0.9494 \\
\hline Substrates|Dist & 0.0782 & 0.286 & 0.3321 & 0.5584 & 0.312 & $0.0003^{\mathrm{a}} *$ \\
\hline Dist|Substrates & 0.2578 & 0.264 & 0.0549 & -0.371 & 0.281 & 0.9882 \\
\hline Predation|Dist & 0.1218 & 0.274 & 0.2400 & 0.4549 & 0.297 & $0.0032^{a} *$ \\
\hline Dist|Predation & 0.4083 & 0.203 & $0.0003^{\mathrm{a}}$ & -0.2836 & 0.303 & 0.9520 \\
\hline
\end{tabular}



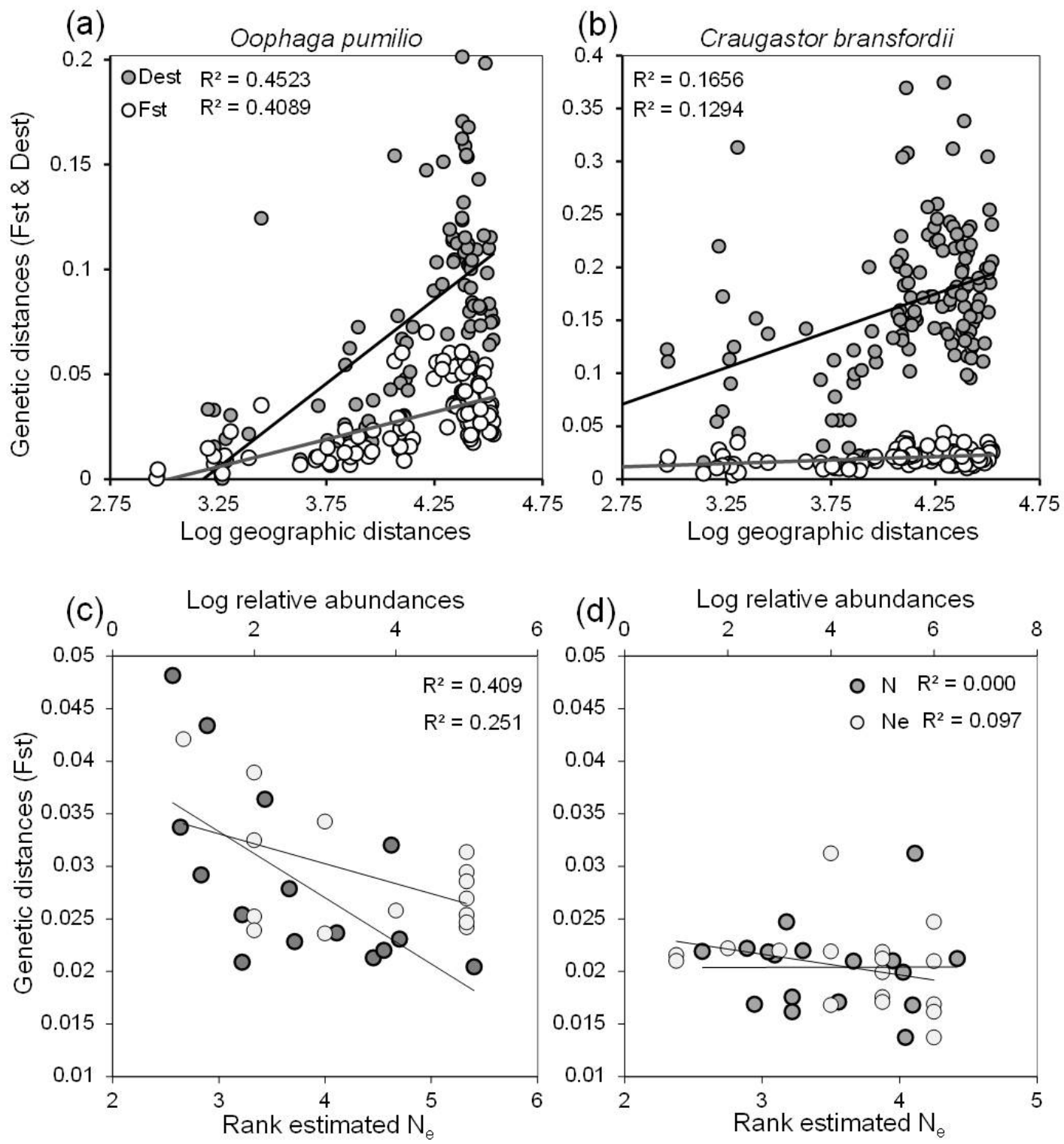

Fig 3.1. Isolation by distance relationships for (A) O. pumilio (A) and (B) C. bransfordii Filled circles represent pairwise Jost's D and open circles represent FST. Relationship between average FST for each site and population size for (C) O. pumilio and (D) C. bransfordii. Rank estimates of $\mathrm{Ne}$ (open circles) for each population are given on the lower $\mathrm{x}$-axis and log relative abundances (counts; filled circles) are given on the upper $\mathrm{x}$ axis. 

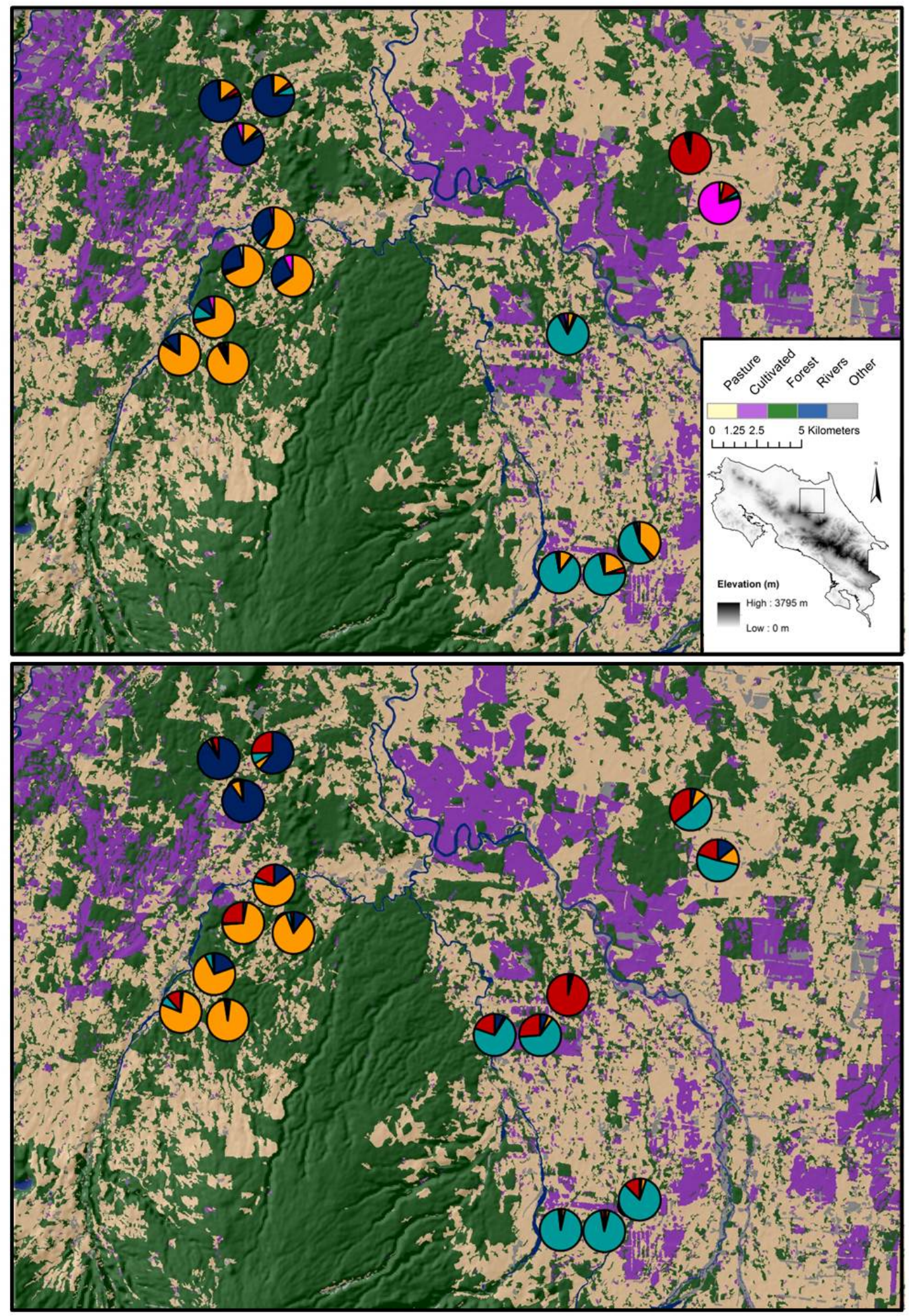

Fig 3.2. Map of study area and pie charts showing percent ancestry of populations for $O$.

pumilio (above) and C. bransfordii (below). 


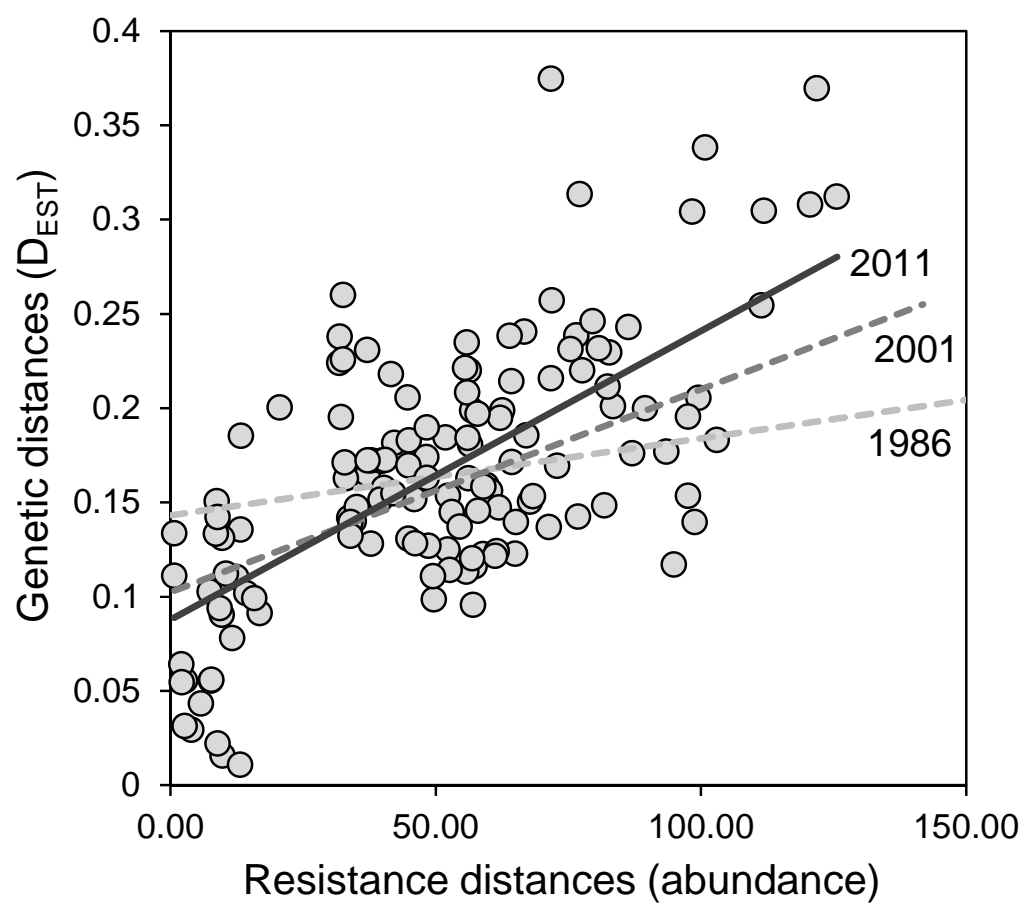

Fig 3.3. Pairwise genetic distances (Dest) and resistance distances derived from abundance data for C. bransfordii. Trendlines show linear relationships for years 1986, 2001, and 2011. 


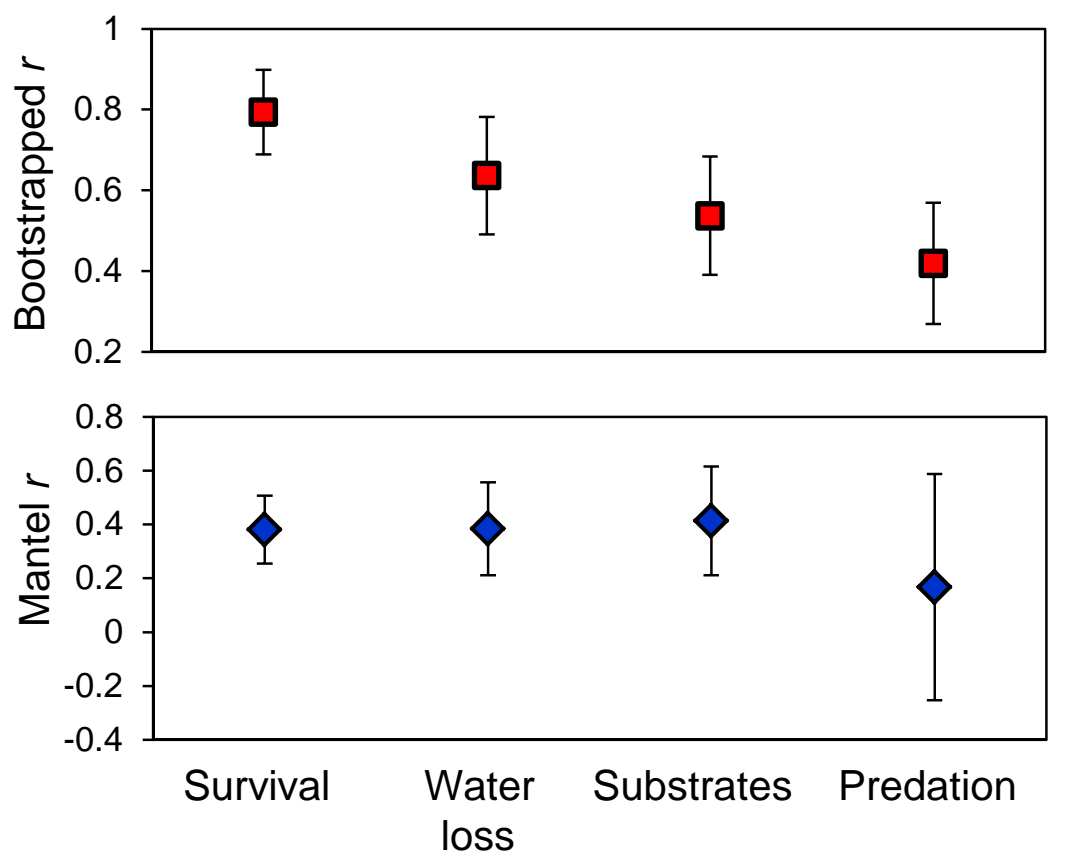

Fig 3.4. Model support for experiment-derived resistance estimates for litter frogs from genetic data (blue diamonds; average partial Mantel $r$ for landscape-genetic correlations across all combinations of null models and genetic distances) and abundance data (average bootstrapped correlation coefficients for current density maps compared between experiment and abundance-parameterized circuit models). Note different scales and low average model support for predation on the basis of both genetic data and survey data. 


\section{CONCLUSIONS}

My dissertation research provides a case study of landscape connectivity for two amphibians in northeastern Costa Rica that has methodological, conservation, and theoretical implications beyond the study system. I combined experiments, field surveys, connectivity modeling, and landscape genetics to investigate local processes underlying connectivity, to translate experimental results to landscape resistance estimates, and to evaluate the explanatory power of empirical resistance estimates using population genetic data. My results show that resistance to dispersal associated with land use change can influence population differentiation over short time periods and that local dispersal risks, especially species responses to microclimates in altered habitats, can scale up to landscape patterns of population genetic diversity.

In Chapter 1, I used translocation experiments to gauge the resistance of pastures to movement of Oophaga pumilio in relation to forest habitat. Results indicated greater risks associated with moving through pastures. Higher temperatures and lower humidity conditions commonly encountered in pastures reduced movement performance of O.pumilio measured as movement speeds. Orientation of displaced individuals in pastures suggested greater motivation of displaced individuals to return to forest and limited perceptual ranges. Most forest patches in the study landscape are separated by 100-400 m of pasture. Limited ability to detect forest habitat at distances greater than $25 \mathrm{~m}$ suggests that even short-distance dispersal through pastures will be risky, because time spent searching for habitat will increases exposure to unfavorable microclimatic conditions. 
Chapter 2 describes the measurement of local mechanisms related to habitatspecific dispersal risks and use of experiments to parameterize connectivity models. For both focal species, extreme temperatures associated with palmito and pasture land uses resulted in increased water loss and mortality over one-hour trials. Species also exhibited reduced movement speeds across thick pasture grasses suggesting energetic costs to movement as well as desiccation risk may be important determinants of landscape resistance to amphibian movements. Model validation using abundance data for the three land uses generally indicated high support for resistance estimates from microclimate and substrate resistance experiments. This chapter demonstrates the value of experiments for estimating relative dispersal costs for connectivity analyses in conservation planning and landscape ecology studies. Empirically-derived cost values provide objective means to model contrasts among landscape elements as well as insights into processes underlying landscape connectivity.

In Chapter 3, I use resistance models developed in Chapter 2 to analyze landscape effects on population genetic structure of the two focal species. I found idiosyncratic responses among species to landscape structure, which underscores the importance of species-specific considerations in corridor design and other conservation strategies aimed at maintaining landscape connectivity. For one species, there was continuity among results of experiments, relative abundance data, and population genetic response to landscape change, illustrating that dispersal risks differ among land uses and that local dispersal risks can scale up to influence landscape patterns of population differentiation.

The land use scenario in Sarapiquí is common throughout Mesoamerica (FAO 2009) and represents a state-shift for the ecosystems that are found there (Barnosky et al. 
2012). Natural ecological and evolutionary processes within these landscapes are likely forever altered. Biodiversity conservation in the context of agricultural landscapes will need to focus on multiple scales, e.g., individual reserves and reserve networks, and will need to incorporate elements of altered landscapes into conservation planning, such as remnant trees, riparian corridors, forest fragments, and land uses themselves. Conceptual models that define habitat and non-habitat portions of the landscape are oversimplifications. Land uses are often used to a certain extent by native species (Kurz et al. 2014) and knowledge of the relative habitat value and resistances of common land uses should be used to buffer existing protected areas (e.g., by incentivizing or zoning for land uses around protected areas that provide habitat) and increase connectivity among them. 


\section{LITERATURE CITED}

Barnosky AD, Hadly EA, Bascompte J., Berlow EL, Brown JH, Fortelius M, Getz WM, Harte J, Hastings, A, Marquet PA, Martinez ND, Mooers A, Roopnarine P, Vermeij G, Williams JW, Gillespie RG, Kitzes J, Marshall C, Matzke N, Mindell DP, Revilla E, Smith AB. (2012) Approaching a state-shift in Earth's biosphere. Nature, 486, 52-58.

FAO. 2009. State of the world's forests. FAO, United Nations, Rome, Italy.

Kurz DJ, Nowakowski AJ, Tingley MW, Donnelly MA, Wilcove DS (2014) Forest-land use complementarity modifies community structure of a tropical herpetofauna. Biological Conservation, 170, 246-255. 
VI. VITA

\section{AARON JUSTIN NOWAKOWSKI}

2006

B.S. Forest Resources

University of Georgia

Athens, GA

\section{PUBLICATIONS}

Kurz, D. J., Nowakowski, A.J., Tingley, M., Donnelly, M.A., and Wilcove, D. Forestland use complementarity modifies community structure of a tropical herpetofauna. Biological Conservation 170:246-255.

Kurz, D. J., N. A. McGinty, S. A. Stankavich, A. J. Nowakowski, and G. A. Smith. Wetland restoration projects can promote mammalian assemblages comparable to those in natural wetlands. American Midland Naturalist 170: 260-273.

Nowakowski, A. J., Willoughby, J. A., DeWoody, A. J., and Donnelly, M. A. Polymorphic microsatellite loci for a neotropical leaf-litter frog (Craugastor bransfordii) characterized through Illumina sequencing. Conservation Genetics Resources. Accepted

Nowakowski, A. J., N. H. Hyslop, J. I. Watling, and M. A. Donnelly. 2013. Matrix type alters structure of aquatic vertebrate assemblages in cypress domes. Biodiversity and Conservation 22:497-511.

Nowakowski, A. J., B. Otero, M. Allen, M. Diez-Escobar, and M. A. Donnelly. 2013. Landscape resistance to movement of Oophaga pumilio in the lowlands of northeastern Costa Rica. Animal Conservation 16:188-197.

Nowakowski, A. J., and J.C. Maerz. 2009. Estimation of larval stream salamander density in three proximate streams in the Georgia Piedmont. Journal of Herpetology 43:503-509.

Robinson, D., A. Warmsley, A. J. Nowakowski, K. E. Reider, and M. A.Donnelly. The value of remnant trees in pastures for a neotropical poison frog. Journal of Tropical Ecology 29: 345-352.

Watling, J. I., A. J. Nowakowski, M. A. Donnelly, and J. L. Orrock. 2011. Meta-analysis reveals the importance of matrix-mediated connectivity effects for animals in fragmented habitat. Global Ecology and Biogeography 20:209-217. 